\title{
Bibliographie pascalienne 2000-2015
}

\section{(2) OpenEdition}

1 Journals

Édition électronique

URL : http://journals.openedition.org/ccibp/1165

DOI : 10.4000/ccibp. 1165

ISSN : 2493-7460

Éditeur

Centre international Blaise Pascal

\section{Édition imprimée}

Date de publication : 15 décembre 2015

Pagination : 25-59

ISBN : 978-2-84516-671-4

ISSN : 0249-6674

\section{Référence électronique}

« Bibliographie pascalienne 2000-2015 », Courrier du Centre international Blaise Pascal [En ligne], 37 | 2015, mis en ligne le 16 mai 2018, consulté le 27 janvier 2021. URL : http://journals.openedition.org/ ccibp/1165; DOI : https://doi.org/10.4000/ccibp.1165

Ce document a été généré automatiquement le 27 janvier 2021.

Centre international Blaise Pascal 


\section{Bibliographie pascalienne 2000-2015}

1 Ce bilan bibliographique de quinze années d'études pascaliennes vise à en mettre sous les yeux de nos lecteurs les orientations principales.

2 Les titres recueillis ci-dessous sont ceux des publications qui nous ont été signalées ou communiquées.

3 Rappelons qu'il est toujours souhaitable que les auteurs déposent au Centre International Blaise Pascal un exemplaire de leurs publications. Les ouvrages publiés à l'étranger intéressent particulièrement le CIBP, car il est parfois difficile de les suivre exactement. Les omissions qui nous seront signalées feront ultérieurement l'objet d'une mise au point.

\section{Année 2000}

« Pascal, Cuuvres complètes, t. II », La lettre de la Pléiade, n 3, janvier-mars 2000, p. 4.

5 ADAM Michel, L'eucharistie chez les penseurs français du dix-septième siècle, Georg Olms Verlag AG, Hildesheim, 2000, $254 \mathrm{p}$.

6 ADINOLFI Isabella, Il cerchio spezzato. Linee di antropologia in Pascal e Kierkegaard, Roma, Città Nuova, 2000.

7 ADORNO Francesco Paolo, Pascal, Les Belles Lettres, Paris, 2000.

8 ADORNO Francesco Paolo, La ragione ordinata : saggio su Pascal, Napoli, Edizioni La Città del Sole, 2000.

9 ALIAEV Gennadyi, «B. Pascal et S. Franc : dialogue à travers des siècles ", Sententiae 1, Colloque international «Pluralisme de la rationalité dans la philosophie moderne: phénomène de Pascal », Kiev, 2000, p. 160-167.

10 ANSART Guillaume, "Le concept de figure dans les Pensées ", Poétique, 121, 2000, p. 49-59.

11 ATTALI Jacques, Blaise Pascal ou le génie français, Fayard, Paris, 2000, 340 p.

12 BERTHON Maurice-Édouard, Les grands concepts scientifiques et leur évolution, Éditions TEC et DOC, Paris, 2000, 496 p. 

207, avril-juin 2000. Kiev, 2000, p. 13-21. Bordeaux III, 28-30 janvier 1999, p. 149-159. $n^{\circ} 278$, décembre 2000, p. 58-63. 2000, p. 247-261. Montaigne, Pascal, Beauchesne, Paris, 2000, 240 p. Paris, Janvier 2000, p. 41-58. Narr Verlag, Tübingen, 2000, p. 115-125. 2000, p. 966-977. istituzioni culturali e l'editoria, 2000, p. 43-48.

BIET Christian et JULLIEN Vincent (dir.), L'Indicible et la vacuité au XVII siècle, XVII siècle,

BITCHKO Igor, «La logique pascalienne du cœur », Sententiae 1, Colloque international «Pluralisme de la rationalité dans la philosophie moderne : phénomène de Pascal»,

BLANCHARD Jean-Vincent, «Optique et rhétorique au XVII ${ }^{e}$ siècle : de l'ekphrasis jésuite au fragment pascalien", in Recherches des jeunes dix-septièmistes: actes $d u V^{e}$ colloque $d u$ Centre international de rencontres sur le XVII siècle, Université Michel-de-Montaigne,

BLAY Michel, "La science du mouvement au XVII ${ }^{\mathrm{e}}$ siècle ", Les infinis, Pour la science,

BOISDEFFRE Pierre de, "Mauriac entre Pascal et Racine ", in DURAND Jean-François (dir.), Pascal-Mauriac. L'œuvre en dialogue, L'Harmattan, Paris, 2000, p. 293-300.

BONET Pierrette, "Misère humaine et grâce divine chez Pascal et Mauriac ", in DURAND Jean-François (dir.), Pascal-Mauriac. L'ouvre en dialogue, L'Harmattan, Paris,

BORD André, La vie de Blaise Pascal. Une ascension spirituelle suivie d'un essai, Plotin,

BOUCHILLOUX Hélène, "Vérité phénoménale et vérité essentielle chez Pascal», in PÉCHARMAN Martine (dir.), Pascal. Qu'est-ce que la vérité ?, p. 63-88.

BOUCHILLOUX Hélène, "Pascal et la Logique de Port-Royal», Sources et effets de la Logique de Port-Royal, Revue des Sciences philosophiques et théologiques, t. 84, $\mathrm{n}^{\circ} 1$, Vrin,

BOUCHILLOUX Hélène, "Comment interpréter le fragment Lafuma 786 des Pensées ", Courrier du Centre International Blaise Pascal, $\mathrm{n}^{\circ}$ 1, 1999 (2000), p. 47-48.

BOURCHEIX Jean-Paul, « Pascal, Mauriac et l'apostolat du chrétien », in DURAND JeanFrançois (dir.), Pascal-Mauriac. L'œuvre en dialogue, L'Harmattan, Paris, 2000, p. 123-138.

BOUVIER Michel, « A propos du Pari de Pascal », XVII siècle, no 207, 2-2000, p. 339-342.

BREMONDY François, «Le plan retrouvé. Les Pensées de Pascal classées par Francis Kaplan », Concepts, $\mathrm{n}^{\circ}$ 1, éd. Sils-Maria, Mons, Belgique, 2000 (cet article peut être lu sur le site http://www.dtext.com/francis-kaplan/pascal-pensees.html).

BRESSOLETTE Michel, «Pascal dans les derniers Bloc-notes », in DURAND Jean-François (dir.), Pascal-Mauriac. L'œeuvre en dialogue, L'Harmattan, Paris, 2000, p. 69-79.

CAGNAT-DEBCEUF Constance, «Fléchier lecteur de Pascal. Ou de l'art du plagiat », in LESNE-JAFFRO Emmanuèle (dir.), Fléchier et les Grands Jours d'Auvergne, Actes d'une journée d'étude, Université Blaise Pascal-Clermont-Ferrand, 3 octobre 1997, Biblio 17, Gunter

CANTILLON Alain, Article «Pascal », in Le Robert des grands écrivains de langue française,

CARENA Carlo, «Le soir mon mari nous lit un peu... Lecture e libri giansenisti in casa Manzoni ", in Manzoni scrittore e lettore europeo, Ufficio centrale per i beni librari, le 
CAVE Terence, «Fragments d'un moi futur: Pascal, Montaigne, Rabelais », in FANLO Jean-Raymond, "D'une fantastique bigarrure ». Le texte composite à la Renaissance. Études offertes à André Tournon, Paris, Champion, 2000, p. 105-118.

CHALAYE Gérard, «Pascal ou l'“anti-Teilhard de Chardin” dans le Bloc-notes de François Mauriac (1955-1964)», in DURAND Jean-François (dir.), Pascal-Mauriac. L'œuvre en dialogue, L'Harmattan, Paris, 2000, p. 383-403.

CHANUT Florence, "La maison de Pascal à "Clairmont" ", Courrier du Centre International Blaise Pascal, n² 21, 1999 (2000), p. 8-46.

CHIRPAZ François, Pascal. La condition de l'homme, Michalon, Paris, 2000, 126 p.

CLÉRO Jean-Pierre, «La temporalité du vrai et de la vérité dans les Pensées », in PÉCHARMAN Martine (dir.), Pascal. Qu'est-ce que la vérité ?, p. 29-62.

COMTE-SPONVILLE André, « Nous sommes des gens ordinaires », Chronique, Psychologies, Février 2000, p. 31.

Courrier du Centre International Blaise Pascal, $n^{\circ} 21$, Centre d'Études sur les Réformes, l'Humanisme et l'Âge Classique, Clermont-Ferrand, 1999 (2000).

DEDEYAN Rita-Carole, Dictionnaire de citations classiques utiles aux politiques et à tous leurs électeurs, Condé-sur-Noireau, Éditions Charles Corlet, 2000.

DELAHAYE Jean-Paul, Merveilleux nombres premiers. Voyage au cœur de l'arithmétique, Paris, Pour la science, Belin, 2000.

DELCROIX Maurice, «Deux vies de Jésus », in DURAND Jean-François (dir.), PascalMauriac. L'œuvre en dialogue, L'Harmattan, Paris, 2000, p. 211-227.

DESCOMBES René, Les carrés magiques. Histoire, théorie et technique du carré magique, de l'antiquité aux recherches actuelles, Vuibert, Paris, 2000, $494 \mathrm{p}$.

DESCOTES Dominique, « Le vide dans le vide », XVII siècle, $n^{\circ}$ 207, 2-2000, p. 257-272.

DESCOTES Dominique, «Les anges quadrateurs », in FERREYROLLES Gérard (dir.), Littérature et religion, Littératures classiques, $n^{\circ} 39$, Printemps 2000, p. 179-196.

DESCOTES Dominique, « Pascal : Lettres de A. Dettonville (Cédérom PC et Macintosh)», in FERREYROLLES Gérard (dir.), Port-Royal au miroir du XXe siècle, Chroniques de Port-Royal, 49, 2000, p. 219-221.

DESCOTES Dominique, "Sur les arguments mathématiques dans l'Apologie de Pascal », in MOTHU Alain, Révolution scientifique et libertinage, Brepols, Turhout, 2000, p. 251-273.

DOUDET Marie-Sophie, "Ils ne nous aideront pas... Mauriac, Pascal et Malraux ", in DURAND Jean-François (dir.), Pascal-Mauriac. L'œuvre en dialogue, L'Harmattan, Paris, 2000, p. 327-354.

DOYLE William, Jansenism, Studies in European History, Mcmillan Press, Houndmills and London, 2000, $110 \mathrm{p}$.

DURAND Jean-François (dir.), Pascal-Mauriac. L'œuvre en dialogue, L'Harmattan, Paris, 2000,420 p.

DURAND Jean-François, « L'opacité du monde », in DURAND Jean-François (dir.), PascalMauriac. L'œuvre en dialogue, L'Harmattan, Paris, 2000, p. 141-159.

DYE Michel, «Influence et limites de la pensée pascalienne dans Ce qui était perdu et Les Anges noirs ", in DURAND Jean-François (dir.), Pascal-Mauriac. L'œuvre en dialogue, L'Harmattan, Paris, 2000, p. 93-109. 

d'Auvergne, Clermont-Ferrand, 2000, $106 \mathrm{p}$. L'Harmattan, Paris, 2000, p. 235-246. Chroniques de Port-Royal, $\mathrm{n}^{\circ}$ 49, 2000, p. 71-86. $\mathrm{n}^{\circ} 49,2000$. Champion, Printemps 2000. Printemps 2000, p. 197-206. Kiev, 2000, p. 88-94. Kiev, 2000, p. 151-159. de Pascal », Kiev, 2000, p. 168-177. Ellipses, 2000, $208 \mathrm{p}$. p. 1-16.

EBER Régine, Travaillons l'histoire des sciences physiques. Hydrostatique et loi des gaz parfaits. Chimie: histoire des éléments, Centre Régional de Documentation Pédagogique

ETOA Marcelin Vounda, «Misère et grandeur de l'homme: Mauriac illustrateur de Pascal», in DURAND Jean-François (dir.), Pascal-Mauriac. L'œuvre en dialogue,

FERREIRA I. L., BROENS M.C., «A noção de costume na concepção moral de Blaise Pascal », Revista de Iniciação Científica, São Paulo, v. I, 2000, p. 209-215.

FERREYROLLES Gérard, "Goldmann visionnaire ", Port-Royal au miroir du XXe siècle,

FERREYROLLES Gérard (dir.), Port-Royal au miroir du XXe siècle, Chroniques de Port-Royal,

FERREYROLLES Gérard (dir.), Littérature et religion, Littératures classiques, $\mathrm{n}^{\circ} 39$, Paris,

FESENKO Valentine, «Une lecture pascalienne du Noud de vipères », in DURAND JeanFrançois (dir.), Pascal-Mauriac. L'œuvre en dialogue, L'Harmattan, Paris, 2000, p. 263-275.

FORCE Pierre, "Conditions d'efficacité du discours apologétique dans les Pensées », in FERREYROLLES Gérard (dir.), Littérature et religion, Littératures classiques, $\mathrm{n}^{\circ} 39$,

GARDIES Jean-Louis, "La Logique de Port-Royal: esquisse d'un bilan », Revue des Sciences philosophiques et théologiques, t. 84, $\mathrm{n}^{\circ} 1$, Vrin, Paris, janvier 2000, p. 83-92.

GINDIKIN Simon, Histoires de mathématiciens et de physiciens, Cassini, Paris, 2000, 246 p.

GOLOVASHENKO Irina, «Déplacement de l'esprit à la culture : la poétique du lieu commun ", Sententiae 1, Colloque international «Pluralisme de la rationalité dans la philosophie moderne : phénomène de Pascal », Kiev, 2000, p. 226-232.

GOMILKO Olga, «Les passions selon Pascal», Sententiae 1, Colloque international «Pluralisme de la rationalité dans la philosophie moderne: phénomène de Pascal ",

2 GORAK Ganna, «B. Pascal et la conception philosophico-anthropologique du monde », Sententiae 1, Colloque international «Pluralisme de la rationalité dans le philosophie moderne : phénomène de Pascal », Kiev, 2000, p. 66-74.

3 GORSKIY Vilen, «Phénomène de B. Pascal dans le contexte européen : un regard du rivage de l'ukrainologie historico-philosophique », Sententiae 1, Colloque international «Pluralisme de la rationalité dans la philosophie moderne : phénomène de Pascal »,

4 GOUDJIN Olga, "La notion de la tradition chez Pascal», Sententiae 1, Colloque international «Pluralisme de la rationalité dans la philosophie moderne : phénomène

GUICHARD Jacqueline, L'infini au carrefour de la philosophie et des mathématiques, Paris,

6 HAJEK Alan, «Objecting vaguely to Pascal's wager », Philosophical studies, 98, 2000, 
HAMMOND Nicholas, « Reading between the cracks : the deliberate discorder of Pascal's Pensées », Times Literary Supplement, 19 mai 2000, p. 7.

HASEKURA Takaharu, "Commentaire des Pensées de Pascal (10), L. 212, 213 », Bulletin of the graduate division of littérature of Waseda University, vol. 45, $\mathrm{n}^{\circ} 2,2000$, p. 45-58.

HATZFELD Marjolaine, « Lacan, lecteur de Pascal », Textuel, 39, 2000, p. 25-32.

HERON Pierre-Maris, « Nous, les écrivains du péché : Mauriac devant l'œuvre et la vie de Jouhandeau », in DURAND Jean-François (dir.), Pascal-Mauriac. L'œuvre en dialogue, L'Harmattan, Paris, 2000, p. 301-325.

HUNTER Graeme, "Motion and rest in the Pensées. A note on Pascal's modernism », International journal for Philosophy of religion, 47, 2000, p. 87-99.

HUREL Daniel-Odon et LAUDIN Gérard, Académies et sociétés savantes en Europe (1650-1800), Paris, Champion, 2000.

3 J.-L. P., «Les carrosses à cinq sols. Pascal a inventé la machine... à casser l'orgueil », La Montagne, samedi 28 octobre 2000, p. 3.

4 JULLIEN Vincent, « Silences cosmologiques », XVII siècle, $\mathrm{n}^{\circ}$ 207, 2-2000, p. 235-256.

KHOMA Oleg, «Textes pascaliens : types de l'instance narrative, status de la vérité, thème du nuance", Sententiae 1 , Colloque international «Pluralisme de la rationalité dans la philosophie moderne : phénomène de Pascal », Kiev, 2000, p. 22-34.

KIRNOZE Zoïa, « Dans la tradition de Pascal et de Dostoïevski : problèmes de conscience dans le cycle de Thérèse Desqueyroux ", in DURAND Jean-François (dir.), Pascal-Mauriac. L'œuvre en dialogue, Paris, L'Harmattan, 2000, p. 405-416.

KLITCHUK Alina, «Les vues religio-philosophiques sur l'être humain (selon les motifs de l'œuvre de B. Pascal et E. Gilson) », Sententiae 1, Colloque international «Pluralisme de la rationalité dans la philosophie moderne: phénomène de Pascal », Kiev, 2000, p. 185-191.

KOUTZEPAL Svitlana, « Pascal : "une trace/la trace" dans la conception de l'homme de la philosophie moderne postmoderne française », Sententiae 1, Colloque international "Pluralisme de la rationalité dans la philosophie moderne: phénomène de Pascal ", Kiev, 2000, p. 35-42.

9 KYRIACOPOULOS Laurent, « Peut-on tout de même parler d'un "triangle de Pascal" ? ", Revue d'histoire des mathématiques, 6, 200, p. 167-217.

Bo LACAN Jacques, Problèmes cruciaux pour la psychanalyse, Séminaire 1964-1965, Paris, Éditions de l'Association Freudienne Internationale, 2000.

81 LARCAN Alain, «René Taveneaux, un grand historien (1911-2000) », Le Pays lorrain, septembre 2000, p. 163-182.

82 LAZZERI Christian, "Pascal et la loi naturelle », Sententiae 1, Colloque international «Pluralisme de la rationalité dans la philosophie moderne: phénomène de Pascal ", Kiev, 2000, p. 123-139.

3 LE GALL André, Pascal, Flammarion, Paris, 2000, 598 p.

LEITENBERGER Frank, "Pascal's theorem and quantum deformation», Letters in mathematical physics, 51, 2000, p. 47-53. 
LEQUIN Yves-Marie, "Écriture et conversion : la source augustinienne », in DURAND Jean-François (dir.), Pascal-Mauriac. L'œuvre en dialogue, L'Harmattan, Paris, 2000, p. 277-290.

LESAULNIER Jean, "Conversations littéraires et philosophiques dans le salon de Madame de Sablé », in HUREL Daniel-Odon et LAUDIN Gérard (dir.), Académies et sociétés savantes en Europe (1650-1800), Paris, Champion, 2000, p. 49-64.

LESNE-JAFFRO Emmanuèle (dir.), Fléchier et les Grands Jours d'Auvergne, Acte d'une journée d'étude, Université Blaise Pascal, Clermont-Ferrand, 3 octobre 1997, Biblio 17, 122, Tübingen, Gunter Narr Verlag, 2000.

LE TOUZE Philippe, "Les trois nocturnes », in DURAND Jean-François (dir.), PascalMauriac. L'œuvre en dialogue, L'Harmattan, Paris, 2000, p. 195-210.

LUNDWALL Éric, Les carrosses à cinq sols. Pascal entrepreneur, Science infuse, Paris, 160 p.

MAGNARD Pierre, "On se fait une idole de la vérité même ", in PÉCHARMAN Martine (dir.), Pascal. Qu'est-ce que la vérité ?, Paris, PUF, 2000, p. 15-28.

MAGNARD Pierre, «Un corps plein de membres pesants », Revue Philosophique de la France et de l'Etranger, $\mathrm{n}^{\circ}$ 2, avril-juin 2000, 1137, p. 193-200.

MAGNION Gilles, "La voix de Salomon de Tultie », in MAZOUER Charles (dir.), Recherches des jeunes dix-septièmistes, Actes $d u 5^{e}$ colloque du Centre International de Rencontres sur le XVII siècle, Bordeaux, 28-30 janvier 1999, Tübingen, Biblio 17, Gunter Narr Verlag, 2000, p. 139-147.

93 MAINGUENEAU Dominique, «Les deux ordres de contraintes de la polémique ", in BOUACHA Ali et COSSUTTA F. (éd.), La polémique en philosophie, Éditions universitaires de Dijon, 2000, p. 153-165.

94 MALAKHOV Victor, «La lumière dans les ténèbres (sur l'ontologie de la raison en la philosophie de Pascal)», Sententiae 1, Colloque international «Pluralisme de la rationalité dans la philosophie moderne : phénomène de Pascal », Kiev, 2000, p. 5-12.

MARINS Imaculada Conceição Manhães, «Perspectiva e Ponto de Vista em Blaise Pascal ", Texto apresentado no VII Seminário do PPGF - UFRJ/IFCS e publicado nos Anais, Rio de Janeiro, 2000, p. 63-72.

6 MASSIGNAT Corinne, «Gassendi et l'élasticité de l'air : une étape entre Pascal et la loi de Boyle-Mariotte », Revue d'Histoire des Sciences, t. 53-2, avril-juin 2000, p. 179-203.

MAUCUER Maurice, «Le silence éternel des espaces infinis selon Mauriac, variation romanesque sur une pensée ", in DURAND Jean-François (dir.), Pascal-Mauriac. L'œuvre en dialogue, L'Harmattan, Paris, 2000, p. 179-193.

MAZAURIC Simone, «Pascal et la question du vide: emprunts et réemplois gassendistes ", in Libertinage et philosophie au XVII siècle, 4. Gassendi et les gassendistes et Les passions libertines, Saint-Étienne, Publications de l'Université de Saint-Étienne, 2000, p. 71-84.

99 McKENNA Antony, "Pascal : le cœur et les passions ", in Libertinage et philosophie au XVII siècle, 4.Gassendi et les gassendistes et Les passions libertines, Saint-Étienne, Publications de l'Université de Saint-Étienne, 2000, p. 209-217.

00 MILLET Dominique, «Le "mystère Mauriac" ou la tentation jansénisante ", in DURAND Jean-François (dir.), Pascal-Mauriac. L'œuvre en dialogue, L'Harmattan, Paris, 2000, p. 25-56. 
MOREAU Denis, «Belle occupation que de travailler à une logique ", Sources et effets de la Logique de Port-Royal, Revue des Sciences philosophiques et théologiques, t. 84, $\mathrm{n}^{\circ} 1$, Vrin, Paris, Janvier 2000, p. 5-10.

MOTHU Alain (dir.), Révolution scientifique et libertinage, Brepols, Turnhout, 2000, 312 p.

O'DWYER Michael, "Pascal et Mauriac dans le Journal de Julien Green », in DURAND Jean-François (dir.), Pascal-Mauriac. L'œuvre en dialogue, Paris, L'Harmattan, 2000, p. 355-369.

O'DWYER Michael, « Puritanisme américain et spiritualité pascalienne : une étude de Moïra de Julien Green", in La Rencontre des cultures dans la littérature européenne contemporaine, éd. Polet, Strasbourg, A.C.M. Édition, 2000.

OKOROKOV Valeryi, "Sur l'ontologie des "espaces flambants". L'appel de B. Pascal (raison, foi, existence)», Sententiae 1, Colloque international "Pluralisme de la rationalité dans la philosophie moderne: phénomène de Pascal», Kiev, 2000, p. 102-110.

PAPASOGLI Benedetta, Le « fond du cœur ». Figures de l'espace intérieur au XVII siècle, Paris, Champion, 2000.

PARMENTIER Bérengère, Le siècle des moralistes, Paris, Seuil, 2000.

PASCAL, Euvres complètes, II, éd. Le Guern, Paris, Gallimard, Pléiade, 2000.

PASCAL Blaise, Pensées, éd. Sellier et Ferreyrolles, Le Livre de Poche, Libraire Générale Française, 2000, 736 p.

PASQUA Hervé, Blaise Pascal penseur de la grâce, Paris, Téqui, 2000, 224 p.

PÉCHARMAN Martine (dir.), "La vérité, destination morale de l'homme dans les Pensées », in PÉCHARMAN Martine (dir.), Pascal. Qu'est-ce que la vérité ?, Paris, PUF, 2000, p. 137-164.

PÉCHARMAN Martine (dir.), Pascal. Qu'est-ce que la vérité ?, Paris, PUF, 2000, 166 p.

PÉCHARMAN Martine, "Préface: la vérité, de la logique à l'anthropologie ", in PÉCHARMAN Martine (dir.), Pascal. Qu'est-ce que la vérité ?, p. 1-12.

PENY Jean-Marie, « Mauriac et l'autre Pascal », in DURAND Jean-François (dir.), PascalMauriac. L'œuvre en dialogue, L'Harmattan, Paris, 2000, p. 111-122.

PLAINEMAISON Jacques, «Enquête sur Mauriac et Pascal dans le tome III du Bloc-notes (1961-1964)», in DURAND Jean-François (dir.), Pascal-Mauriac. L'œuvre en dialogue, L'Harmattan, Paris, 2000, p. 57-67.

PLAINEMAISON Jacques, «Deux aspects de la correction fraternelle dans l'œuvre de Blaise Pascal », Courrier du Centre International Blaise Pascal, n 21, 1999 (2000), p. 3-7.

17 Pluralisme de la rationalité dans la philosophie moderne: phénomène de Pascal, Colloque international, Sententiae 1, Kiev, 2000.

8 PROLEEV Serguiy, "Obéissance et pouvoir de la raison: paraphrase de Pascal», Sententiae 1, Colloque international «Pluralisme de la rationalité dans la philosophie moderne : phénomène de Pascal », Kiev, 2000, p. 35-42.

Promenade au puy de Dôme, Bibliothèque, Clermont-Ferrand, 2000, $112 \mathrm{p}$.

PRONIAKIHN Volodimir, "La philosophie de Pascal et la théologie occidentale contemporaine ", Sententiae 1, Colloque international « Pluralisme de la rationalité dans la philosophie moderne : phénomène de Pascal », Kiev, 2000, p. 178-184. 
ROCCHI Jean, Giordano Bruno après le procès, Complexe, sl, 2000, 306 p.

SAGNOL Marc, «V. Benjamin et L. Goldmann, lecteurs de Pascal », Sententiae 1, Colloque international «Pluralisme de la rationalité dans la philosophie moderne : phénomène de Pascal », Kiev, 2000, p. 84-87.

SAVELIEVA Marian, «Mode magique d'acquisition du savoir certain dans l'expérience de Pascal», Sententiae 1, Colloque international «Pluralisme de la rationalité dans la philosophie moderne : phénomène de Pascal », Kiev, 2000, p. 51-65.

SEAILLES André, «Les "Puissances trompeuses" chez Pascal et Mauriac ", in DURAND Jean-François (dir.), Pascal-Mauriac. L'œuvre en dialogue, L'Harmattan, Paris, 2000, p. 229-233.

SELLIER Philippe, «Impressions pascaliennes », in DURAND Jean-François (dir.), PascalMauriac. L'œuvre en dialogue, Paris, L'Harmattan, 2000, p. 17-23.

SELLIER Philippe, Port-Royal et la littérature, II, Le siècle de saint Augustin, La Rochefoucauld, $M^{\text {me }}$ de Lafayette, Sacy, Racine, Paris, Champion, 2000, 294 p.

Sententiae 1, Colloque international «Pluralisme de la rationalité dans la philosophie moderne : phénomène de Pascal », Kiev, 2000, 254 p.

SEVE Bernard, "Vérité au delà du pyrrhonisme, erreur en deçà ? La triple vérité du pyrrhonisme dans les Pensées de Pascal ", in PÉCHARMAN Martine (dir.), Pascal. Qu'est-ce que la vérité ?, Paris, PUF, 2000, p. 115-136.

SFEZ Gérald, Les doctrines de la raison d'État, Paris, Armand Colin, 2000, 224 p.

SHAMRAY Victoria, "L'image négative de l'ordre social dans l'œuvre de Pascal", Sententiae 1, Colloque international «Pluralisme de la rationalité dans la philosophie moderne : phénomène de Pascal », Kiev, 2000, p. 140-150.

SHIOKAWA Tetsuya, "Le "pari" de Pascal : de l'apologétique à la spiritualité », in FERREYROLLES Gérard (dir.), Littérature et religion, Littératures classiques, $\mathrm{n}^{\circ} 39$, Printemps 2000, p. 207-220.

SHIOKAWA Tetsuya, « Pascal en Extrême-Orient ", in FERREYROLLES Gérard (dir.), PortRoyal au miroir du XXe siècle, Chroniques de Port-Royal, 49, 2000, p. 121-134.

SOLLERS Philippe, «Le temps de Pascal », L'infini, 70, 2000, p. 3-5.

Sources et effets de la Logique de Port-Royal, Revue des Sciences philosophiques et théologiques, t. 84, $\mathrm{n}^{\circ}$ 1, Paris, Vrin, Janvier 2000, 134 p.

SPASENLO Natalia, « Métamorphoses de l'individualisme dans la philosophie politique moderne ", Sententiae 1, Colloque international «Pluralisme de la rationalité dans la philosophie moderne : phénomène de Pascal », Kiev, 2000, p. 192-202.

6 SPENGLER Jaime, A ordem como estatuto ontológico da existência humana em Pascal, Dissertação (Mestrado em Filosofia), Pontificium Athenaeum Antonianum, Facultas Philosophiae, Roma, 2000.

7 TABACHKOVSKIY Vitaliy, «Dilemme de l'essentiel et de l'existentiel dans la réflexion anthropologique », Sententiae 1, Colloque international "Pluralisme de la rationalité dans la philosophie moderne : phénomène de Pascal », Kiev, 2000, p. 75-83.

TABARROK Alexander, « Believe in Pascal's wager? Have I got a deal for you! », Theory and decision, 48, 2000, p. 123-128. 
TAKEMOTO Toshio, «Endô, lecteur de Pascal et de Mauriac », in DURAND Jean-François (dir.), Pascal-Mauriac. L'œeuvre en dialogue, L'Harmattan, Paris, 2000, p. 371-382.

TATON René, «L'Essay pour les coniques de Pascal », in TATON René, Études d'histoire des sciences, Turnhout, Brepols, 2000, p. 99-114.

TATON René, Études d'histoire des sciences, Turnhout, Brepols, 2000, 544 p.

THOMPSON Brian, "Mauriac et Pascal à la lumière du Mémorial ", in DURAND JeanFrançois (dir.), Pascal-Mauriac. L'œuvre en dialogue, Paris, L'Harmattan, 2000, p. 161-177.

TREMOLIERES François, «Approches de l'indicible dans le courant mystique français (Bremond et Certeau lecteurs des mystiques) », XVII siècle, nº 207, 2-2000, p. 273-298.

VAN VLIET Jan, "Gambling on faith : a holistic examination of Blaise Pascal's Wager ", The Westminster Theological Journal, Westminster Theological Seminary, Chestnut Hill, Philadelphia, Pennsylvania, vol. 62, n 1, Spring 2000, p. 33-63.

YABUUTI Kiyosi, Une histoire des mathématiques chinoises, Paris, Belin, Pour la science, 2000, $192 \mathrm{p}$.

YUDIN Olexandre, "La poétique du performatif dans les Pensées de Pascal (la performativité comme un moyen interprétatif et la question de la valeur artistique des Pensées) », Sententiae 1, Colloque international «Pluralisme de la rationalité dans la philosophie moderne : phénomène de Pascal », Kiev, 2000, p. 233-238.

ZAHITCHENKO Georgyi, « Souci du "roseau pensant". L'appel des époques : B. Pascal et M. Heidegger ", Sententiae 1, Colloque international «Pluralisme de la rationalité dans la philosophie moderne : phénomène de Pascal », Kiev, 2000, p. 95-101.

ZOLKINA Svitlana, "Le thème de l'homme chez Pascal et son développement dans la philosophie existentielle», Sententiae 1, Colloque international "Pluralisme de la rationalité dans la philosophie moderne: phénomène de Pascal», Kiev, 2000, p. 111-122.

\section{Année 2001}

ADORNO Francesco Paolo, « Pascal et le droit naturel », in CLÉRO Jean-Pierre (éd.), Les Pascal à Rouen, 1640-1648, Colloque de l'Université de Rouen, p. 357-374.

ARNAULD Antoine, Textes philosophiques, éd. Denis Moreau, PUF, Paris, 2001.

BÉNAC Karine, "Marivaux disciple de Pascal? Les "deux ordres" du divertissement dans les Journaux de Marivaux », Littératures, 45, automne 2001, p. 151-168.

BISCHOFF Jean-Louis, Dialectique de la misère et de la grandeur chez Blaise Pascal, Paris, L'Harmattan, 2001.

BLANC André, « Une Provinciale inédite? », DESCOTES Dominique, McKENNA Antony et THIROUIN Laurent (éd.), Le rayonnement de Port-Royal, Mélanges en l'honneur de Philippe Sellier, Paris, Champion, 2001, p. 301-307.

BORD André, "La vocation de Jacqueline », in CLÉRO Jean-Pierre (éd.), Les Pascal à Rouen, 1640-1648, Colloque de l'Université de Rouen, p. 347-353.

BORD André, "Pascal: essai de biographie spirituelle", in DESCOTES Dominique, McKENNA Antony et THIROUIN Laurent (éd.), Le rayonnement de Port-Royal, Mélanges en l'honneur de Philippe Sellier, Paris, Champion, 2001, p. 259-270. 

p. 525-239. Colloque de l'Université de Rouen, p. 321-346. l'Université de Rouen, 2001. l'Université de Rouen, p. 107-127. Universitaires Blaise Pascal, 2001. p. 2-3.

BOUCHILLOUX Hélène, "La genèse de l'apologétique pascalienne ", in CLÉRO JeanPierre (éd.), Les Pascal à Rouen, 1640-1648, Colloque de l'Université de Rouen, p. 279-294.

BOUCHILLOUX Hélène, "Le statut de l'amour-propre chez Pascal et Malebranche ", Port-Royal et l'Oratoire, Chroniques de Port-Royal, 50, Paris, Bibliothèque Mazarine, 2001,

BOUCHILLOUX Hélène, "La querelle de l'amour: Pascal, Malebranche, Fénelon », in DESCOTES Dominique, McKENNA Antony et THIROUIN Laurent (éd.), Le rayonnement de Port-Royal, Mélanges en l'honneur de Philippe Sellier, Paris, Champion, 2001, p. 95-108.

BRAS Gérard, « Pascal et le conservatisme en politique », in CLÉRO Jean-Pierre (éd.), Les Pascal à Rouen, 1640-1648, Colloque de l'Université de Rouen, p. 375-386.

CANTARUTTI Guilia, La scrittura aforistica, il Mulino, Bologna, 2001.

CARRAUD Vincent, «La physique dans le Récit des deux conférences: Pascal, Saint-Ange et l'atomisme du Novateur ", in CLÉRO Jean-Pierre (éd.), Les Pascal à Rouen, 1640-1648,

CLÉRO Jean-Pierre (éd.), Les Pascal à Rouen, 1640-1648, Colloque de l'Université de Rouen (GRHIS-UPRESA 6064-CERHIS), 17-19 novembre 1999, Rouen, Publications de

CLÉRO Jean-Pierre, «Une arithmétique pour la main. Réflexions sur la machine arithmétique ", in CLÉRO Jean-Pierre (éd.), Les Pascal à Rouen, 1640-1648, Colloque de

DELAMARRE Bernadette Marie, Pascal et la cité des hommes, Paris, Ellipses, 2001.

DESCOTES Dominique, "Les problèmes de la traduction dans le Triangle arithmétique ", in VIALLON Marie (dir.), La traduction à la Renaissance et à l'âge classique, Publications de l'Université de Saint-Étienne, Saint-Étienne, 2001, p. 39-71.

DESCOTES Dominique, "La rhétorique des expériences sur le vide », in CLÉRO JeanPierre (éd.), Les Pascal à Rouen, 1640-1648, Colloque de l'Université de Rouen, p. 237-261.

DESCOTES Dominique, Blaise Pascal. Littérature et géométrie, Clermont-Ferrand, Presses

DESCOTES Dominique, McKENNA Antony et THIROUIN Laurent (éd.), Le rayonnement de Port-Royal, Mélanges en l'honneur de Philippe Sellier, Paris, Champion, 2001.

DESCOTES Dominique, «Port-Royal et les indivisibles», in DESCOTES Dominique, McKENNA Antony et THIROUIN Laurent (éd.), Le rayonnement de Port-Royal, Mélanges en l'honneur de Philippe Sellier, Paris, Champion, 2001, p. 185-199.

DUCHÊNE Roger, Mon XVII siècle: de la marquise de Sévigné à Marcel Proust, CD-Rom, Éditions du CMR 17, Diffusion Klincksieck, Paris, 2001.

ESCOLA Marc, La Bruyère II. Rhétoriques du discontinu, Paris, Champion, 2001.

Examen critique des apologistes de la religion chrétienne, attribuable à Jean Lévesque de Burigny, éd. critique par Alain Niderst, Paris, Champion, 2001.

FAU Jean, « Pascal créateur d'entreprises », Lettre de l'URIS d'Auvergne, 14, octobre 2001,

4 FERREYROLLES Gérard, "De la causalité historique chez Pascal», in DESCOTES Dominique, McKENNA Antony et THIROUIN Laurent (éd.), Le rayonnement de Port-Royal, Mélanges en l'honneur de Philippe Sellier, Paris, Champion, 2001, p. 309-332. 

Paris, Champion, 2001, 1180 p. and London, The John Hopkins Press, 2001. 2001. Nationale de France, 2001. et raison, Paris, Ellipses, 2001. sceptiques, Paris, Champion, 2001, $732 \mathrm{p}$. Gérard Watelet, 2001. de Poitiers, 2001. Philippe Sellier, Paris, Champion, 2001, p. 369-398. l'Université de Rouen, p. 137-157. Corée, 48, 2001, p. 253-263. p. 21-30.

FONTAINE Nicolas, Mémoires ou histoire des Solitaires de Port-Royal, éd. Pascale Thouvenin,

FRANCK Claude, «Tout sur le calcul », La vie du collectionneur, 8 juin 2001, p. 10-15.

FRANKLIN James, The science of conjecture. Evidence and probability before Pascal, Baltimore

GARDIES Jean-Louis, Qu'est-ce que et pourquoi l'analyse? Essai de définition, Paris, Vrin,

GÉRARD Mireille, "Madame de Sévigné et le souvenir de Pascal», in DESCOTES Dominique, McKENNA Antony et THIROUIN Laurent (éd.), Le rayonnement de Port-Royal, Mélanges en l'honneur de Philippe Sellier, Paris, Champion, 2001, p. 449-462.

GERMAIN Marie Odile et THIBAULT Danièle, Brouillons d'écrivains, Paris, Bibliothèque

GILBERT Thérèse et ROUCHE Nicolas, La notion d'infini. L'infini mathématique entre mystère

GIOCANTI Sylvia, Penser l'irrésolution. Montaigne, Pascal, La Mothe Le Vayer : trois itinéraires

GOBRY Ivan, La reine Christine. La très secrète et scandaleuse reine de Suède, Pygmalion,

GRASSET Bernard, Les Pensées de Pascal, une interprétation de l'Écriture, Thèse, Université

GUION Béatrice, "Nicole, lecteur de Pascal», in DESCOTES Dominique, McKENNA Antony et THIROUIN Laurent (éd.), Le rayonnement de Port-Royal, Mélanges en l'honneur de

JONES Matthew L., "Writing and Sentiment: Blaise Pascal, the vacuum, and the Pensées ", Studies in Hisory and Philosophy of Science, vol. 32, p. 139-141.

JOUSLIN Olivier, "Polémique et mondanité dans l'affaire Saint-Ange ", in CLÉRO JeanPierre (éd.), Les Pascal à Rouen, 1640-1648, Colloque de l'Université de Rouen, p. 295-320.

KOYANAGI Kimiyo, «Cet effrayant petit livret... Expériences nouvelles touchant le vide de Blaise Pascal », in CLÉRO Jean-Pierre (éd.), Les Pascal à Rouen, 1640-1648, Colloque de

LAFOND Jean, "La scrittura aforistica da Montaigne a Champfort », CANTARUTTI Guilia, La scrittura aforistica, il Mulino, Bologna, 2001, p. 15-46.

LEE Whan, «La pensée politique de Pascal », Études de langue et littérature françaises,

Le fonds pascalien à Clermont-Ferrand, recensé par Dominique Descotes, Courrier du Centre International Blaise Pascal, 22-23, Clermont-Ferrand, 2000-2001.

2 LE GUERN Michel, « Histoire hypothétique de La Logique de Port-Royal », in DESCOTES Dominique, McKENNA Antony et THIROUIN Laurent (éd.), Le rayonnement de Port-Royal, Mélanges en l'honneur de Philippe Sellier, Paris, Champion, 2001, p. 161-172.

LEMARCHAND Guy, «Rouen au milieu du XVII ${ }^{\mathrm{e}}$ siècle : une grande ville de France », in CLÉRO Jean-Pierre (éd.), Les Pascal à Rouen, 1640-1648, Colloque de l'Université de Rouen, 
LESAULNIER Jean, «Itinéraires normands entre Rouen et Port-Royal autour de 1640 », in CLÉRO Jean-Pierre (éd.), Les Pascal à Rouen, 1640-1648, Colloque de l'Université de Rouen, p. 71-86.

LUDWIN Dawn M., Blaise Pascal's quest for the ineffable, New York, Peter Lang, 2001.

MAGNARD Pierre, "L'homme entre rien et tout », Port-Royal et l'Oratoire, Chroniques de Port-Royal, 50, Paris, Bibliothèque Mazarine, 2001, p. 433-445.

MAGNARD Pierre, Le vocabulaire de Pascal, Paris, Ellipses, 2001.

MAGNARD Pierre, «Un corps plein de membres pensants", in DESCOTES Dominique, McKENNA Antony et THIROUIN Laurent (éd.), Le rayonnement de Port-Royal, Mélanges en l'honneur de Philippe Sellier, Paris, Champion, 2001, p. 333-340.

MAZAURIC Claude, « Note sur la verrerie de Saint-Sever au temps d'Étienne Pascal », in CLÉRO Jean-Pierre (éd.), Les Pascal à Rouen, 1640-1648, Colloque de l'Université de Rouen, p. 159-178.

MAZAURIC Simone, «Les expériences sur le vide et le statut de l'expérience », in CLÉRO Jean-Pierre (éd.), Les Pascal à Rouen, 1640-1648, Colloque de l'Université de Rouen, p. 179-195.

McKENNA Antony, "Les Pensées de Pascal: une ébauche d'apologie sceptique ", in MOREAU Pierre-François (dir.), Le retour des philosophies antiques à l'âge classique, II, Le scepticisme au XVI et au XVII e siècle, Paris, Albin Michel, 2001, p. 348-361.

McKENNA Antony, Pierre Bayle, témoin et conscience de son temps. Un choix d'articles du Dictionnaire historique et critique, présentés et édités par Antony McKenna, Paris, Champion, 2001.

MERKER Claude, Le chant du cygne des indivisibles. Le calcul intégral dans la dernière cuvre scientifique de Pascal, Besançon, Presses Universitaires Franc-Comtoises, 2001.

MESNARD Jean, "Le double Mystère de Jésus ", in DESCOTES Dominique, McKENNA Antony et THIROUIN Laurent (éd.), Le rayonnement de Port-Royal, Mélanges en l'honneur de Philippe Sellier, Paris, Champion, 2001, p. 271-288.

MESNARD Jean, "Sur la composition dans les Provinciales de Pascal », Kwansei Gakuin University School of sociology Journal, 89, mars 2001, p. 23-29.

MEURILLON Christian, « Le Chancelier, les nu-pieds et la machine : Pascal père et fils à Rouen ", in CLÉRO Jean-Pierre (éd.), Les Pascal à Rouen, 1640-1648, Colloque de l'Université de Rouen, p. 89-105.

MICHAUX Bernard, «Pascal, Descartes et les artisans », in CLÉRO Jean-Pierre (éd.), Les Pascal à Rouen, 1640-1648, Colloque de l'Université de Rouen, p. 197-215.

MICHON Hélène, "Bérulle et Pascal: de l'anéantissement », Port-Royal et l'Oratoire, Chroniques de Port-Royal, 50, Paris, Bibliothèque Mazarine, 2001, p. 447-488.

MONTANDON Alain, "Gli spazi bianchi dell'aforisma", in CANTARUTTI Guilia, La scrittura aforistica, il Mulino, Bologna, 2001, p. 47-76.

MOREAU Pierre-François (dir.), Le scepticisme au XVI et au XVII siècle, Le retour des philosophies antiques à l'âge classique II, Paris, A. Michel, 2001.

MORIARTY Michael, "Imagination et rapports sociaux chez Pascal et Malebranche ", Port-Royal et l'Oratoire, Chroniques de Port-Royal, 50, Paris, Bibliothèque Mazarine, 2001, p. 525-539. 
NADEAU Christian, Le vocabulaire de saint Augustin, Paris, Ellipses, 2001.

NATOLI Charles M., "Les Provinciales: ruse contre ruse, force contre force?», in DESCOTES Dominique, McKENNA Antony et THIROUIN Laurent (éd.), Le rayonnement de Port-Royal, Mélanges en l'honneur de Philippe Sellier, Paris, Champion, 2001, p. 289-299.

NICOLLE Jean-Marie, «Le calcul du temps dans les assurances maritimes à l'époque de B. Pascal ", in CLÉRO Jean-Pierre (éd.), Les Pascal à Rouen, 1640-1648, Colloque de l'Université de Rouen, p. 129-135.

NIDERST Alain, « Pascal et la vie intellectuelle rouennaise », in CLÉRO Jean-Pierre (éd.), Les Pascal à Rouen, 1640-1648, Colloque de l'Université de Rouen, p. 49-69.

PASCAL, L'Art de persuader, précédé de L'Art de conférer de Montaigne, Préface de Marc Fumaroli, Paris, Rivages Poche, Petite Bibliothèque, Payot et Rivages, 2001, 150 p.

PASCAL Blaise, De l'art de persuader, Postface de Jérôme Vérain, sl, Mille et une nuits, 2001.

PAVLOVITS Tamás, "Pascal et Montaigne: deux apologistes modernes", in ELMARSAFY Ziad, Philosophies of Classical France. Philosophies au siècle classique, Romanice 14, Weidler Buchverlag, 2001, p. 1261-182.

PÉCHARMAN Martine, «Le divertissement selon Pascal ou la fiction de l'immortalité ", Cités 7, Paris, PUF, p. 13-19.

PÉCHARMAN Martine, «La justice selon Pascal », in SAMANA G., La justice, Ellipses, 2001, p. 113-128.

Pierre Bayle, Témoin et conscience de son temps. Un choix d'articles du Dictionnaire historique et critique, présentés et édités par Antony McKenna, Paris, Champion, 2001.

PIQUÉ Nicolas, "Apologétique, histoire et raison chez Pascal et Arnauld », in CLÉRO Jean-Pierre (éd.), Les Pascal à Rouen, 1640-1648, Colloque de l'Université de Rouen, p. 265-278.

POIRIER Jean-Paul, Mystification à l'Académie des sciences, Paris, Le Pommier, 2001.

Port-Royal et l'Oratoire, Chroniques de Port-Royal, 50, Paris, Bibliothèque Mazarine, 2001, $592 \mathrm{p}$.

Pour un musée Blaise Pascal et de sciences et techniques, Projet culturel, Musée du Ranquet, Hôtel de Fontfreyde, 2001, 2 vol.

POUZET Régine, Chronique des Pascal. «Les affaires du monde » d'Étienne Pascal à Marguerite Périer (1588-1733), Paris, Champion, 2001, 698 p.

QUANTIN Jean-Louis, Le rigorisme chrétien, Paris, Cerf, 2001.

ROMANO Antonella, « Enseignement des mathématiques et de la philosophie naturelle au collège de Rouen (première moitié du XVII ${ }^{e}$ siècle) ", in CLÉRO Jean-Pierre (éd.), Les Pascal à Rouen, 1640-1648, Colloque de l'Université de Rouen, p. 217-235.

ROMEO Maria Vita, «A proposito di scienza e fede in Pascal », Synaxis, XIX, 1-2001, p. 117-136.

ROUKHOMOVSKY Bernard, Lire les formes brèves, Paris, Nathan, 2001.

SAKA P., "Pascal's wager and the many Gods objection ", Religious studies, 37, 2001, p. 321-341.

SELLIER Philippe, Joie et mystique chez Pascal, Conférence donnée le 7 avril 2001 aux Granges de Port-Royal des Champs, Paris, Association des Amis des Granges de Port-Royal, 2001. 
Courrier du Centre international Blaise Pascal, 37 | 2015 japonais). Tezukayama VIII), 2001, p. 65-82 (en français). Champion, 2001, p. 351-368. Publications de l'Université de Saint-Étienne, 2001. l'Université de Rouen, p. 31-47.

\section{Année 2002} p. 239-246. Champion, 2002. 2002, p. 157-166. Tempe, mai 2000, Tübingen, Narr, 2002, p. 181-187. Ferrand, Éditions du miroir, 2002. Buenos Aires, 2002.

SERROR Frédéric, Mystère pascal ou la mort du père Noël, sl, Éditions Le Pommier, 2001.

SHIOKAWA Tetsuya, Lire les Pensées de Pascal, Tokyo, Iwanami Shoten, 2001 (en

TAKEDA Hiroki, « La physique pascalienne et sa méthode vues sous l'angle du problème de la pesanteur", in Tezukazama Gakuzyutsu ronsyu 8 (Bulletin de l'Université de

THIROUIN Laurent, «Transition de la connaissance de l'homme à Dieu : examen d'une liasse des Pensées ", in DESCOTES Dominique, McKENNA Antony et THIROUIN Laurent (éd.), Le rayonnement de Port-Royal, Mélanges en l'honneur de Philippe Sellier, Paris,

VIALLON Marie (dir.), La traduction à la Renaissance et à l'âge classique, Saint-Étienne,

ZYLBERBERG Michel, «Les relations internationales de Rouen dans le premier XVII ${ }^{e}$ siècle ", in CLÉRO Jean-Pierre (éd.), Les Pascal à Rouen, 1640-1648, Colloque de

ADORNO Francesco, "L'efficacité de la volonté chez Pascal et Adorno ", in WETSEL David et CANOVAS Frédéric (dir.), Pascal. New trends in Port-Royal studies. Actes du $33^{\mathrm{e}}$ congrès annuel de la North American Society for Seventeenth-Century French Literature, tome 1, Arizona State, Tempe, mai 2000, Tübingen, Narr, 2002, p. 91-100.

ALMQUIST Katherine, «Individual will and contract law in Pascal's Lettres Provinciales », in WETSEL David et CANOVAS Frédéric (dir.), Pascal. New trends in Port-Royal studies. Actes du $33^{e}$ congrès annuel de la North American Society for Seventeenth-Century French Literature, tome 1, Arizona State, Tempe, mai 2000, Tübingen, Narr, 2002,

BELIN Christian, L'âge de la conversation intérieure. La méditation au XVII siècle, Paris,

BJORNSTAD Hall, «The road not to be taken : a benjaminian approach to a pascalian baroque ", in WETSEL David et CANOVAS Frédéric (dir.), Pascal. New trends in Port-Royal studies. Actes du $33^{e}$ congrès annuel de la North American Society for SeventeenthCentury French Literature, tome 1, Arizona State, Tempe, mai 2000, Tübingen, Narr,

BOITANO John F., The polemics of libertine conversions in Pascal's Pensées. A dialectics of rational and occult libertine beliefs, Biblio 17, Tubingen, 2002.

BOLD Stephen, «Hyperbole in the Pensées », in WETSEL David et CANOVAS Frédéric (dir.), Pascal. New trends in Port-Royal studies. Actes du $33^{\mathrm{e}}$ congrès annuel de la North American Society for Seventeenth-Century French Literature, tome 1, Arizona State,

BONNET Olivier et GAZAGNES Philippe, Sur les traces de Michelin... à Clermont, Clermont-

BORD André, "Pascal à la lumière de saint Jean de la Croix », Sapientia, vol. LVII, 211, 

janv.-mars 2002, p. 3-20. Paris, Nolin, 2002. p. 23-27. Librairie Droz, 2002. Ferrand, 2001-2002, 25 p. Ferrand, 2002. $\mathrm{n}^{\circ} 1$, janv.-mars 2002, p. 21-40. Champion, 2002, p. 139-145. International Blaise Pascal, 24, 2002.
BOUCHILLOUX Hélène, "Apologie et théologie dans les Pensées de Pascal in Pascal », in Religion, Philosophie, Psychanalyse, Revue philosophique de la France et de l'étranger, $\mathrm{n}^{\circ} 1$,

CANTILLON Alain, «"Nous n'avions entrepris qu'un travail littéraire" : Victor Cousin éditeur de Pascal ", in Quelques "dix-septième siècle»: fabrications, usages et réemplois, Cahiers du centre de recherches historiques (CRH-GRIHL), École des Hautes Études en Sciences Sociales-CNRS, avril 2002, $\mathrm{n}^{\circ}$ 28-29, p. 79-90.

COTTRET Bernard, COTTRET Monique et MICHEL Marie-José, Jansénisme et puritanisme,

Courrier du Centre International Blaise Pascal, 24, 2002.

CRAVERI Benedetta, L'âge de la conversation, Paris, Gallimard, 2002.

CUZIN Jean-Claude, «Le pari de Pascal», Servir d'exemple, $\mathrm{n}^{\circ} 41$, décembre 2002,

DE BUJANDA J. M., Index librorum prohibitorum 1600-1966, Montréal, Médiaspaul, Genève,

DELFORGE Frédéric, Jacqueline Pascal, 1625-1661, Paris, Nolin, 2002.

FERDANT-GAUTIER Anne, De l'éternuement à la "besogne", ou de la gloire à la servitude de l'homme: étude d'un fragment des Pensées de Blaise Pascal, mémoire DEA Clermont-

FERDANT-GAUTIER Anne, Le corps objet de haine et outil de rédemption dans la Prière pour demander à Dieu le bon usage des maladies, de Blaise Pascal, Mémoire de DEA, Clermont-

FERREYROLLES Gérard, "Les païens dans la stratégie argumentative de Pascal ", in Pascal. Religion, Philosophie, Psychanalyse, Revue philosophique de la France et de l'étranger,

FERREYROLLES Gérard, "Compendium sur l'imagination dans les Pensées », in L'imagination au XVII' siècle, Littératures classiques, $\mathrm{n}^{\circ} 45$, printemps 2002, Paris,

FERREYROLLES Gérard, "Anthropologie et politique chez Pascal », Revue de langue et littérature françaises, 26 novembre 2002, p. 321-336.

FORCE Pierre, «Ad hominem arguments in Pascal's Pensées », in E. Koch (éd.), Classical unities: place, time, action, Biblio 17, $\mathrm{n}^{\circ}$ 131, Tübingen, G. Narr, 2002, p. 393-403.

FORCE Pierre, "L'argumentation sceptique dans les Pensées", in WETSEL David et CANOVAS Frédéric (dir.), Pascal. New trends in Port-Royal studies. Actes du $33^{\mathrm{e}}$ congrès annuel de la North American Society for Seventeenth-Century French Literature, tome 1, Arizona State, Tempe, mai 2000, Tübingen, Narr, 2002, p. 129-136.

GACHON Marc, «La "pascaline”, du Grand Pascal, ressuscitée par un "touche-à-tout" de génie ! », La Galipote, 100, été 2002, p. 40-41.

GASTINEL Bernard, «Une reconnaissance d'Étienne Pascal au XIVe siècle », in La parenté Pascal, Appel à la création d'une commission généalogique, Supplément au Courrier du Centre 
GIPPER Andreas, «Figuralität und Rhetorik. Zum Problem des uneigentlichen Sprechens in den Pensées Blaise Pascals ", Romanistisches Jahrbuch, vol.53, 2002, p. 142-157.

GUION Béatrice, Pierre Nicole moraliste, Paris, Champion, 2002.

HACKING Ian, L'émergence de la probabilité, Paris, Seuil, 2002.

HAMMOND Nicholas, "L'illusion de la parole chez Pascal », in L'illusion au XVII siècle, Littératures classiques, $\mathrm{n} \mathrm{n}^{\circ} 44$, hiver 2002, Paris, Champion, p. 305-311.

HAMMOND Nicholas, "Mémoire et éducation chez Pascal», in WETSEL David et CANOVAS Frédéric (dir.), Pascal. New trends in Port-Royal studies. Actes du $33^{\mathrm{e}}$ congrès annuel de la North American Society for Seventeenth-Century French Literature, tome 1, Arizona State, Tempe, mai 2000, Tübingen, Narr, 2002, p. 269-276.

HARRINGTON Thomas More, "Stratégie et philosophie dans les Pensées de Pascal ", Cahiers d'histoire des littératures romanes, Heidelberg, 1-2, 2002, p. 183-210.

HARRINGTON Thomas, "Ambiguïté et bivalence dans les Pensées de Pascal», in WETSEL David et CANOVAS Frédéric (dir.), Pascal. New trends in Port-Royal studies. Actes du $33^{\mathrm{e}}$ congrès annuel de la North American Society for Seventeenth-Century French Literature, tome 1, Arizona State, Tempe, mai 2000, Tübingen, Narr, 2002, p. 137-142.

HOWELL Robin, «Polemical stupidity in the Lettres Provinciales », in WETSEL David et CANOVAS Frédéric (dir.), Pascal. New trends in Port-Royal studies. Actes du $33^{\mathrm{e}}$ congrès annuel de la North American Society for Seventeenth-Century French Literature, tome 1, Arizona State, Tempe, mai 2000, Tübingen, Narr, 2002, p. 231-237.

HUA Laurent et ROUSSEAU Jean, Fermat a-t-il démontré son grand théorème? L'hypothèse "Pascal», Paris, L'Harmattan, 2002.

JAMES Edward, «Pascal on the limits of human understanding and the possibility of apologetic ", French studies bulletin, A quarterly supplement, 82, 2002, p. 4-6.

JONES Matthew L., "Geometry and fallen humanity in Pascal and Leibniz », in WETSEL David et CANOVAS Frédéric (dir.), Pascal. New trends in Port-Royal studies. Actes du $33^{\mathrm{e}}$ congrès annuel de la North American Society for Seventeenth-Century French Literature, tome 1, Arizona State, Tempe, mai 2000, Tübingen, Narr, 2002, p. 239-246.

JULLIEN Vincent, "Les fictions des mathématiciens du XVII ${ }^{e}$ siècle restent à michemin ", in L'imagination au XVII siècle, Littératures classiques, $\mathrm{n}^{\circ} 45$, printemps 2002, Paris, Champion, 2002, p. 77-87.

KRAWCZYK Dariusz, « Des anachronismes dans les éditions des Pensées de Pascal », in ABRAMOWICZ Maciej et MATYASZEWSKI Pawel (dir.), Dawne literatury romanskie: speyfika, zwiaki, dziedzictwo, Lublin, Redakcja Wydawnictw, Katolickiego Uniwersytetu lubelskiego, 2002, p. 272-284.

LACAN Jacques, D'un Autre à L'autre, Séminaire 1968-1969, Paris, Éditions de l'Association Freudienne Internationale (Publication hors commerce), 2002 (deuxième édition).

LAGARDE Alain, Le cœur a ses raisons que la raison ne connait point. Pascal, Nantes, Pleins feux, 2002.

La parenté Pascal, Appel à la création d'une commission généalogique, Supplément au Courrier du Centre International Blaise Pascal, 24, 2002.

La solitude et les solitaires de Port-Royal, Chroniques de Port-Royal, 51, Paris, Bibliothèque Mazarine, 2002. 
281 LE GUERN Michel, "Le tri des papiers, le tri des arguments ", in Pascal. Religion, Philosophie, Psychanalyse, Revue philosophique de la France et de l'étranger, $\mathrm{n}^{\circ}$ 1, janv.-mars 2002, p. 41-54.

LE GUERN Michel, «Une logique pascalienne de la proposition », in Le voyage et la langue. Mélanges en l'honneur d'Anouar Louca et d'André Roman, Institut français de Damas, 2002, p. 229-235.

LESAULNIER Jean, Images de Port-Royal, Paris, Nolin, 2002.

L'imagination au XVII siècle, Littératures classiques, $\mathrm{n}^{\circ} 45$, printemps 2002, Paris, Champion, 2002.

L'illusion au XVII' siècle, Littératures classiques, ${ }^{\circ}$ 44, hiver 2002, Paris, Champion, 2002.

L'innocence persécutée. Dialogues, Édition critique établie par Marie-Françoise BaverelCroissant, Publications de l'Université de Saint-Étienne, 2002.

287 MACKENZIE Louis, "Évidence, regard, preuve : le poids de la vision chez Pascal », in WETSEL David et CANOVAS Frédéric (dir.), Pascal. New trends in Port-Royal studies. Actes du 33e congrès annuel de la North American Society for Seventeenth-Century French Literature, tome 1, Arizona State, Tempe, mai 2000, Tübingen, Narr, 2002, p. 143-148.

MAINGUENEAU Dominique, "Double adresse et double contrainte dans les Provinciales ", in SIESS J. et VALENCY G., La double adresse, Paris, L'Harmattan, 2002, p. 87-102.

MAINGUENEAU Dominique, "L'ornement de la parole dans le jansénisme et l'humanisme dévot ", in DORNIER C. et SIESS J. (dir.), Éloquence et vérité intérieure, Paris, Champion, 2002, p. 79-94.

MARINER Francis, "Family perspectives in Gilberte Périer's Vie de Monsieur Pascal », in WETSEL David et CANOVAS Frédéric (dir.), Pascal. New trends in Port-Royal studies. Actes du $33^{e}$ congrès annuel de la North American Society for Seventeenth-Century French Literature, tome 1, Arizona State, Tempe, mai 2000, Tübingen, Narr, 2002, p. 203-217.

291 MARTY Alain, «Les formes pascaliennes ", in Mathématiques et architecture, Tangente, Hors-série, 14, Éditions Pôle, sans date (2002), p. 82-86. MESNARD JEAN, "Histoire secrète de la recherche pascaliennne au $\mathrm{XX}^{\mathrm{e}}$ siècle ", in WETSEL David et CANOVAS Frédéric (dir.), Pascal. New trends in Port-Royal studies. Actes $\mathrm{du} 33^{\mathrm{e}}$ congrès annuel de la North American Society for Seventeenth-Century French Literature, tome 1, Arizona State, Tempe, mai 2000, Tübingen, Narr, 2002, p. 13-38. MESNARD Jean, "Pascal et la doctrine de la double vérité », in Averroes (1126-1198) oder der Triumph des Rationalismus, Heidelberg, C. Winter, 2002, p. 333-344. MICHON Hélène, «De l'utilisation des figures dans les Pensées de Pascal », in Littérature, rites et liturgies, Paris, Imago, 2002, p. 92-105. MICHON Hélène, "L'irreprésentable dans les Pensées de Pascal ", Revue d'Histoire Littéraire de la France, janvier-février 2002, 1, PUF, p. 33-43.

MICHON Hélène, "Pascal et la relation d'altérité », La solitude et les solitaires de PortRoyal, Chroniques de Port-Royal, 51, Paris, Bibliothèque Mazarine, 2002, p. 347-359.

297 MICHON Hélène, «Pascal et Aristote », Courrier du Centre International Blaise Pascal, 24, 2002, p. 8-25. 
NAGASE Haruo, L'ordre et sa violation : l'invention de la Pascaline et sa signification dans la pensée de Pascal, Université d'Okayama, Faculté des Lettres, 2002 (en japonais).

NORO Yasushi, « Note sur la naissance et la mort d'Amable Bourzeis », Courrier du Centre International Blaise Pascal, 24, 2002, p. 47-50.

O'DWYER Michael, «Puritanisme américain et spiritualité pascalienne. Une étude de Moïra de Julien Green », in GORMAILE O. (dir.), La Rencontre des cultures dans la littérature contemporaine, Paris, Dupli Média, 2002, p. 105-115.

PARKER Thomas, «Intensionality and non causa pro causa in Pascal », in WETSEL David et CANOVAS Frédéric (dir.), Pascal. New trends in Port-Royal studies. Actes du $33^{\mathrm{e}}$ congrès annuel de la North American Society for Seventeenth-Century French Literature, tome 1, Arizona State, Tempe, mai 2000, Tübingen, Narr, 2002, p. 173-180.

PAROLINI Rocco, Il Pascal dialettico del XX $X^{e}$ secolo : excursus storico, Università degli Studi di Ferrara, 2002.

PASCAL Blaise, Trois discours sur la condition des grands, Concepts, Revue semestrielle de philosophie, Mons, Sils-Maria, 2002, p. 3-12.

PASCAL Blaise, Scritti di fisica, Introduzione, traduzione e note di Maria Vita Romeo, Catania, Edizioni Greco, 2002.

PASCAL Blaise, Il Vangelio dei Vangeli di Blaise Pascal. Abrégé de la vie de Jésus-Christ, éd. Carlo Carena, Biblioteca di parole perdute, Torino, Umberto Allemadi et Co, 2002.

PERATONER Alberto, Blaise Pascal. Ragione, rivelazione et fondazione dell'etica, Il percorso dell'Apologie, Con un saggio di Carmelo Vigna, Libreria Editirce Cafoscarina, Venise, 2002, 2 vol.

POUGET-DOMPMARTIN C., «Les Pensées de Pascal : comment s'écrit la coupure. Notes sur le manuscrit, les variantes, et les différentes éditions des feuillets parmi lesquels fut trouvé le texte du Pari", Bulletin de l'Association freudienne internationale, $1^{\text {er }}$ trimestre 2002, p. 7-9.

PUGH Anthony, "Imagination and the unity of the Pensées ", in WETSEL David et CANOVAS Frédéric (dir.), Pascal. New trends in Port-Royal studies. Actes du $33^{\mathrm{e}}$ congrès annuel de la North American Society for Seventeenth-Century French Literature, tome 1, Arizona State, Tempe, mai 2000, Tübingen, Narr, 2002, p. 65-73.

RICHARDT Aimé, Le Jansénisme de Jansénius à la mort de Louis XIV, Paris, François-Xavier de Guibert, 2002.

RILEY Patrick, "Blaise Pascal, Jeanne Guyon and the paradox of the moi haïssable ", Papers on French Seventeenth Century Literature, 29, 56, 2002, p. 223-240.

SCHÄRER Kurt, «Vom schwierigen Umgang mit dem Bruchstückhaften », in SCHÄRER Kurt et SONDEREGGER Erwin (dir.), Brüche, Torsi, Unvollendetes. Über das Fragmentische in Leben, Kunst und Wissenschaft, Chronos, 2002, p. 99-118.

SCHOLAR Richard, «La force de l'imagination de Montaigne: Camus, Malebranche, Pascal ", L'imagination au XVII siècle, Littératures classiques, $\mathrm{n}^{\circ} 45$, printemps 2002, Paris, Champion, 2002, p. 127-138.

SECRETAN Philibert, Le pouvoir et le salut, Paris, L'Harmattan, 2002.

SEIFE Charles, Zéro. La biographie d'une idée dangereuse, Paris, J.-C. Lattès, 2002. 
SELLIER Philippe, «Critique et poétique, Valéry ou Pascal », Critique, 656-657, janvierfévrier 2002, p. 72-80.

SELLIER Philippe, "Pascal : imaginaire et théologie", in WETSEL David et CANOVAS Frédéric (dir.), Pascal. New trends in Port-Royal studies. Actes du $33^{\mathrm{e}}$ congrès annuel de la North American Society for Seventeenth-Century French Literature, tome 1, Arizona State, Tempe, mai 2000, Tübingen, Narr, 2002, p. 39-57.

«Séminaire sur les Pensées de Pascal », Courrier du Centre International Blaise Pascal, 24, 2002, p. 26-46.

SHIOKAWA Tetsuya, "Les limites de l'apologétique pascalienne », in WETSEL David et CANOVAS Frédéric (dir.), Pascal. New trends in Port-Royal studies. Actes du $33^{\mathrm{e}}$ congrès annuel de la North American Society for Seventeenth-Century French Literature, tome 1, Arizona State, Tempe, mai 2000, Tübingen, Narr, 2002, p. 149-156.

STILWELL John, Mathematics and its history, Second edition, New York, Springer, 2002.

TABET Emmanuelle, Chateaubriand et le XVII ${ }^{e}$ siècle, Paris, Champion, 2002.

"Table générale des numéros 1 à 50, 1950-2000", Chroniques de Port-Royal, Paris, Bibliothèque Mazarine, 2002.

THIROUIN Laurent, «Le moraliste et les fantômes : la controverse classique autour de l'illusion théâtrale ", in L'illusion au XVII e siècle, Littératures classiques, $\mathrm{n}^{\circ} 45$, hiver 2002, Paris, Champion, p. 265-283.

TOLLET Daniel (dir.), Le Jansénisme et la Franc-Maçonnerie en Europe centrale aux XVII et XVIII siècles, Paris, PUF, 2002.

WEAVER F. Ellen, Mademoiselle de Joncoux. Polémique janséniste à la veille de la bulle Unigenitus, Paris, Cerf, 2002.

WEAVER F. Ellen, La Contre-réforme et les Constitutions de Port-Royal, Paris, Cerg, 2002.

WETSEL David et CANOVAS Frédéric (dir.), Pascal. New trends in Port-Royal studies. Actes du $33^{\mathrm{e}}$ congrès annuel de la North American society for seventeenth-century french literature, tome 1, Arizona State, Tempe, mai 2000, Tübingen, Narr, 2002.

\section{Année 2003}

ADORNO Francesco, "Astuteness and limits of penitence ", Anthropology and aesthetics, Res. 44, Autumn 2003, p. 145-158.

ARMOGATHE Jean-Robert et CARRAUD Vincent, "Bibliographie cartésienne (1960-1996) », Centro interdisciplinare di studi su Descartes e il seicento, Lecce, Conte, 2003.

BALAN-NISTOR Doina, Omul în orizontul cãutaãrii, Blaise Pascal, Iasi, Performantica, 2003.

BOUCHILLOUX Hélène, "Pascal and the social world », in HAMMOND Nicholas (dir.), The Cambridge companion to Pascal, Cambridge, 2003, p. 201-215.

BRAIDER Christopher, «Pascal's machine : science and theology in the Provinciales and the Pensées ", in Le savoir au XVII siècle, actes du $34^{e}$ congrès annuel de la North American Society fort seventeenth century french literature, Univ. of Virginia, 14-16 mars 2002, p. 345-355. 
CANTILLON Alain, Le Pari-de-Pascal: une série d'énonciations entre 1660 et 1850, Thèse, EHESS, 2003.

CANTILLON Alain, «La vive voix posthume de Pascal: instituer le malentendu en 1670 ", in Le Malentendu, généalogie du geste herméneutique, actes du colloque tenu en février 2002 à la Sorbonne et à l'Université Paris VIII, CLÉMENT Bruno et ESCOLA Marc (dir.), Saint-Denis, PUV, coll. La Philosophie hors de soi, 2003, p. 89-105.

CHÂTELLIER Louis, Les espaces infinis et le silence de Dieu. Science et religion, XVI ${ }^{e}$-XIX ${ }^{e}$ siècle, Paris, Aubier, 2003.

CLARKE Desmond M., " Pascal's philosophy of science ", in HAMMOND Nicholas (dir.), The Cambridge companion to Pascal, Cambridge, 2003, p. 102-121.

CUSSAC Hélène, "La retraite chez Gil Blas : entre Pascal et Rousseau ", in WAGNER Jacques (dir.), Lectures de Gil Blas de Lesage, Clermont-Ferrand, Presses Universitaires Blaise Pascal, 2003, p. 143-161.

DERRIENNIC Yves, « Pascal et les problèmes du chevalier de Méré. De l'origine du calcul des probabilités aux mathématiques financières d'aujourd'hui», Gazette des mathématiciens, Société mathématique de France, juillet 2003, nº 97, p. 45-71.

DESCOTES Dominique, "Pascal et le problème des démonstrations multiples ", in La preuve, Le temps des savoirs, 5, Paris, Odile Jacob, 2003, p. 75-99.

DESCOTES Dominique et PROUST Gilles, "Le droit a ses époques». De Pascal à Domat, CDRom PC, CERHAC et CIBP, Clermont-Ferrand, Presses Universitaires Blaise Pascal, 2003.

DESCOTES Dominique, Pascal. La théologie et le calcul, Pour la science, Les génies de la science, $\mathrm{n}^{\circ}$ 16, août-novembre 2003.

«Deuxième synthèse du séminaire sur les Pensées de Pascal : compte rendu général 2001-2002 ", Courrier du Centre International Blaise Pascal, 25, 2003, p. 22-40.

DUNCAN Craig, "Do vague probabilities really scotch Pascal's wager? », Philosophical studies, 112, 2003, p. 279-290.

DURAN José Rafael Solano, Dos tipos de ética. La polémica moral entre Pascal y los Jesuitas a raiz de las Cartas a un Provincial, Pontificia universitas Gregoriana, Facultas theologiae, Roma, 2003.

EDWARDS A. W. F., « Pascal's work on probability », in HAMMOND Nicholas (dir.), The Cambridge companion to Pascal, Cambridge, 2003, p. 40-52.

ELMARSAFY Ziad, Freedom, slavery, and absolutism: Corneille, Pascal, Racine, Lewisburg, Bucknell University Press, London, Associated University Presses, 2003.

ELSTER Jon, « Pascal and decision theory », in HAMMOND Nicholas (dir.), The Cambridge companion to Pascal, Cambridge, 2003, p. 53-74.

FERRARI Osvaldo et BORGES Jorge Luis, «Blaise Pascal», in Retrouvailles: dialogues inédits, tr. B. Fillaudeau, Paris, Corti, 2003, p. 70-77.

FORCE Pierre, «Pascal and philosophical method", in HAMMOND Nicholas (dir.), The Cambridge companion to Pascal, Cambridge, 2003, p. 216-234.

FOUKE Daniel C., "Pascal's physics", in HAMMOND Nicholas (dir.), The Cambridge companion to Pascal, Cambridge, 2003, p. 75-101.

GHEERAERT Tony, Le chant de la grâce. Port-Royal et la poésie d'Arnauld d'Andilly à Racine, Paris, Champion, 2003. 

companion to Pascal, Cambridge, 2003, p. 122-143. Université Lyon 3, 2003, p. 117-127. France, avril-juin 2003, $\mathrm{n} \mathrm{n}{ }^{\circ}$ 2, p. 267-273. 2003. Pensées, Lyon, PUL, 2003. p. 155-178. Vuibert, 2003.

HAMMOND Nicholas (dir.), The Cambridge companion to Pascal, Cambridge, 2003.

HAMMOND Nicholas, "Pascal's Pensées and the art of persuasion", in HAMMOND Nicholas (dir.), The Cambridge companion to Pascal, Cambridge, 2003, p. 235-252.

HASEKURA Takaharu, «Commentaire des Pensées de Pascal », L. 214 », Études françaises, Section française de la Faculté des lettres Université Waseda, $\mathrm{n}^{\circ}$ 10, 2003, p. 16-41. JOUSLIN Olivier, « Pascal poète en prose ", XVII ${ }^{e}$ siècle, octobre 2003, n 221, p. 713-747. JOUSLIN Olivier, "Pascal et sa créature : un monstre de mots. Le jésuite dans les Provinciales ", in GHEERAERT T., COTTIGNIES L. VENET G., La beauté et ses monstres dans l'Europe des XVI'-XVII siècles, Paris, Presses Sorbonne nouvelle, 2003, p. 203-215.

JULLIARD Jacques, Le choix de Pascal, Paris, Desclée de Brouwer, 2003.

KHALFA Jean, «Pascal's life and times ", in HAMMOND Nicholas (dir.), The Cambridge

KHALFA Jean, "Pascal's theory of knowledge ", in HAMMOND Nicholas (dir.), The Cambridge companion to Pascal, Cambridge, 2003, p. 122-143.

KOCH Erec, "Sacred/secular rhetoric in Pascal's Lettres Provinciales", in Intersections. Actes du $35^{\mathrm{e}}$ colloque annuel de la North American Society for Seventeenth Century Literature, Dartmouth College, 8-10 mai 2003, Tübingen, Narr, 2005, p. 327-335.

KOYANAGI Kimiyo, "Datation des écrits de physique de Pascal - une nouvelle évaluation de la Préface sur le Traité du vide ", The Journal of the faculty of foreign studies, Aichi Prefectural University, 4, 2003, p. 133-150 (en japonais).

LANCELOT Claude, Mémoires touchant la vie de M. de Saint-Cyran, Paris, Nolin, 2003.

LANDRY Jean-Pierre, «Pascal et la douceur », in PRAT M.-H. et SERVET P. (dir.), Le doux aux $\mathrm{XVI}^{e}$ et XVII ${ }^{e}$ siècles : écriture, esthétique, politique, spiritualité, Cahiers du GADGES, Lyon,

LE GUERN Michel, Pascal et Arnauld, Paris, Champion, 2003.

LE GUERN Michel, «Les lettres de Jacqueline Pascal », Revue d'Histoire Littéraire de la

LOEVLIE Elisabeth Marie, Literary silences in Pascal, Rousseau, and Beckett, Oxford, New York, Oxford University Press (Oxford modern languages and literature monographs),

MAGNIONT Gilles, Traces de la voix pascalienne. Examen des marques de l'énonciation dans les

MAIERHOFER Martina. Zur Genealogie des Imaginären: Montaigne, Pascal, Rousseau, Tübingen, Günter Narr, Romanica Monacensia, 64, 2003.

MAIRE Catherine, "Le "jansénisme" selon Bernard Hroethuysen ", Cahiers du Centre de Recherches historiques, octobre 2003, $\mathrm{n}^{0} 32, \mathrm{p} .113-122$.

MARTINS Andrei Venturini, « O trágico diante do acaso », Lumen, São Paulo, v. 9, 2003,

MAURY Jean-Pierre, À l'origine de la recherche scientifique: Mersenne, éd. S. Taussig, Paris, 
McKENNA Antony, "The reception of Pascal's Pensées in the seventeenth and eighteenth centuries ", in HAMMOND Nicholas (dir.), The Cambridge companion to Pascal, Cambridge, 2003, p. 253-263.

MERSENNE Marin, La vérité des sciences contre les sceptiques ou pyrrhoniens, éd. D. Descotes, Paris, Champion, 2003.

MESNARD Jean, «De la pièce d'archives au portrait psychologique. Le cas de Blaise Pascal », Histoire et archives, 14, juillet-décembre 2003, p. 49-66.

MICHON Hélène, "Réflexions sur le statut de la rhétorique dans l'apologétique pascalienne », XVII siècle, $\mathrm{n}^{\circ}$ 219, avril-juin 2003, p. 271-285.

MORIARTY Michael, "Grace and religious belief in Pascal ", in HAMMOND Nicholas (dir.), The Cambridge companion to Pascal, Cambridge, 2003, p. 144-161.

NATAN Stéphane, Les Pensées de Pascal : d'un projet apologétique à un texte poétique, Thèse, Université Lyon III, 2003, 3 vol.

NATAN Stéphane, «La tonalité ironique et ludique des Pensées de Pascal », L'information littéraire, 2, 2003, p. 29-34.

NICA Dana, "Blaise Pascal: la raison des Essais», Analele Stiitifice ale Universitatii «Alexandru Ioan Cuza » din Iasi (serie noua), Limbi si Literaturi straine, t. VI-VII, 2003-2004, p. 66-78.

NOILLE-CLAUZADE Christine, L'univers du style. Analyses de la rhétorique classique, coll. Recherches textuelles, Université de Metz, 2003.

OUAKNIN Marc-Alain, Mystères des chiffres, Paris, Assouline, 2003.

PARISH Richard, «Pascal's Lettres provinciales : from flippancy to fundamentals », in HAMMOND Nicholas (dir.), The Cambridge companion to Pascal, Cambridge, 2003, p. 182-200.

PASCAL Blaise, Pensées, édition présentée, établie et annotée par Philippe Sellier, Paris, Agora, Pocket, 2003.

PASCAL Blaise, Entretien avec Sacy sur la philosophie, présentation de R. Scholar, Paris, Actes Sud, 2003.

PASCAL Blaise, Pensieri, nuova edizione a cura di Philippe Sellier, secondo "l'ordine" pascaliano, introduzione e traduzionne di Benedetta Papasogli, Roma, Città Nuova editirice, 2003.

PASCAL Jacqueline, A rule for children and other writings, éd. J. J. Cormley, SJ, ChicagoLondon, University of Chicago Press, 2003.

PEROUSE Marie, "Pascal trahi? L'édition de 1670 et l'exemple du pyrrhonisme", Courrier du Centre International Blaise Pascal, 25, 2003, p. 41-44.

PHILIPS Henry, « Pascal's reading and the inheritance of Montaigne and Descartes », in HAMMOND Nicholas (dir.), The Cambridge companion to Pascal, Cambridge, 2003, p. 20-39.

PLAINEMAISON Jacques, Blaise Pascal polémiste, Presses Universitaires Blaise Pascal, Clermont-Ferrand, 2003.

POMMIER René, ô Blaise ! À quoi tu penses ?, Bruxelles, Éditions du centre d'action laïque, 2003.

RÉGENT Anne, «Pascal, de la polémique à l'apologie », Courrier du Centre International Blaise Pascal, 25, 2003, p. 4-21. 
REGUIG-NAYA Delphine, Le corps des idées. Pensées et poétiques du langage dans l'augustinisme du second Port-Royal, Thèse, Université Jean-Monnet, Saint-Étienne, 3 vol., 2003.

RIBARD Dinah, "Nom d'auteur et effet de lecture : L'Entretien de Pascal avec M. de Sacy », XVII ${ }^{\mathrm{e}}$-XIX ${ }^{\mathrm{e}}$ siècle", XVII siècle, avril-juin 2003, n 219 , p. 259-270.

RIBARD Dinah, «Nom d'auteur et effet de lecture : l'Entretien de Pascal avec M. de Sacy, XVII ${ }^{e}$-XIXe $"$, XVII ${ }^{e}$ siècle, avril-juin 2003, no 219, p. 259-270.

RICHARDT Aimé, Les savants du Roi Soleil, Paris, F.-X. de Guibert, 2003.

ROGERS Ben, "Pascal's life and times", in HAMMOND Nicholas (dir.), The Cambridge companion to Pascal, Cambridge, 2003, p. 4-19.

ROMEO Maria Vita, Verità e bene. Saggio su Pascal, Catane, Cooperativa Universitaria Editrice catanese di Magisterio, 2003.

SELLIER Philippe, Essais sur l'imaginaire classique. Pascal, Racine, Précieuses et moralistes, Fénelon, Paris, Champion, 2003.

SELLIER Philippe, «Un fragment axial des Pensées de Pascal : l'Entretien sur Épictète et Montaigne ", Il confronto letterario, $\mathrm{n}^{\circ}$ 39, 2003, p. 15-26.

SHEA William R., Designing experiments and games of chance, The unconventional science of Blaise Pascal, Watson Publishing International, 2003.

SHIOKAWA Tetsuya, Recherches pascaliennes, Tokyo, Iwanami Shoten, 2003 (en japonais).

SUIRE Yannis, "L'œuvre de dessèchement des Marais poitevins", XVII ${ }^{e}$ siècle, octobre 2003, $\mathrm{n}^{\circ} 221$, p. 611-636.

SUSINI Laurent, "La vraie éloquence en question dans les Pensées de Pascal», Revue d'Histoire Littéraire de la France, PUF, janvier-mars 2003, n 1, p. 17-29.

TAKEDA Hiroki, «La notion d'espace chez Pascal. La situation historique et la position de Pascal », in Sapientia (Bulletin de l'Université d'Eichi), 2003, p. 121-139 (en japonais).

THIBON Gustave, Ils sculptent en nous le silence: rencontres: Kierkegaard, saint Jean de la Croix, André Gide, Gabriel Marcel, Chateaubriand, Sénèque, Victor Hugo, Lanza del Vasto, Alain, Pascal, Racine, Maurras, Mistral, Olivier de Serres, Henri Moreau, Jacques Maritain, Simone Weil, préface de Philippe Barthelet, Paris, F.X. de Guibert, 2003.

Travaux d'étudiants sur les Pensées et les Provinciales, Centre d'Etudes sur les Réformes, l'Humanisme et l'Âge Classique, Centre International Blaise Pascal, Clermont-Ferrand, 2003.

TROUSSON Raymond et VERCRUYSSE Jeroom, Dictionnaire général de Voltaire, Paris, Champion, 2003.

WETSEL David, «Pascal and holy writ », in HAMMOND Nicholas (dir.), The Cambridge companion to Pascal, Cambridge, 2003, p. 162-181.

\section{Année 2004}

9 Alphonse Dupront devant Pascal, Fascinations et résistances, Cahiers Alphonse Dupront, 9-10, 2004.

BOUCHILLOUX Hélène, Pascal, Paris, Vrin, 2004. 
411 BOUCHILLOUX Hélène, « Le sage, le philosophe le politique chez Pascal : qu'est-ce qu'un roi de concupiscence? ", in Le philosophe, le sage et le politique de Machiavel aux Lumières, Publications de l'Université de Saint-Étienne, 2004.

CARENA Carlo, "Le Pensées, texto da tradurre », in PAPASOGLI Benedetta (dir.), Le Pensées di Pascal: dal disegno all'edizione, Studi francesi, $\mathrm{n}^{\circ} 143$, Torino, Rosenberg et Sellier, mai-août 2004, p. 321-328.

CLÉRO Jean-Pierre, Les raisons de la fiction. Les philosophes et les mathématiques, Paris, Colin, 2004.

Courrier du Centre International Blaise Pascal, $\mathrm{n}^{\circ}$ 26, Clermont-Ferrand, 2004. Stuttgart, Steiner, 2004.

DENIS Delphine et SPICA Anne-Elisabeth (dir.), Les langages au XVII siècle, Littératures classiques, $\mathrm{n}^{\circ}$ 50, printemps 2004, Paris, Champion, 2004. DESCOTES Dominique, "L'interprétation des nombres chez Pascal ", in SHIOKAWA Tetsuya (dir.), Littérature et mystique dans la France moderne, Research project report, Université de Tokyo, mai 2004, p. 19-29. DESCOTES Dominique, «Le problème de l'ordre chez Pascal », in PAPASOGLI Benedetta (dir.), Le Pensées di Pascal: dal disegno all'edizione, Studi francesi, $\mathrm{n}^{\circ} 143$, Torino, Rosenberg et Sellier, mai-août 2004, p. 281-300. EMMANUELLE Sœur, avec Philippe ASSO, Vivre, à quoi ça sert ?, Paris, Flammarion, 2004. FERREYROLLES Gérard, «Pascal et les païens », in SHIOKAWA Tetsuya (dir.), Littérature et mystique dans la France moderne, Research project report, Université de Tokyo, mai 2004, p. 7-17. GODFROY-GENIN Anne-Sophie, De la doctrine de la probabilité à la théorie des probabilités. Pascal, la Logique de Port-Royal, Jacques Bernoulli, Thèse de l'Université Paris IV, 2004. GUENANCIA Pierre, "Remarques sur le corps comme figure chez Pascal », in JAQUET Chantal et PAVLOVITS Tamas, Les significations du "corps" dans la philosophie classique, Paris, L'Harmattan, 2004, p. 91-105.

HALLYN Fernand, Les structures rhétoriques de la science. De Kepler à Maxwell, Paris, Seuil, 2004.

HAMMOND Nicholas, Framentary voices. Memory and education at Port-Royal, Biblio 17, Tübingen, Gunter Narr Verlag, 2004. HÉBERT Élisabeth, Instruments scientifiques à travers l'histoire, Paris, Ellipses, 2004. JAQUET Chantal et PAVLOVITS Tamas, Les significations du "corps » dans la philosophie classique, Paris, L'Harmattan, 2004. JOUSLIN Olivier, "Rien ne nous plaît que le combat ». Pascal et le dialogue polémique, Thèse Paris IV, 2004, 2 vol. jeudi 6 mai 2004, cahier $\mathrm{n}^{\circ} 3$, p. 8. LE BLANC Marianne, D'acide et d'encre. Abraham Bosse (1604?-1676) et son siècle en perspectives, Paris, CNRS Éditions, 2004.

430 LE NOXAIIC Armand, Les métamorphoses du vide, Bibliothèque scientifique, Pour la science, Paris, Belin, 2004. 

l'ADASTA, nº 57, janvier 2004, p. 3. Revista de Filosofia, 45 (109), Jun 2004, p. 7-31. p. 57-76. Bibliothèque Mazarine, 2004, p. 107-127. Paris, Nathan, 2004. Connaissance et Savoir, 2004.

LESAULNIER Jean et McKENNA Antony, Dictionnaire de Port-Royal, Paris, Champion, 2004.

LESAULNIER Jean, «Les hébraïsants de Port-Royal », Port-Royal et le royaume d'Israël, Chroniques de Port-Royal, 53, Paris, Bibliothèque Mazarine, 2004, p. 29-45.

Les "Jeunes Pousses de l'ADASTA», Groupe Blaise Pascal, «Blaise Pascal, savant d'Auvergne, génie de la science et de la pensée ", Auvergne Sciences, Bulletin de

LIOURE Michel, «Présence de Pascal dans les romans de Mauriac », in François Mauriac, lecture et création, Paris, L'Harmattan, 2004, p. 217-238.

LUÍS CÉSAR GUIMARÃES Oliva, «A história como sacrifício em Blaise Pascal », Kriterion,

MANENT Pierre, « L'Israël de Pascal », Port-Royal et le royaume d'Israël, Chroniques de PortRoyal, 53, Paris, Bibliothèque Mazarine, 2004, p. 129-136.

MARINS Imaculada Conceição Manhães, Pascal $e$ as Modalidades da Razão: uma Interpretação da Concepção de Deus e Jesus Cristo nos Pensamentos, Tese de Doutorado, Rio de Janeiro, UFRJ/IFCS. Biblioteca Depositária, SIBI/UFRJ, 2004.

MARTINS Andrei Venturini et SILVA Gilberto Cabral, «O pecado de Pascal e o acaso de Darwin », Último Andar (PUCSP), São Paulo, v. 10, n. 10, 2004, p. 125-144.

MARTINS Andrei Venturini, "Controvérsias acerca do conceito de natureza em Blaise Pascal », Último andar, São Paulo, v. I, n. 11, 2004, p. 113-136.

MATTON Sylvain, Autour de la "grande expérience » de Pascal. Trois médecins philosophes du XVII siècle (Pierre Mosnier, G. B. de Saint-Romain, Guillaume Lamy), Paris, Champion, 2004.

MERKER Claude, «La méthode des indivisibles racontée lors d'un stage ", Repères, Revue des Instituts de Recherche sur l'enseignement des mathématiques, ${ }^{\circ} 54$, janvier 2004,

MESNARD Jean, «La couronne de Port-Royal des Champs», Port-Royal des Champs, Chroniques de Port-Royal, 54, Paris, Bibliothèque Mazarine, 2004, p. 101-128.

MESNARD Jean, "Achèvement et inachèvement dans les Pensées de Pascal», in PAPASOGLI Benedetta (dir.), Le Pensées di Pascal : dal disegno all'edizione, Studi francesi, $\mathrm{n}^{\circ}$ 143, Torino, Rosenberg et Sellier, mai-août 2004, p. 301-320.

MESNARD Jean, "Préface en forme de contrepoint ", in Alphonse Dupront devant Pascal, Fascinations et résistances, Cahiers Alphonse Dupront, 9-10, 2004, p. 2-43.

MICHON Hélène, «Les traces de la pensée de Philon le Juif dans l'apologétique pascalienne", Port-Royal et le royaume d'Israël, Chroniques de Port-Royal, 53, Paris,

MONTHÉARD Thérèse, "Quelques personnages illustres", Port-Royal des Champs, Chroniques de Port-Royal, 54, Paris, Bibliothèque Mazarine, 2004, p. 35-56.

MORALI Claude, Pascal. Pensées. Fragments classés sur la religion et la condition de l'homme,

NATAN Stéphane, Les Pensées de Pascal. D’un projet apologétique à un texte poétique, Paris,

PAPASOGLI Benedetta, «L'espace des Pensées et le fragment du Pari », in PAPASOGLI Benedetta (dir.), Le Pensées di Pascal : dal disegno all'edizione, Studi francesi, $\mathrm{n}^{\circ} 143$, Torino, Rosenberg et Sellier, mai-août 2004, p. 273-280. 
PAPASOGLI Benedetta (dir.), Le Pensées di Pascal : dal disegno all'edizione, Studi francesi, $\mathrm{n}^{\circ}$ 143, Torino, Rosenberg et Sellier, mai-août 2004.

PAPASOGLI Benedetta, "Le Pensées tra frammento e progetto", in Théorie et pratique du fragment, Actes du colloque international de la Società universitaria per gli studi di lingua et letteratura francese, Venise, Genève, Slatkine Érudition, 2004, p. 47-59.

PASCAL Blaise, Les Provinciales, Pensées et opuscules divers, éd. G. Ferreyrolles et P. Sellier, La Pochothèque, Le Livre de poche et Classiques Garnier, sl, 2004.

PASCAL Blaise, Pensieri, Edizione con teste a fronte, a cura di Carlo Carena, Prefazione di Giovanni Raboni, Biblioteca della Pléiade, Torino, Giulio Einaudi, 2004.

PAVLOVITS Tamas, "Corps et connaissance chez Pascal», in JAQUET Chantal et PAVLOVITS Tamas, Les significations du "corps» dans la philosophie classique, Paris, L'Harmattan, 2004, p. 107-124.

Port-Royal des Champs, Chroniques de Port-Royal, 54, Paris, Bibliothèque Mazarine, 2004.

Port-Royal et le royaume d'Israël, Chroniques de Port-Royal, 53, Paris, Bibliothèque Mazarine, 2004.

REGUIG-NAYA Delphine, «Les contrariétés du langage de Port-Royal : incarnation et expression", in DENIS Delphine et SPICA Anne-Élisabeth (dir.), Les langages au XVII ${ }^{e}$ siècle, Littératures classiques, $\mathrm{n}^{\circ}$ 50, printemps 2004, Paris, Champion, 2004, p. 51-62.

ROMEO Maria Vita, Il numero e l'infinito. L'itinerario pascaliano dalla scienza alla filosofia, Catania, Cooperativa Universitaria Editrice Catanese di Magisterion 2004.

SAINTE-BEUVE, Port-Royal, éd. P. Sellier, Paris, Laffont, coll. Bouquins, 2004, 2 vol.

SELLIER Philippe, "Les leçons de la Lettre pour porter à rechercher Dieu», in PAPASOGLI Benedetta (dir.), Le Pensées di Pascal: dal disegno all'edizione, Studi francesi, $n^{\circ}$ 143, Torino, Rosenberg et Sellier, mai-août 2004, p. 251-259.

SELLIER Philippe, «Joie et mystique chez Pascal», in Pour un vocabulaire mystique au XVII siècle, Torino, Aragno, 2004, p. 179-198.

SFEZ Gérald, "Pascal et la diversité de la justice ", XVII ${ }^{e}$ siècle, avril 2004, n 203 , p. 303-315.

SIOUFFI Gilles, "Le souci de définition chez quelques philosophes classiques du langage : Bacon, Hobbes, Pascal et Leibniz », in DENIS Delphine et SPICA Anne-Élisabeth (dir.), Les langages au XVII siècle, Littératures classiques, $\mathrm{n}^{\circ}$ 50, printemps 2004, Paris, Champion, 2004, p. 25-50.

TAKEDA Hiroki, «La notion infinitésimale et la portée de la géométrisation du monde chez Pascal ", in Sapientia (Bulletin de l'Université d'Eichi), 2004, p. 153-173 (en japonais).

THIROUIN Laurent, «Le cycle du divertissement », in PAPASOGLI Benedetta (dir.), Le Pensées di Pascal: dal disegno all'edizione, Studi francesi, $\mathrm{n}^{\circ} 143$, Torino, Rosenberg et Sellier, mai-août 2004, p. 260-272.

6 VAN DER SCHUREN Éric, "L'optique en sourdine : l'édition princeps des Pensées de Pascal », in ROUKHOMOVSKY Bernard (dir.), L'optique des moralistes de Montaigne à Chamfort, Paris, Champion, 2005, p. 105-124.

WIEL Véronique, «Malebranche en dialogue avec Pascal: la question des Contrariétés », XVII siècle, juillet 2004, nº 224, p. 461-476. 


\section{Année 2005}

AQUINO João Emiliano Fortaleza de, «A condição humana, a condição dos Grandes e a
condição da justicia. Apresentação Tres discursos sobre a condição dos grandes de Blaise Pascal », Kalagatos, Fortaleza, vol. II, fasc. 4, 2005, p. 201-206.

BAUSOLA Adriano, Introduzione a Pascal, 6 e éd., Rome-Bari, éd. Laterza, 2005.

BEHRENS Rudolf, GIPPER Andreas, MELLINGHOFF-BOURGERIE Viviane (dir.), Croisements d'anthropologies. Pascals Pensées im Geflecht der Anthropologien, Universitätvelag, Heidelberg, 2005.

BEHRENS Rudolf, «Bourdieu versteht Pascal. Zu einer aktualisierenden Lektüre der Hermeneutik der Sozialwelt in den Pensées ", in BEHRENS Rudolf, GIPPER Andreas, MELLINGHOFF-BOURGERIE Viviane (dir.), Croisements d'anthropologies. Pascals Pensées im Geflecht der Anthropologien, Universitätvelag, Heidelberg, 2005, p. 375-404.

BELIN Christian, "L'imaginaire contourné des Pensées ", XVII siècle, juin 2005, nº 228, p. 443-.

BORD André, Pascal vu par sa sœur Gilberte, Paris, Téqui, 2005.

BOUCHILLOUX Hélène, «Le cartésianisme et l'anti-cartésianisme de l'anthropologie pascalienne ", in BEHRENS Rudolf, GIPPER Andreas, MELLINGHOFF-BOURGERIE Viviane (dir.), Croisements d'anthropologies. Pascals Pensées im Geflecht der Anthropologien, Universitätvelag, Heidelberg, 2005, p. 131-142.

BOURGEOIS Muriel, «Pascal et Salomon de Tultie. Histoires de clés et de lecture », Littératures classiques, 54, 2005, p. 221-234.

6 CANTILLON Alain, "Qu'importe qui parle, de qui et à qui dans Les Provinciales?", Littératures classiques, 54, 2005, p. 135-158.

CARRAUD Vincent, «Bemerkungen über die zweite Anthroppologie: Das Denken als Entfremdung ", in BEHRENS Rudolf, GIPPER Andreas, MELLINGHOFF-BOURGERIE Viviane (dir.), Croisements d'anthropologies. Pascals Pensées im Geflecht der Anthropologien, Universitätvelag, Heidelberg, 2005 p. 161-182.

8 CARRAUD Vincent, «Approfondir trop et parler de tout: les Principia philosophiae dans les Pensées (note complémentaire sur « Disproportion de l'homme») », in La lecture des Principia philosophiae de Descartes, Revue d'histoire des sciences, tome 58-1, janvierjuin 2005, Paris, PUF, p. 289-52.

49 CHEVALLEY Catherine, "Ce que Pascal doit à la physique des Principia », in La lecture des Principia philosophiae de Descartes, Revue d'histoire des sciences, tome 58-1, janvierjuin 2005, Paris, PUF, p. 9-27.

CIANCIO Claudio, "Pascal contro Cartesio : l'altro inizio del moderno", in PEZZINO Giuseppe (dir.), L'incerto potere della ragione, Catania, CUECM, 2005, p. 17-32.

CONCHE Marcel, Philosopher à l'infini, Paris, PUF, 2005.

Courrier du Centre International Blaise Pascal, $\mathrm{n}^{\circ}$ 27, Clermont-Ferrand, 2005.

DESCOTES Dominique, «Pascal et le langage », in PEZZINO Giuseppe (dir.), L'incerto potere della ragione, Catania, CUECM, 2005, p. 33-57. 
DESCOTES Dominique, "Pascal mathématicien", in Savants et inventeurs d'Auvergne, Auvergne sciences, Bulletin de l'ADASTA, édition spéciale, $n^{\circ}$ 61, 2005, p. 12-17.

Discours et enjeux de la vanité, Littératures classiques, $\mathrm{n}^{\circ}$ 56, Paris, Champion, automne 2005.

DUBREUCQ Éric, "L'intériorité désertée et le fond du cœur. Le rapport à soi dans la liasse de Pascal sur le Divertissement », http://revues.org/document381.html, 2005.

DUCIMETIÈRE Nicolas, « Un livre pour deux frères... : l'exemplaire Arnauld de l'édition originale des Pensées de Pascal (1670) », in Courrier du Centre International Blaise Pascal, $\mathrm{n}^{\circ}$ 26, Clermont-Ferrand, 2004, p. 24-28.

DUCROT Oswald, «De l'intérêt de choisir entre peu et un peu », Bulletin hispanique, I, 2005, p. 109-117.

DUMOULIN Bernard, "De Pascal à Teilhard", in Catalogue d'exposition Teilhard 2005, Pierre Teilhard de Chardin, 3 mai-31 août, Ranquet, Hôtel de Fontfreyde, ClermontFerrand, 2005, p. 116-123.

ESCOLA Marc, « "Une singularité d'esprit et conséquemment de style”. De Montaigne à La Bruyère et de Pascal à Michaud », Littératures, 137, mars 2005, p. 93-107.

FERREYROLLES Gérard, "Pascal et Denys l'Aréopagite ", in BEHRENS Rudolf, GIPPER Andreas, MELLINGHOFF-BOURGERIE Viviane (dir.), Croisements d'anthropologies. Pascals Pensées im Geflecht der Anthropologien, Universitätvelag, Heidelberg, 2005, p. 17-38.

FLOUR Bertrand, «L'empreinte de Pascal dans l'œuvre graphique de Bertrand Flour ", in Courrier du Centre International Blaise Pascal, $n^{\circ} 27$, Clermont-Ferrand, 2005, p. 51-54.

FUMAROLI Marc, «De Montaigne à Pascal: les humanités, la science moderne et la foi », II, Commentaire, 112, 2005-2006, p. 967-976.

GIRARD Jacques, Hommes et femmes célèbres ou remarquables d'Auvergne, du Bourbonnais et $d u$ Velay. Dictionnaire biographique et historique, Olliergues, Éditions de la Montmarie, 2005.

GRIPER Andreas, « Der Mensch als Leser der Natur. Das Subjekt im Spannungsverältnis von christlicher Anthropoliogie une modernen Naturwissenschafter in Pascals Pensées ", in BEHRENS Rudold, GIPPER Andreas, MELLINGHOFF-BOURGERIE Viviane (dir.), Croisements d'anthropologies. Pascals Pensées im Geflecht der Anthropologien, Universitätvelag, Heidelberg, 2005, p. 183-202.

6 GUÉRIN Michel, "La croyance comme pierre de touche de l'anthropologie ", in BEHRENS Rudolf, GIPPER Andreas, MELLINGHOFF-BOURGERIE Viviane (dir.), Croisements d'anthropologies. Pascals Pensées im Geflecht der Anthropologien, Universitätvelag, Heidelberg, 2005, p. 297-310.

GUION Béatrice, "Car quel siècle a-t-on jamais vu où la vanité ait été plus désordonnée ? Vanités augustiniennes ", in Discours et enjeux de la vanité, Littératures classiques, $\mathrm{n}^{\circ}$ 56, Paris, Champion, automne 2005, p. 279-293.

HIGAKI Julie, Péguy et Pascal. Les trois ordres et l'ordre du cœur, Clermont-Ferrand, Presses Universitaires Blaise Pascal, 2005.

HURTUBISE Pierre, La casuistique dans tous ses états. De Martin Azpilcueta à Alphonse de Liguori, Ottawa, Université de Saint-Paul, Novalis, 2005.

KABLITZ Andreas, "Pascals zeiten. Zeitanalyse und Geschichte in den Pensées », in BEHRENS Rudolf, GIPPER Andreas, MELLINGHOFF-BOURGERIE Viviane (dir.), 
Croisements d'anthropologies. Pascals Pensées im Geflecht der Anthropologien, Universitätvelag, Heidelberg, 2005, p. 111-130.

KAPP Volker, "L'esthétique théologique de Pascal selon Hans Urs von Balthasar », in BEHRENS Rudolf, GIPPER Andreas, MELLINGHOFF-BOURGERIE Viviane (dir.), Croisements d'anthropologies. Pascals Pensées im Geflecht der Anthropologien, Universitätvelag, Heidelberg, 2005, p. 361-374.

KOCH Erec, "Sacred/secular rhetoric in Pascal's Lettres Provinciales", in Intersection, Biblio 17, $\mathrm{n}^{\circ}$ 161, Tübingen, G. Narr, 2005, p. 327-335.

KOYANAGI Kimiyo, "Confrontation des imprimés du Manuscrit Guerrier; G1-5, dit Préface sur le Traité du vide de Pascal », The journal of the Faculty of foreign studies, Aichi Prefectural University, $\mathrm{n}^{\circ}$ 37, 2005, p. 131-162 (en japonais).

KRUSE Margot, "Zum Zusammenhang von figurativem Denken und anthropologischer Reflexion in Pascals Pensées », in BEHRENS Rudolf, GIPPER Andreas, MELLINGHOFFBOURGERIE Viviane (dir.), Croisements d'anthropologies. Pascals Pensées im Geflecht der Anthropologien, Universitätvelag, Heidelberg, 2005, p. 143-160.

L'abbaye de Port-Royal des Champs, VIII ${ }^{\mathrm{e}}$ centenaire, Chroniques de Port-Royal, Paris, Bibliothèque Mazarine, 2005.

LANDRY Jean-Pierre, "Figures et figuratifs dans les Pensées de Pascal», in La parole masquée, Cahiers du GADGES, 2, Centre Jean Prévost, Lyon, Université Lyon 3, 2005, p. 167-183.

507 MAINGUENEAU Dominique, «Déplacer quelques frontières. À propos des lettres de Pascal aux Roannez », Littérature, n 140, décembre 2005, p. 42-55.

MAINGUENEAU Dominique, «Détachement et surdestinataire : la correspondance entre Pascal et les Roannez ", in Semen 20: le rapport de places dans l'épistolaire, Besançon, Presses universitaires de Franche-Comté, 2005, p. 83-96.

MARTINS Andrei Venturini, «Sobre a conversão do pecador : comentário e tradução ", Último Andar (PUCSP), São Paulo, v. I, n. 12, 2005, p. 145-157.

MARTINS Andrei Venturini, «Resenha : A primeira Provinciale de Blaise Pascal », Agnes (São Paulo), v. 03, 2005, p. 137-144.

511 MARTINS Andrei Venturini, "As faces do silêncio em Blaise Pascal ", Último Andar (PUCSP), v. 13, 2005, p. 139-158.

512 MATZAT Wolfgang, "Subjektivitätsmuster in Pascals Pensées" in BEHRENS Rudolf, GIPPER Andreas, MELLINGHOFF-BOURGERIE Viviane (dir.), Croisements d'anthropologies. Pascals Pensées im Geflecht der Anthropologien, Universitätvelag, Heidelberg, 2005, p. 203-216.

513 MAYAUD Pierre-Noël, Le conflit entre l'Astronomie nouvelle et l'Écriture sainte aux XVI et XVII siècles. Un moment de l'histoire des idées. Autour de l'affaire Galilée, Paris, Champion, 2005, 5 vol., t. III, p. 944-945.

514 McKenNA Antony, "La politique libertine à la lumière des Pensées de Pascal ", Littératures classiques, $\mathrm{n}^{\circ} 55$, été 2005 , p. 77-91.

515 MÉCHOULAN Éric, «Le libertinage politique de Pascal », Littératures classiques, n ${ }^{5} 5$, été 2005, p. 93-103.

516 MELLINGHOFF-BOURGERIE Viviane, "Faute ou péché originel? L'anthropologie pascalienne des Pensées entre Érasme et Bossuet », in BEHRENS Rudolf, GIPPER Andreas, 
MELLINGHOFF-BOURGERIE Viviane (dir.), Croisements d'anthropologies. Pascals Pensées im Geflecht der Anthropologien, Universitätvelag, Heidelberg, 2005, p. 85-109.

MERSENNE Marin, L'impiété des déistes, édition et annotation par Dominique Descotes, Paris, Champion, 2005.

MICHON Hélène, "La vanité : de Pascal à La Rochefoucauld », in Discours et enjeux de la vanité, Littératures classiques, $n^{\circ}$ 56, Paris, Champion, automne 2005, p. 267-278.

MISONO Keisuke, "Léonard de Marandé, polémiste antijanséniste ", in Courrier du Centre International Blaise Pascal, $\mathrm{n}^{\circ}$ 26, Clermont-Ferrand, 2004, p. 7-23.

NAGASE Haruo, "La machine arithmétique de Pascal et le nombre négatif ", Études de langue et littérature européennes, Université d'Okayama, 23, 2005, p. 1-11 (en japonais).

NATAN Stéphane, "Les Pensées de Pascal et la force des détours ", Nottingham french studies, 44, 2005, p. 1-7.

NATAN Stéphane, "Les Pensées de Pascal et les adverbes d'intensité », L'information littéraire, 57, 2005, p. 36-50.

NATAN Stéphane, Les Pensées de Pascal. D’un projet apologétique à un texte poétique, Paris, Connaissances et Savoirs, 2005. 72, 2005, p. 3-16.

NATOLI Charles, Fire in the dark. Essays ont Pascal's Pensées and Provinciales, Woolbridge (Suffolk), Rochester (NY), University of Rochester Press, 2005.

PALASAN Daniela, L'ennui chez Pascal et l'acédie, Cluj-Napoca, Eikon, 2005.

PAROLINI Rocco, Il « renversement " nella teologia della storia e nella polemica anti-gesuita di Blaise Pascal, Ferrare, Università degli Studi di Ferrara, 2005.

PASCAL Blaise, LEMPEREUR Richard, Pensées, Extraits, Paris, Éditions Alternatives, 2005.

PASCAL Blaise, Pensées, éd. et tr. de R. Ariew, Indianapolis, Hackett, 2005. PEZZINO Giuseppe (dir.), L'incerto potere della ragione, Catania, CUECM, 2005, p. 59-107.

PERATONER Alberto, «Une anthropologie pour l'éthique. Mouvances de la "philosophie de la pratique" pascalienne ", in BEHRENS Rudolf, GIPPER Andreas, MELLINGHOFFBOURGERIE Viviane (dir.), Croisements d'anthropologies. Pascals Pensées im Geflecht der Anthropologien, Universitätvelag, Heidelberg, 2005, p. 249-276.

PÉROUSE Marie, "Quelque chose de ce grand dessein ": les premières éditions des Pensées (1670-1678), Thèse, Lyon II, 2005.

PEZZINO Giuseppe (dir.), L'incerto potere della ragione, Catania, CUECM, 2005.

PICAVET Emmanuel, « Vanité du moi et sujet de la décision : Pascal, Bossuet, Fénelon », in Discours et enjeux de la vanité, Littératures classiques, $\mathrm{n}^{\circ} 56$, Paris, Champion, automne 2005, p. 119-132.

"Quatrième synthèse du séminaire sur les Pensées de Pascal, compte rendu général 2003-2004 », in Courrier du Centre International Blaise Pascal, $\mathrm{n}^{\circ} 27$, Clermont-Ferrand, 2005, p. 39-50.

ROMEO Maria Vita, "L'autorità della ragione nel Pascal scienzato ", in PEZZINO Giuseppe (dir.), L'incerto potere della ragione, Catania, CUECM, 2005, p. 109-138. 
ROMEO Maria Vita, «Pascal en Italie: une décennie d'études », in Courrier du Centre International Blaise Pascal, $\mathrm{n}^{\circ}$ 27, Clermont-Ferrand, 2005, p. 39-50.

SALAZAR Philippe-Joseph, "Efficacité rhétorique exemplaire. Les Pensées dans les Causeries $d u$ lundi de Sainte-Beuve", in BEHRENS Rudolf, GIPPER Andreas, MELLINGHOFF-BOURGERIE Viviane (dir.), Croisements d'anthropologies. Pascals Pensées im Geflecht der Anthropologien, Universitätvelag, Heidelberg, 2005, p. 331-344.

SCHLÜTER Gisela, "Der Häresiebegriff im Kontext : Pascal und Bayle ", in BEHRENS Rudolf, GIPPER Andreas, MELLINGHOFF-BOURGERIE Viviane (dir.), Croisements d'anthropologies. Pascals Pensées im Geflecht der Anthropologien, Universitätvelag, Heidelberg, 2005, p. 277-296.

SELLIER Philippe, «Pascal et Montaigne : le filtre augustinien », in BEHRENS Rudolf, GIPPER Andreas, MELLINGHOFF-BOURGERIE Viviane (dir.), Croisements d'anthropologies. Pascals Pensées im Geflecht der Anthropologien, Universitätvelag, Heidelberg, 2005, p. 3-16. SUSINI Laurent, La lumière et le feu. La "vraie éloquence " à l'œuvre dans les Pensées de Pascal, Thèse, Paris IV, 2005, 3 vol.

THIROUIN Laurent, PÉROUSE Marie et PROUST Gilles, «Une "nouvelle pensée" de Pascal », in Courrier du Centre International Blaise Pascal, $n^{\circ} 27$, Clermont-Ferrand, 2005, p. 3-6.

THIROUIN Laurent, «Le moi haïssable, une formule équivoque ", in BEHRENS Rudolf, GIPPER Andreas, MELLINGHOFF-BOURGERIE Viviane (dir.), Croisements d'anthropologies. Pascals Pensées im Geflecht der Anthropologien, Universitätvelag, Heidelberg, 2005, p. 217-247.

4 TIETZ Manfred, "Das Bild des Judentums in Pascals Pensées une die Funtion der christlichen Adversus Judaeos-Literatur", in BEHRENS Rudolf, GIPPER Andreas, MELLINGHOFF-BOURGERIE Viviane (dir.), Croisements d'anthropologies. Pascals Pensées im Geflecht der Anthropologien, Universitätvelag, Heidelberg, 2005, p. 39-68.

5 "Troisième synthèse du séminaire sur les Pensées de Pascal. Compte rendu général 2002-2003 ", in Courrier du Centre International Blaise Pascal, $\mathrm{n}^{\circ} 26$, Clermont-Ferrand, 2004, p. 29-45.

VAN DELFT Louis, «Revisiter les Pensées avec Nietsche, Du Bos, Montaigne et Alain », in BEHRENS Rudolf, GIPPER Andreas, MELLINGHOFF-BOURGERIE Viviane (dir.), Croisements d'anthropologies. Pascals Pensées im Geflecht der Anthropologien, Universitätvelag, Heidelberg, 2005, p. 345-360.

VAN der SCHUEREN, «L'optique en sourdine : l'édition princeps des Pensées de Pascal », in ROUKHOMOVSKY B. (dir.), L'optique des moralistes de Montaigne à Chamfort, Paris, Champion, 2005, p. 105-124.

VERNES Jean-René, Le principe de Pascal-Hume et le fondement des sciences physiques, Paris, L'Harmattan, 2005.

VIGNA Carmelo, « Pascal e l'ateo moderno », in PEZZINO Giuseppe (dir.), L'incerto potere della ragione, Catania, CUECM, 2005, p. 139-152.

VITIELlO R., «Le Provinciali di Blaise Pascal (1656-7) fra Sorbona e Port-Royal. Un pamphlet filosofico, quasi un romanzo di formazione ", in KAZON I. et SICILIANI DE CUMIS N. (éd.), La filosofia nella Scuola e nell'Università, Rome, Lithos, 2005, p. 65-77. 
551 WALDENFELS Bernhard, « Der Mensch als Doppelwesen », in BEHRENS Rudolf, GIPPER Andreas, MELLINGHOFF-BOURGERIE Viviane (dir.), Croisements d'anthropologies. Pascals Pensées im Geflecht der Anthropologien, Universitätvelag, Heidelberg, 2005, p. 311-330.

\section{Année 2006}

ALCANTARA Jean-Pascal, "Pascal et Calvin », in DESCOTES Dominique (dir.), Pascal auteur spirituel, Paris, Champion, 2006, p. 113-142.

AMIEL Gérard, "Remarques sur l'esprit de finesse ", in Lacan et Pascal, La célibataire, Revue de psychanalyse, 13, automne 2006, p. 111-118.

AQUINO João Emiliano Fortaleza de, "Divertissement, segunda natureza e historia : consideraçãos sobre a leitura benjaminiana dos Pensamentos de Blaise Pascal», Kalagatos, Fortaleza, vol. III, fasc. 5, 2006, p. 103-116.

ARMOGATHE Jean-Robert, «Pascal e o amor-próprio », Kriterion, 2006, v. 47, n. 114, p. 223-236.

BAUSTERT Raymond, La querelle janséniste extra muros ou la polémique autour de la procession des jésuites de Luxembourg, 20 mai 1685, Tübingen, Gunter Narr Verlag, 2006.

BELIN Christian, «La tradition méditative : écriture, procédures, mystères ", in BELIN Christian (dir.), La méditation au XVII siècle. Rhétorique, art, spiritualité, Paris, Champion, 2006, p. 15-31.

«Bibliographie pascalienne pour les années 2004-2006 », Courrier du Centre International Blaise Pascal, $\mathrm{n}^{\circ} 28$, Clermont-Ferrand, 2006, p. 44-48.

BIRCHAL Telma de Souza, « La vraie morale se moque de la morale : questões éticas em Pascal », Kriterion, v. 43, n. 106, 2002, p. 60-76.

BJøRNSTAD Hall, "Créature sans créateur : pour une anthropologie baroque dans les Pensées de Pascal », Oslo, Université d'Oslo, Acte humaniora, 2006.

BJøRNSTAD Hall, "Désapprendre à mourir: Pascal and the philosophers of death ", Papers on French Seventeenth Century Literature, 33, 65, 2006, p. 26-39.

BORD André, Lumière et ténèbres chez Pascal, Paris, Téqui, 2006.

BORD André, «L'évolution spirituelle de Pascal de 1652 à 1654, le Mémorial », in DESCOTES Dominique (dir.), Pascal auteur spirituel, Paris, Champion, 2006, p. 5569-30.

BOSCO Domenico, « Pascal : un'estetica della grazia ? Un qualche appunto », in ROMEO Maria Vita (dir.), Abraham : individualità e assoluto, Atti delle giornate Pascal 2004, p. 23-64.

BOUCHILLOUX Hélène, «Dieu, le vide et le divertissement ", Magazine littéraire, Hors série $\mathrm{n}^{\circ} 10,2006$, p. 36-37.

BOURGEOIS Muriel, «Ce qui s'appelle penser, pour Pascal », in GUION Béatrice, SEGUIN Maria Susana, MENANT Sylvain et SELLIER Philippe, Poétique de la pensée. Études sur l'âge classique et le siècle philosophique. En hommage à Jean Dagen, Paris, Champion, 2006, p. 111-123.

BRINI Jean, "Le pari est-il un jeu? ", in Lacan et Pascal, La célibataire, Revue de psychanalyse, 13, automne 2006, p. 147-152.

CACHO Jorge, "Disgrâce ", in Lacan et Pascal, La célibataire, Revue de psychanalyse, 13, automne 2006, p. 161-167. 

psychanalyse, 13, automne 2006, p. 9-21. Champion, 2006, p. 219-237. CERHAC, Clermont-Ferrand, 2006, p. 289-308. mars 2006, p. 29-44. présentation du film). psychanalyse, 13, automne 2006, p. 67-80.

CARENA Carlo, «L"io" nelle Pensées di Pascal », in ROMEO Maria Vita (dir.), Abraham : individualità e assoluto, Atti delle giornate Pascal 2004, p. 65-79.

CARENA Carlo, " Manzoni e il giansenismo ", Rivista de filosofia neo-scoalstica, Università cattolica del sacro Cuore, Milano, Anno XCVIII, Gennaio-Marzo 2006, p. 139-150.

CATHELINEAU Pierre-Christophe, "Quelques réflexions sur l'argument du pari », in Lacan et Pascal, La célibataire, Revue de psychanalyse, 13, automne 2006, p. 153-160.

CHASSAING Jean-Louis, « Le songe et le réveil ", in Lacan et Pascal, La célibataire, Revue de

CLÉRO Jean-Pierre, "Mathématique, littérature et langue vernaculaire. Est-il indifférent qu'un savoir se constitue en une langue plutôt que dans une autre? ", in Bonnes lettres/Belles lettres: actes des colloques du Centre d'études et de recherches Éditer/ Interpréter de l'Université de Rouen, Paris, Champion, 2006, p. 439-460.

Courrier du Centre International Blaise Pascal, 28, Clermont-Ferrand, 2006.

DESCAMPS Geneviève, "Du Mémorial au Mystère de Jésus: contemplation et dialogue intérieur avec Jésus ", in DESCOTES Dominique (dir.), Pascal auteur spirituel, Paris,

DESCOTES Dominique (dir.), Pascal auteur spirituel, Paris, Champion, 2006.

DESCOTES Dominique, «Le raisonnement par l'absurde dans les Écrits sur la Grâce », in DESCOTES Dominique (dir.), Pascal auteur spirituel, Paris, Champion, 2006, p. 393-432.

DESCOTES Dominique, "Paradoxes spirituels chez Pascal», in DESCOTES Dominique (dir.), Pascal auteur spirituel, Paris, Champion, 2006, p. 455-468.

DESCOTES Dominique «Pascal et le problème du plagiat», in COUTON Marie, FERNANDEZ Isabelle, JÉRÉMIE Christian et VÉNUAT Monique, Emprunt, plagiat, réécriture aux $\mathrm{XV}^{e}, \mathrm{XVI} I^{e}, \mathrm{XVII}$ siècles. Pour un nouvel éclairage sur la pratique des lettres à la Renaissance,

DESCOTES Dominique, «Quelques réflexions sur l'argument du pari », in Lacan et Pascal, La célibataire, Revue de psychanalyse, 13, automne 2006, p. 25-38.

DEVILLAIRS Laurence, "La spiritualité anti-pascalienne de Fénelon », in DESCOTES Dominique (dir.), Pascal auteur spirituel, Paris, Champion, 2006, p. 393-432.

DEVILLAIRS Laurence, "Le Christ comme idéal de la pratique mystique ", Institut d'histoire de la Réformation, Bulletin annuel, XXVI (2004-2005), Université de Genève,

DIEUTRE Vincent, Fragments sur la Grâce, Paris, Celluloid Dreams, 2006 (Livret de

EMERICH Choula, "Le pari de Pascal", in Lacan et Pascal, La célibataire, Revue de

FAVEREAU Catherine, « Le je dans les textes mystiques de Pascal », in Lacan et Pascal, La célibataire, Revue de psychanalyse, 13, automne 2006, p. 39-51.

FERREYROLLES Gérard, «L'augustinisme dans la vie intellectuelle française au

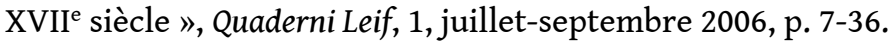

FERREYROLLES Gérard, «Les citations de saint Thomas dans les Écrits sur la grâce », in DESCOTES Dominique (dir.), Pascal auteur spirituel, Paris, Champion, 2006, p. 143-159. 
FERRON Catherine, «Pascal : une enfance? ", in Lacan et Pascal, La célibataire, Revue de psychanalyse, 13, automne 2006, p. 141-146.

FUMAROLI Marc, «De Montaigne à Pascal : les humanités, la science moderne et la foi ", in Exercices de lecture. De Rabelais à Paul Valéry, Paris, NRF, Gallimard, 2006, p. 293-326.

GABRIEL Frédéric, «Politique, christologie et ecclésiologie dans les Pensées de Pascal », Kriterion, v. 47, n. 114, 2006, p. 273-301.

GHEERAERT Tony, «Pascal et les reines de village : baroque et maniérisme à PortRoyal », Études Epistémè, n 9, printemps 2006, p. 285-305.

« Giornate Pascal 2005 », Quaderni Leif, 1, juillet-septembre 2006, p. 140-141.

GRASSET Bernard, «Enquête sur les vers de Pascal au dos de tableaux », in Port-Royal et l'humanisme, Chroniques de Port-Royal, Paris, Bibliothèque Mazarine, 2006, p. 365-371.

GRASSET Bernard, "L'humanisme biblique des Pensées de Pascal », Science et esprit, vol. 58, mai-août 2006, fascicule 3, p. 251-264.

GUION Béatrice, SEGUIN Maria Susana, MENANT Sylvain et SELLIER Philippe, Poétique de la pensée. Études sur l'âge classique et le siècle philosophique. En hommage à Jean Dagen, Paris, Champion, 2006.

HENNEQUIN Paul-Louis, "La Pascaline", in Lacan et Pascal, La célibataire, Revue de psychanalyse, 13, automne 2006, p. 81-88.

HIGAKI Julie, «Pascal et saint Paul », in DESCOTES Dominique (dir.), Pascal auteur spirituel, Paris, Champion, 2006, p. 71-112.

JEAN Thierry, "C'est quoi un névrosé ?", in Lacan et Pascal, La célibataire, Revue de psychanalyse, 13, automne 2006, p. 183-187.

JEHASSE Jean, «Guez de Balzac et Pascal, ou deux apologies comparées », in Port-Royal et l'humanisme, Chroniques de Port-Royal, Paris, Bibliothèque Mazarine, 2006, p. 127-135.

JOUSLIN Olivier, «L'éthique polémique de Pascal », in FERREYROLLES Gérard (dir.), La polémique au XVII siècle, Littératures classiques, 59, été 2006, p. 117-139.

JULLIEN Vincent, Philosophie naturelle et géométrie au XVII siècle, Paris, Champion, 2006.

JULLIEN Vincent, Les ombres de la place Royale, Paris, Stock, 2006.

KOYANAGI Kimiyo, «Au sujet du Manuscrit G1-5, écrit inachevé de Pascal, dit Préface. Sur le traité du vide », in ROMEO Maria Vita (dir.), Abraham : individualità e assoluto, Atti delle giornate Pascal 2004, p. 81-99.

Lacan et Pascal, La célibataire, Revue de psychanalyse, 13, automne 2006, p. 25-38.

LAURENT Jérôme et ROMANO Claude, Le néant. Contribution à l'histoire du non-être dans la philosophie occidentale, Paris, PUF, 2006.

LIMONGI, M.I.M.P., «A ordem da concupiscência e a grandeza do homem em Pascal ", Trans/Form/Ação, v. 29, 2006, p. 45-61.

MAIA NETO José R., «As principais forças dos pirrônicos" (Laf. 131) e sua apropriação por Huet », Kriterion, v. 47, n. 114, 2006, p. 237-257.

MARINO Gordon, «Despair and depression", in ROMEO Maria Vita (dir.), Abraham : individualità e assoluto, Atti delle giornate Pascal 2004, p. 101-114. 
McKENNA Antony, "Le libertin interlocuteur de Pascal dans les Pensées ", in ROMEO Maria Vita (dir.), Abraham: individualità e assoluto, Atti delle giornate Pascal 2004, p. 115-129.

McKENNA Antony, «Pascal et Gassendi : la philosophie du libertin dans les Pensées », XVII siècle, 233, octobre 2006, p. 635-647.

MÉCHOULAN Éric, «Un roi avec divertissement: l'étranger intérieur et l'hantologie topique ", in Étrange topos étranger : actes du XVI e colloque de la SATOR, éd. Vernet, Laval, Presses de l'Université de Laval, 2006, p. 77-86.

MESNARD Jean, «Humanisme et christianisme chez Pascal », in ROMEO Maria Vita (dir.), Abraham : individualità e assoluto, Atti delle giornate Pascal 2004, p. 131-168.

613 MESNARD JEAN, «Bible et liturgie dans le Mémorial », in DESCOTES Dominique (dir.), Pascal auteur spirituel, Paris, Champion, 2006, p. 187-217.

614 MESNARD Jean, BEZANÇON Jean-Noël, SELLIER Philippe, FERREYROLLES Gérard, MICHON Hélène, ARMOGATHE Jean-Robert, «La veillée du Mémorial, en l'église SaintJacques-du-Haut-Pas, le mardi 23 novembre $2004 »$, Courrier du Centre International Blaise Pascal, 28, Clermont-Ferrand, 2006, p. 4-26.

615 MESNARD Jean, «Sur une "nouvelle pensée" de Pascal, authentique ou fabriquée? », Courrier du Centre International Blaise Pascal, 28, Clermont-Ferrand, 2006, p. 27-36.

616 MESNARD Jean, "L'exemple dans les Pensées de Pascal ", in GUION Béatrice, SEGUIN Maria Susana, MENANT Sylvain et SELLIER Philippe, Poétique de la pensée. Études sur l'âge classique et le siècle philosophique. En hommage à Jean Dagen, Paris, Champion, 2006, p. 569-585.

617 MICHON Hélène, «L'écriture mystique du Mémorial », in DESCOTES Dominique (dir.), Pascal auteur spirituel, Paris, Champion, 2006, p. 163-185.

618 MICHON Hélène, "L'Écrit sur la conversion du pécheur: entre jansénisme et bérullisme», in DESCOTES Dominique (dir.), Pascal auteur spirituel, Paris, Champion, 2006, p. 257-273.

619 MOCHIZUKI Yuka, «La délectation dans les Écrits sur la grâce. Une orientation nouvelle dans les controverses jansénistes", in DESCOTES Dominique (dir.), Pascal auteur spirituel, Paris, Champion, 2006, p. 351-392.

NACHT Marc, "Quelques réflexions sur l'argument du pari", in Lacan et Pascal, La célibataire, Revue de psychanalyse, 13, automne 2006, p. 189-193.

NADAÏ Jean-Christophe de, «Le sacrifice de Jésus-Christ dans la Lettre aux Périer », in DESCOTES Dominique (dir.), Pascal auteur spirituel, Paris, Champion, 2006, p. 239-256.

NAGASE Haruo, "La machine arithmétique de Pascal et la notion de nombre négatif », Journal of the Faculty of Letters, Université d'Okayama, 46, 2006, p. 93-102.

GASE Haruo, "La machine arithmétique de Pascal et les Pensées 》, in Symposium. Mélanges offerts au professeur Koichi Takaoka, Tokyo, Asahi Shuppan, 26, 2006, p. 435-444 (en japonais).

NATAN Stéphane, «Les Pensées de Pascal : au royaume des nécessités », Symposium, 60, 2006, p. 93-108.

625 NATAN Stéphane, "Le décor des Pensées de Pascal: un monde clos et ténébreux", Romance quarterly, 53, 4, 2006, p. 305-315. 

Ferrara, 2006. Mazarine, 2006, p. 85-97. p. 119-132. Catania, CUECM, 2006. septembre 2006, p. 37-59. juillet-septembre 2006, p. 124-129. changé le monde, Paris, Ellipses, 2006. science classique, Paris, Albin Michel, 2006. juillet-septembre 2006, p. 11-19. p. 863-873.

OLIVA Luís C.G., "Antecedentes filosóficos e teológicos do conceito pascaliano de natureza humana », Kriterion, v. 47, n. 114, 2006, p. 367-408.

OLIVO Gilles, "Nós geramos átomos em lugar da realidade das coisas: Pascal e o ateísmo do infinito ", Kriterion, v. 47, n. 114, 2006, p. 409-423.

PAPASOGLI Benedetta, "Pascal: l'io e la memoria ", in ROMEO Maria Vita (dir.), Abraham : individualità e assoluto, Atti delle giornate Pascal 2004, p. 169-185.

PAROLINI Rocco, La tattica persuasiva di Blaise Pascal : il "renversement " gradevole, Annali dell'Università di Ferrara, Nuova serie, sezione III, Filosofia, $\mathrm{n}^{\circ} 80$, Università degli Studi di

Pascal im Kontext, édition électronique multi-langage en CD-Rom (texte français/latin d'après Blaise Pascal, Euvres complètes, éd. Louis Lafuma, Paris, Éditions du Seuil, 1963; traduction allemande par Ulrich Kunzmann), Berlin, Karsten Worm, Infosoftware, 2006, ISBN 3-932094-35-2 (système d'exploitation : Windows).

PAVLOVITS Tamás, «Le bon usage de la raison et le problème de l'humanisme chez Pascal ", in Port-Royal et l'humanisme, Chroniques de Port-Royal, Paris, Bibliothèque

PÉNICAUD Pierre, "Les dernières tribulations des pascalines de Clermont-Ferrand ", Courrier du Centre International Blaise Pascal, 28, Clermont-Ferrand, 2006, p. 37-43.

Port-Royal et l'humanisme, Chroniques de Port-Royal, Paris, Bibliothèque Mazarine, 2006.

RICARD Hubert, « Cogito cartésien et sujet du pari pascalien. Lacan lecteur de Descartes et de Pascal ", in Lacan et Pascal, La célibataire, Revue de psychanalyse, 13, automne 2006,

ROMEO Maria Vita (dir.), Abraham : individualità e assoluto, Atti delle giornate Pascal 2004,

ROMEO Maria Vita, «La ricerca pascaliana dell'infinito », in ROMEO Maria Vita (dir.), Abraham : individualità e assoluto, Atti delle giornate Pascal 2004, p. 187-205.

ROMEO Maria Vita, "Una politica "selon le cœur" ", Quaderni Leif, 1, juillet-

ROMEO Maria Vita, « Pascal : perché non possiamo non dirlo cristiano », Quaderni Leif, 1,

SAMUELI Jean-Jacques et BOUDENOT Jean-Claude, Trente livres de mathématiques qui ont

SEIDENGART Jean, Dieu, l'univers et a sphère infinie. Penser l'infinité cosmique à l'aube de la

SELLIER Philippe, «Pascal : colorations oratoriennes ", in DESCOTES Dominique (dir.), Pascal auteur spirituel, Paris, Champion, 2006, p. 31-54.

SELLIER Philippe, «Le fer rouge de Pascal. Triste page des casuistes ", L'Erasmo, 31,

SELLIER Philippe, "L'incantation intertextuelle ", in GUION Béatrice, SEGUIN Maria Susana, MENANT Sylvain et SELLIER Philippe, Poétique de la pensée. Études sur l'âge classique et le siècle philosophique. En hommage à Jean Dagen, Paris, Champion, 2006,

STELLA Pietro, Il giansenismo in Italia, Roma, Edisioni di storia e letteratura, 2006. 

auteur spirituel, Paris, Champion, 2006, p. 325-349. p. 491-512. Paris, Champion, 2006, p. 275-298. auteur spirituel, Paris, Champion, 2006, p. 299-322. psychanalyse, 13, automne 2006, p. 53-65. psychanalyse, 13, automne 2006, p. 133-139. Teologica della Sardegna, XV, 2006, p. 151-190.

\section{Année 2007} Editori Riuniti, 2007. Amsterdam, 2007, p. 285-293. Princípios (UFRN), v. 14, nº 22, 2007, p. 145-165. Paris, PUF, 2007.

STIKER-MÉTRAL Charles-Olivier, «La manière d'écrire de Pascal dans les Écrits sur la grâce. La théologie à l'usage des honnêtes gens ? ", in DESCOTES Dominique (dir.), Pascal

TABET Emmanuelle, «L'écriture de la conversion chez Sainte-Beuve de Volupté à PortRoyal », in DESCOTES Dominique (dir.), Pascal auteur spirituel, Paris, Champion, 2006,

TARASOV Boris, Paskal, Moskva, Molodaïa Gvardiya, 2006 (en russe).

THIROUIN Laurent, « La santé du malheur. Santé et maladie dans la Prière pour demander à Dieu le bon usage des maladies ", in DESCOTES Dominique (dir.), Pascal auteur spirituel,

THIROUIN Laurent, "Se divertir, se convertir», in DESCOTES Dominique (dir.), Pascal

THIROUIN Laurent, «La vanité (pour rire)", in Lacan et Pascal, La célibataire, Revue de

VAN DELFT Louis, «Pascal et "la troisième oreille" de Nietzsche. Pour l'écoute des Pensées", in GUION Béatrice, SEGUIN Maria Susana, MENANT Sylvain et SELLIER Philippe, Poétique de la pensée. Études sur l'âge classique et le siècle philosophique. En hommage à Jean Dagen, Paris, Champion, 2006, p. 915-926.

VEKEN Cyril, «L'analyse comme pari ", in Lacan et Pascal, La célibataire, Revue de

VINCI Daniele, « "Arco di fuoco, ponte sugli abissi". Romano Guardini e Hans Urs von Balthasar lettori di Pascal ", in Theologica e Historica, Annali della Pontificia Facolta

VITTORIO Massimo, «La critica pascaliana al giuridicismo casistico », in ROMEO Maria Vita (dir.), Abraham : individualità e assoluto, Atti delle giornate Pascal 2004, p. 207-219.

WANEGFFELEN Thierry, «Pascal, la frontière et le milieu : à propos du catholicisme moderne. Les Écrits sur la grâce et le concile de Trente », in DESCOTES Dominique (dir.), Pascal auteur spirituel, Paris, Champion, 2006, p. 13-30.

ADORNO Francesco Paolo, La disciplina dell'amore. Pascal, Port-Royal et la politica, Rome,

ALBIAC Gabriel, «À la place de Dieu : sur les paradoxes du politique chez Pascal et Spinoza ", in BOVE Laurent, BRAS Gérard et MÉCHOULAN Éric (dir.), Pascal et Spinoza. Pensées du contraste: de la géométrie du hasard à la nécessité de la liberté, Paris, Éditions

65 AQUINO João Emiliano Fortaleza de, "Segunda natureza e justiça em Blaise Pascal »,

ARMOGATHE Jean-Robert, La nature du monde: science nouvelle et exégèse au XVII siècle,

ATLAN Henri «Géométrie du hasard et intemporalité », in BOVE Laurent, BRAS Gérard et MÉCHOULAN Éric, Pascal et Spinoza. Pensées du contraste : de la géométrie du hasard à la nécessité de la liberté, Paris, Éditions Amsterdam, 2007, p. 137-147. 
661 ATTALI Jacques, «Un génie, libre et autodidacte », in Pascal miroir de notre vie, Le magazine littéraire, $\mathrm{n}^{\circ} 469$, novembre 2007, p. 40-41.

BALIBAR Étienne, «L'histoire de l'Église doit être proprement appelée l'histoire de la vérité. Un essai d'interprétation du texte pascalien ", in BOVE Laurent, BRAS Gérard et MÉCHOULAN Éric (dir.), Pascal et Spinoza. Pensées du contraste : de la géométrie du hasard à la nécessité de la liberté, Paris, Éditions Amsterdam, 2007, p. 77-89.

BAYEN Bruno, "Les Provinciales, une vitalité contagieuse qui me paraît unique», in Pascal miroir de notre vie, Le magazine littéraire, $\mathrm{n}^{\circ} 469$, novembre 2007, p. 43.

BOUCHILlOUX Hélène, "Grandeur de l'esprit, misère de l'homme ", in Pascal miroir de notre vie, Le magazine littéraire, $\mathrm{n}^{\circ} 469$, novembre 2007, p. 54-55.

BOUCHILLOUX Hélène, «L'unique objet de l'Écriture est la charité : Pascal et Spinoza devant la Bible ", in BOVE Laurent, BRAS Gérard et MÉCHOULAN Éric (dir.), Pascal et Spinoza. Pensées du contraste: de la géométrie du hasard à la nécessité de la liberté, Paris, Éditions Amsterdam, 2007, p. 57-65.

BOURGEOIS Muriel, "De quoi Pascal peut-il bien parler?", Pascal a-t-il écrit les Pensées ?, Littératures, Presses universitaires du Mirail, 55, 2007, p. 111-129.

BOVE Laurent, BRAS Gérard et MÉCHOULAN Éric (dir.), Pascal et Spinoza. Pensées du contraste : de la géométrie du hasard à la nécessité de la liberté, Paris, Éditions Amsterdam, 2007.

BOVE Laurent, "Le désir, la vie et la mort chez Pascal et Spinoza », in BOVE Laurent, BRAS Gérard et MÉCHOULAN Éric (dir.), Pascal et Spinoza. Pensées du contraste: de la géométrie du hasard à la nécessité de la liberté, Paris, Éditions Amsterdam, 2007, p. 199-208.

BRAS Gérard, "Divertissement et servitude : deux pensées de l'aliénation », in BOVE Laurent, BRAS Gérard et MÉCHOULAN Éric (dir.), Pascal et Spinoza. Pensées du contraste : de la géométrie du hasard à la nécessité de la liberté, Paris, Éditions Amsterdam, 2007, p. 229-241.

670 BRISVILLE Jean-Claude, L'entretien de M. Descartes avec M. Pascal le jeune, avec Daniel Mesguich et William Mesguich, enregistré en public au Théâtre de l'œuvre en 2007, DVD, Lycoprod, 2007.

671 CANTILLO Giuseppe, «La presenza di Pascal nell'etica di Romano Guardini », in ROMEO Maria Vita, Il moderno fra Prometeo et Narciso, Atti delle giornate Pascal 2005, Catania, CUECM, 2007, p. 25-49.

672 CANTILLON Alain, « Pendent opera interrupta: le commencement des Pensées-de-Pascal », Pascal a-t-il écrit les Pensées ?, Littératures, Presses universitaires du Mirail, 55, 2007, p. 47-74.

673 «Carlo Carena e le Provinciali di Pascal», Quaderni leif, Semestrale del laboratorio di etica e informazione filosofica, Università degli Studi di Catania, 2/2007, p. 166-167.

674 CARRAUD Vincent, Pascal, des connaissances naturelles à l'étude de l'homme, Paris, Vrin, 2007.

CHARRAK André, « Pascal dans Rousseau : la question de la condition de l'homme », in ROMEO Maria Vita, Il moderno fra Prometeo et Narciso, Atti delle giornate Pascal 2005, Catania, CUECM, 2007, p. 51-64.

676 «Cinquième compte rendu du séminaire sur les Pensées de Pascal ", in Courrier du Centre International Blaise Pascal, 29, Clermont-Ferrand, 2007, p. 26-39. 

Éditions Amsterdam, 2007, p. 123-135. avril 2007, $\mathrm{n}^{\circ} 2$, p. 413-432. magazine littéraire, $\mathrm{n}^{\circ} 469$, novembre 2007, p. 33-35. p. 149-166. littéraire, $\mathrm{n}^{\circ}$ 469, novembre 2007, p. 43. octobre 2007. magazine littéraire, $\mathrm{n}^{\circ} 469$, novembre 2007, p. 59-61. Presses universitaires du Mirail, 55, 2007, p. 19-31. Bibliothèque électronique de Port-Royal, 2007. Mirail, 55, 2007, p. 751-92. $1^{\text {er }}$ décembre 2007, p. 121-150. 105, n 3, août 2007, p. 361-384.

CLÉRO Jean-Pierre, "Remarques sur le type de rationalité à l'œuvre dans le calcul pascalien des partis ", in BOVE Laurent, BRAS Gérard et MÉCHOULAN Éric (dir.), Pascal et Spinoza. Pensées du contraste: de la géométrie du hasard à la nécessité de la liberté, Paris,

COMPAGNON Antoine, "Le funeste Pascal», Revue d'Histoire Littéraire de la France,

COMTE-SPONVILLE André, "Pascal et Spinoza face au tragique », in BOVE Laurent, BRAS Gérard et MÉCHOULAN Éric (dir.), Pascal et Spinoza. Pensées du contraste: de la géométrie du hasard à la nécessité de la liberté, Paris, Éditions Amsterdam, 2007, p. 311-325.

COMTE-SPONVILLE André, "Pascal est-il aussi un grand penseur politique? Propos recueillis par J. Cerf », Magazine Littéraire, 469, 2007, p. 58-59.

Courrier du Centre International Blaise Pascal, 29, Clermont-Ferrand, 2007.

CRISTOFOLIN Paolo, "L'homme libre et le roseau pensant », in BOVE Laurent, BRAS Gérard et MÉCHOULAN Éric (dir.), Pascal et Spinoza. Pensées du contraste : de la géométrie du hasard à la nécessité de la liberté, Paris, Éditions Amsterdam, 2007, p. 327-333.

DANTZIG Charles, « Ne comptez pas sur lui (et c'est très bien) », in Pascal miroir de notre vie, Le magazine littéraire, $\mathrm{n}^{\circ}$ 469, novembre 2007, p. 62.

DELON Michel, "L'éclairage contrasté des Lumières", in Pascal miroir de notre vie, Le

DESCOTES Dominique, "Corollaire et proposition chez Pascal et Spinoza ", in BOVE Laurent, BRAS Gérard et MÉCHOULAN Éric (dir.), Pascal et Spinoza. Pensées du contraste: de la géométrie du hasard à la nécessité de la liberté, Paris, Éditions Amsterdam, 2007,

DIEUTRE Vincent, "Pascal est un miroir ", in Pascal miroir de notre vie, Le magazine

FAUCONNIER Bernard, « Un témoin de la condition humaine ", in Pascal miroir de notre vie, Le magazine littéraire, $\mathrm{n}^{\circ} 469$, novembre 2007, p. 37-40.

Fermat. De défis en conjectures, coll. Les génies de la science, Pour la science, $\mathrm{n}^{\circ} 32$, août-

FERREYROLLES Gérard, "Les enjeux des Provinciales", in Pascal miroir de notre vie, Le

FORCE Pierre, «Écriture fragmentaire et hagiographie: le rôle des textes liminaires dans la réception des Pensées de Pascal ", Pascal a-t-il écrit les Pensées ?, Littératures,

GHEERAERT Tony, À la recherche du Dieu caché. Introduction aux Pensées de Pascal, La

GIOCANTI Sylvia, "L'écriture sceptique d'une apologie de la religion chrétienne: les Pensées de Pascal ", Pascal a-t-il écrit les Pensées ?, Littératures, Presses universitaires du

GRASSET Bernard, "La pensée sapientielle de Pascal», Le Portique, $\mathrm{n}^{\circ} 19$,

GRASSET Bernard, «Une esthétique pascalienne », Revue philosophique de Louvain, tome 
GROARKE Louis, «Philosophy as inspiration: Blaise Pascal and the epistemology of aphorisms ", Poetics today, 28, 3, 2007, p. 393-441.

HALPERN Catherine, «Blaise Pascal (1623-1662). Face à l'infini », Cinq siècles de pensée française, Sciences humaines, Hors série spécial n ${ }^{\circ}$ 6, octobre-novembre 2007, p. 1-13.

JACQUET Chantal, "Force et droit chez Pascal et Spinoza », in BOVE Laurent, BRAS Gérard et MÉCHOULAN Éric (dir.), Pascal et Spinoza. Pensées du contraste: de la géométrie du hasard à la nécessité de la liberté, Paris, Éditions Amsterdam, 2007, p. 295-307.

JOUSLIN Olivier, "Rien ne nous plait que le combat». La campagne des Provinciales de Pascal. Étude d'un dialogue polémique, Clermont-Ferrand, Presses Universitaires Blaise Pascal, 2007, 2 vol.

JULLIARD Jacques, «Pascal est contre tous les intégrismes ", in Pascal miroir de notre vie, Le magazine littéraire, $\mathrm{n}^{\circ} 469$, novembre 2007, p. 41.

KAMBOUCHNER Denis, "Amour-propre et passions du moi, de Pascal à Nicole", in ROMEO Maria Vita, Il moderno fra Prometeo et Narciso, Atti delle giornate Pascal 2005, Catania, CUECM, 2007, p. 65-89.

KLAJNMAN Adrien, «Brunschvicg, lecteur de Spinoza et Pascal », in BOVE Laurent, BRAS Gérard et MÉCHOULAN Éric (dir.), Pascal et Spinoza. Pensées du contraste: de la géométrie du hasard à la nécessité de la liberté, Paris, Éditions Amsterdam, 2007, p. 39-53.

KRUMENACKER Yves et THIROUIN Laurent, Les écoles de pensée religieuse à l'époque moderne, Chrétiens et Sociétés, Documents et mémoires, ${ }^{\circ}$ 5, Lyon, 2006.

LAUX Henri, «L'imagination chez Spinoza : son orientation, son horizon pascalien », in BOVE Laurent, BRAS Gérard et MÉCHOULAN Éric (dir.), Pascal et Spinoza. Pensées du contraste : de la géométrie du hasard à la nécessité de la liberté, Paris, Éditions Amsterdam, 2007, p. 191-197.

LAZZERI Christian, « La politique et la justice », in Pascal miroir de notre vie, Le magazine littéraire, $\mathrm{n}^{\circ} 469$, novembre 2007, p. 56-59.

5 LAZZERI Christian, "Pascal et Spinoza, deux modèles de reconnaissance ", in BOVE Laurent, BRAS Gérard et MÉCHOULAN Éric (dir.), Pascal et Spinoza. Pensées du contraste: de la géométrie du hasard à la nécessité de la liberté, Paris, Éditions Amsterdam, 2007, p. 245-272.

6 LE GUERN Michel, «Sur les variations d'écriture dans les Pensées », Pascal a-t-il écrit les Pensées ?, Littératures, Presses universitaires du Mirail, 55, 2007, p. 11-18.

Les Cisterciens, coll. In situ, Vic-en-Bigorre, MSM, 2007.

MACHEREY Pierre, « Petit dialogue des morts entre Spinoza, Pascal et Fontenelle », in BOVE Laurent, BRAS Gérard et MÉCHOULAN Éric (dir.), Pascal et Spinoza. Pensées du contraste : de la géométrie du hasard à la nécessité de la liberté, Paris, Éditions Amsterdam, 2007, p. 29-337.

9 MAGNIONT Gilles, "L'impatience du réel ou l'inscription du commun dans les fragments pascaliens ", Pascal a-t-il écrit les Pensées ?, Littératures, Presses universitaires du Mirail, 55, 2007, p. 131-147.

MARINS Imaculada Conceição Manhães, «O Indeterminado e a Categoria do Provável : uma Leitura dos Milagres nos Pensamentos de Blaise Pascal », Cognitio-Estudos (PUC-SP), São Paulo, v. 4, n. 2, julho-dezembro 2007, p. 139-147. 
711 MARTINS Andrei Venturini, «Resenha : Quarta à Décima Provinciales de Blaise Pascal », Agnes (PUCSP), v. 1, 2007, p. 141-152. McKENNA Antony, "L'imagination chez Pascal », in BOVE Laurent, BRAS Gérard et MÉCHOULAN Éric (dir.), Pascal et Spinoza. Pensées du contraste : de la géométrie du hasard à la nécessité de la liberté, Paris, Éditions Amsterdam, 2007, p. 183-189.

McKENNA Antony, "Prévost lecteur de Pascal: la métaphysique du sentiment ", in Courrier du Centre International Blaise Pascal, 29, Clermont-Ferrand, 2007, p. 4-9.

714 MÉCHOULAN Éric, "Le peuple et la vérité des apparences chez Pascal et Spinoza », in BOVE Laurent, BRAS Gérard et MÉCHOULAN Éric (dir.), Pascal et Spinoza. Pensées du contraste : de la géométrie du hasard à la nécessité de la liberté, Paris, Éditions Amsterdam, 2007, p. 91-98.

715 MESNARD Jean, « Lettres inédites à Louis Machon dans un dossier relatif à l'affaire des Provinciales à Bordeaux (1660) », in FERRETTI Giuliano et SEGUIN Marc, Mélanges offerts à Jean Glénisson, Université Francophone d'été Saintonge Québec, p. 217-261.

716 MICHON Hélène, L'ordre du cœur: philosophie, théologie et mystique dans les Pensées de Pascal, Paris, Champion Classiques, 2007.

717 MOREAU Pierre-François, "Spinoza et Pascal: deux conceptions de l'Écriture ", in BOVE Laurent, BRAS Gérard et MÉCHOULAN Éric (dir.), Pascal et Spinoza. Pensées du contraste : de la géométrie du hasard à la nécessité de la liberté, Paris, Éditions Amsterdam, 2007, p. 67-76.

718 MORFINO Vittorio, "Retour sur l'enjeu du vide », in BOVE Laurent, BRAS Gérard et MÉCHOULAN Éric (dir.), Pascal et Spinoza. Pensées du contraste : de la géométrie du hasard à la nécessité de la liberté, Paris, Éditions Amsterdam, 2007, p. 167-180.

719 NADEAU Christian, "Qu'est-ce qu'une action collective pour Pascal et Spinoza? », in BOVE Laurent, BRAS Gérard et MÉCHOULAN Éric (dir.), Pascal et Spinoza. Pensées du contraste: de la géométrie du hasard à la nécessité de la liberté, Paris, Éditions Amsterdam, 2007, p. 273-285.

720 NAGASE Haruo, « Bibliographie de la machine arithmétique de Pascal ", Études de langue et littérature européennes, Université d'Okayama, 26, 2007, p. 17-32.

NICOLAS de CUES, Les écrits mathématiques, éd. Jean-Marie Nicolle, Paris, Champion, 2007.

NORMAND Maxime, Sagesse classique: sapiential biblique et littérature morale dans la seconde moitié du dix-septième siècle en France, Thèse de doctorat, Paris IV-Sorbonne, 2007. PAPASOGLI Benedetta, «Espace/espaces: le fragment des trois ordres », Pascal a-t-il écrit les Pensées?, Littératures, Presses universitaires du Mirail, 55, 2007, p. 149-164. PASCAL Blaise, Tanker, intr. de Hall Bjørnstad, Bokklubben, 2007 (Pensées en langue norvégienne).

PASCAL Blaise, Discours sur les passions de l'amour, préface de Jean-Pierre Gaxie, Nantes, Cécile Defaut, 2007.

Pascal a-t-il écrit les Pensées ?, Littératures, Presses universitaires du Mirail, 55, 2007.

"Pascal est aussi un grand penseur politique. Entretien avec André Comte-Sponville", in Pascal miroir de notre vie, Le magazine littéraire, $n^{\circ} 469$, novembre 2007, p. 58-59.

Pascal miroir de notre vie, Le magazine littéraire, $\mathrm{n}^{\circ}$ 469, novembre 2007. 

2007, p. 37-53. Mirail, 55, 2007, p. 33-46. p. 183-192. 2007, p. 10-25. magazine littéraire, $\mathrm{n}^{\circ} 469$, novembre 2007, p. 30-33. $\mathrm{n}^{\circ} 469$, novembre 2007, p. 51. p. 189-205. Pascal 2005, Catania, CUECM, 2007, p. 91-117. Champion, 2007.

PAVLOVITS Tamás, «La raison du suicide chez Pascal et Spinoza », in BOVE Laurent, BRAS Gérard et MÉCHOULAN Éric (dir.), Pascal et Spinoza. Pensées du contraste : de la géométrie du hasard à la nécessité de la liberté, Paris, Éditions Amsterdam, 2007, p. 209-217.

PAVLOVITS Tamás, "Rationality and religious polemic in Pascal's Pensées", in LOSONCZI Peter et XERAVITS Geza (dir.), Reflecting diversity, Historical and thematical perspectives in the jewish and christian tradition, Wien, Berlin, LIT Verlag, 2007, p. 87-100.

PÉCHARMAN Martine, «Le soi selon Pascal ", in ROMEO Maria Vita, Il moderno fra Prometeo et Narciso, Atti delle giornate Pascal 2005, Catania, CUECM, 2007, p. 91-117.

PÉCHARMAN Martine, «L'Anti-Pascal en filigrane de Voltaire », Historia philosophica, 5,

PERATONER Alberto, «Tra amour-propre e charité. L'autenticazione pascaliana della soggetività nella relazione ", in ROMEO Maria Vita, Il moderno fra Prometeo et Narciso, Atti delle giornate Pascal 2005, Catania, CUECM, 2007, p. 119-137.

PÉROUSE Marie, «Discerner qui est l'auteur : une querelle de l'autorité à la naissance des Pensées ", Pascal a-t-il écrit les Pensées?, Littératures, Presses universitaires du

PIAZZESI, "Travailler à bien penser: procedure "terapeutiche" del filosofare nel discorso religioso in Pascal, Kierkegaard e Wittgenstein ", in ROMEO Maria Vita, Il moderno fra Prometeo et Narciso, Atti delle giornate Pascal 2005, Catania, CUECM, 2007,

PLAINEMAISON Jacques, "Les Provinciales: unité et diversité ", Les lettres romanes, Université catholique de Louvain, tome LXI, $\mathrm{n}^{\circ}$ 3-4, 2007, p. 171-183.

POP Calin Cristian, "L'infini et les digressions dans l'œuvre de Blaise Pascal», in Philosphia, Studia Universitatis Babes-Bolyai, 1-2, Cluj University Press, 2007, p. 97-113.

PUJADE-RENAUD Claude, « Démontrer l'existence du vide ne l'exorcise pas », in Pascal miroir de notre vie, Le magazine littéraire, $\mathrm{n}^{\circ} 469$, novembre 2007, p. 42.

QUANTIN Jean-Louis, "Si mes lettres sont condamnées à Rome : les Provinciales devant le Saint-Office ", in Courrier du Centre International Blaise Pascal, 29, Clermont-Ferrand,

RABOUIN David, «Un penseur au cœur de la vérité », in Pascal miroir de notre vie, Le

RABOUIN David, « Le pari pascalien », in Pascal miroir de notre vie, Le magazine littéraire,

RAFFELT Albert, "Heidegger und Pascal - eine verwischte Spur », in N. FISCHER et F.W. von HERRMANN (dir.), Heidegger und die christliche Tradition, Hamburg, Meiner, 2007,

4 RAZZOTTI Bernardo, «La "foeza" dell'uomo tra pragmatismo e parenetica in Agostino e Pascal ", in ROMEO Maria Vita, Il moderno fra Prometeo et Narciso, Atti delle giornate

REGUIG-NAYA Delphine, Le corps des idées. Pensées et poétiques du langage dans l'augustinisme de Port-Royal. Arnauld, Nicole, Pascal, $M^{m e}$ de La Fayette, Racine, Paris, 
RIEGER, Hans-Martin, "Wetten auf Gott?: Die Wette des Blaise Pascal in religionsphilosophischer und theologischer Perspektive ", Zeitschrift für Theologie und Kirche, 2007, Vol. 104, Issue 1, p. 84-116.

ROMEO Maria Vita, Il moderno fra Prometeo et Narciso, Atti delle giornate Pascal 2005, Catania, CUECM, 2007.

ROMEO Maria Vita, "Questioni pascaliani », Quaderni leif, Semestrale del laboratorio di etica e informazione filosofica, Università degli Studi di Catania, 2/2007, p. 113-124.

SCHNEIDER Michel, "La mélancolie d'écrire », in Pascal miroir de notre vie, Le magazine littéraire, $\mathrm{n}^{\circ} 469$, novembre 2007, p. 44-50.

NEIDER Michel, "Une vie sans divertissement", in Pascal miroir de notre vie, Le magazine littéraire, $\mathrm{n}^{\circ} 469$, novembre 2007, p. 35-38.

SELLIER Philippe, "Après qu'Abraham parut: Pascal et le prohphétisme ", in ROMEO Maria Vita, Il moderno fra Prometeo et Narciso, Atti delle giornate Pascal 2005, Catania, CUECM, 2007, p. 193-205.

SELLIER Philippe, «Éditer les Pensées », in Pascal miroir de notre vie, Le magazine littéraire, $\mathrm{n}^{\circ} 469$, novembre 2007, p. 49.

SELLIER Philippe, "La figure du Christ», in Pascal miroir de notre vie, Le magazine littéraire, $\mathrm{n}^{\circ} 469$, novembre 2007, p. 50-52.

SÈVE Bernard, "Le "génie tout libre" de "l'incomparable auteur de l'Art de conférer" ", in Pascal a-t-il écrit les Pensées?, Littératures, Presses universitaires du Mirail, 55, 2007, p. 93-110.

SÉVERAC Pascal, «Pascal et Spinoza : la réforme de la sensibilité », in BOVE Laurent, BRAS Gérard et MÉCHOULAN Éric (dir.), Pascal et Spinoza. Pensées du contraste: de la géométrie du hasard à la nécessité de la liberté, Paris, Éditions Amsterdam, 2007, p. 219-228. SHIOKAWA Tetsuya, «Le temps et l'éternité selon Pascal », in TSUKAMOTO Masanori (dir.), «La conception du temps humain et ses métamorphoses dans la littérature française ", in Research Project Report, avril 2007, p. 93-104.

757 STEIN Erwin, «Calculemus! Die leibnizschen rechenmaschinen. Neue forschunggsergebnisse und nachbauten aux Hannover ", Rundbrief GAMM, 1/2007, p. 6-12. STIKER-MÉTRAL Charles-Olivier, Narcisse contrarié. L'amour propre dans le discours moral en France (1650-1715), Paris, Champion, 2007.

STOFFEL, Jean-François, « Pierre Duhem : Un savant-philosophe dans le sillage de Blaise Pascal », Revista Portuguesa de Filosofia, 1/1/2007, Vol. 63, Issue 1/3, p. 275-307. SUSINI Laurent, Pensées de Blaise Pascal, Foliothèque, Folio, Paris, Gallimard, 2007. TAKEDA Hiroki, "Travaux sur Pascal et le vide au Japon", in Courrier du Centre International Blaise Pascal, 29, Clermont-Ferrand, 2007, p. 40-48. THIROUIN Laurent, « $\mathrm{M}^{\mathrm{me}}$ de Villedieu et le pseudo-Pascal. Désordres et passions de l'amour ", Littératures classiques, 61, 2007, p. 237-258.

3 THIROUIN Laurent, "Composer le hasard", in BOVE Laurent, BRAS Gérard et MÉCHOULAN, Pascal et Spinoza. Pensées du contraste : de la géométrie du hasard à la nécessité de la liberté, Paris, Éditions Amsterdam, 2007, p. 113-122. 
THIROUIN Laurent, «À la recherche du vrai saint Augustin », IN KRUMENACKER Yves et THIROUIN Laurent, Les écoles de pensée religieuse à l'époque moderne, Chrétiens et Sociétés, Documents et mémoires, $\mathrm{n}^{\circ}$ 5, Lyon, 2006, p. 25-64.

VERGELY Bertrand, Pascal ou l'expérience de l'infini, Paris, 2010.

VERLET Agnès, "Un génie déconstruit ", in Pascal miroir de notre vie, Le magazine littéraire, $\mathrm{n}^{\circ} 469$, novembre 2007, p. 35-37.

VOCOS Gerassimos, "Le livre en question", in BOVE Laurent, BRAS Gérard et MÉCHOULAN Éric (dir.), Pascal et Spinoza. Pensées du contraste : de la géométrie du hasard à la nécessité de la liberté, Paris, Éditions Amsterdam, 2007, p. 99-110.

\section{Année 2008}

AQUINO João Emiliano Fortaleza de, «Blaise Pascal : os limites do método geométrico e a noção de "coração" ", Trans/Form/Ação, 2008, v. 31, n. 2, p. 39-59.

ARNAULD D'ANDILLY Robert, Mémoires, suivis de Antoine Arnauld, dit l'abbé Arnauld, Mémoires, édités, présentés et annotés par Régine Pouzet, Paris, Champion, 2008.

BAFARO Georges, Les Pensées. Pascal, Perpignan, Paris, Ellipses, 2008.

BAUDRY DE SAINT-GILLES D'ASSON Antoine, Journal d'un solitaire de Port-Royal, éd. J. Lesaulnier et P. Ernst, Paris, Nolin, 2008.

BELIN Christian, «Le parler prophétique selon Pascal », in Les voix de Dieu : littérature et prophétie en Angleterre et en France à l'âge baroque, Presses Sorbonne Nouvelle, 2008, p. 285-294.

BOUCHILLOUX Hélène Laurent, "Les Provinciales, matrice d'un concept du comique chez Pascal ", La campagne des Provinciales, Chroniques de Port-Royal, 58, Paris, 2008, p. 323-334.

4 CANTILLON Alain, «Énonciation individuelle et énonciation collective (I) - la position auctoriale dans les Provinciales ", La campagne des Provinciales, Chroniques de Port-Royal, 58, Paris, 2008, p. 165-176.

CANTILLON Alain, "Une figure critique des modernités: la persona Pascal», in Religions, ethics, and history in the french long Seventeenth century, p. 79-90.

CLÉRO Jean-Pierre, «Le sursolide de Pascal», in 10 expériences imaginaires qui ont bouleversé la science, Science et avenir, Hors série, $\mathrm{n}^{\circ}$ 153, janvier-février 2008, p. 60-64.

CLÉRO Jean-Pierre, «Une contradiction pascalienne? ", La campagne des Provinciales, Chroniques de Port-Royal, 58, Paris, 2008, p. 363-371.

CLÉRO Jean-Pierre, Pascal, Neuilly, Atlande, 2008.

COUPRIE Alain, Pensées: "Grandeur et misère de l'homme» (édition posthume, 1670), Paris, Hatier, 2008.

DE FRANCESCHI Sylvio Hermann, « Les premiers jansénistes face à la doctrine thomiste. Jansénisme et thomisme à la veille de la campagne des Provinciales ", La campagne des Provinciales, Chroniques de Port-Royal, 58, Paris, 2008, p. 307-322.

DE NADAÏ Jean-Christophe, Jésus selon Pascal, Paris, Desclée, 2008.

DESCOTES Dominique et SERFATI Michel (dir.), Mathématiciens français du XVII siècle. Descartes, Fermat, Pascal, Clermont-Ferrand, Presses Universitaires Blaise Pascal, 2008. 
DESCOTES Dominique, "Constructions du triangle arithmétique de Pascal», in DESCOTES Dominique et SERFATI Michel (dir.), Mathématiciens français du XVIIe siècle. Descartes, Fermat, Pascal, Clermont-Ferrand, Presses Universitaires Blaise Pascal, 2008, p. 239-280.

DESCOTES Dominique, Pascal. Wiskunige van God, Wetenschappelijke, Natuur Wetenschap \& Technieck, Veen Magazines, Diemen, 2008.

DESCOTES Dominique, «Les Provinciales et l'axiomatique des probabilités », La campagne des Provinciales, Chroniques de Port-Royal, 58, Paris, 2008, p. 189-197.

DESCOTES Dominique, «Blaise Pascal, l'homme qui déplaça la montagne!», Éruption, $\mathrm{n}^{\circ} 19$, juillet 2008, p. 29-30.

DESCOTES Dominique, "Universalité et art d'inventer chez Pascal », L'Auvergne en philosophie, I, Portraits et itinéraires, Revue d'Auvergne, $\mathrm{n}^{\circ}$ 580-581, 2006 (paru en 2008), p. 53-62.

DESCOTES Dominique, «Tradition mathématique et modernité de la pensée », in LES LUNDIS DE PORT-ROYAL, Port-Royal pour notre temps, Voisins-le-Bretonneux, Les lundis de Port-Royal, 2008, p. 53-65.

DESCOTES Dominique et PROUST Gilles, «Un projet du Centre International Blaise Pascal : l'édition électronique des Pensées ", Courrier du Centre International Blaise Pascal, $\mathrm{n}^{\circ} 30,2008$, p. 2-14.

Discours sur les passions de l'amour, préface de Jean-Pierre Gaxie, Nantes, Éditions Cécile Defaut, 2008.

791 DUMOULIN Bernard, «Blaise Pascal, un philosophe?", L'Auvergne en philosophie, I, Portraits et itinéraires, Revue d'Auvergne, $\mathrm{n}^{\circ}$ 580-581, 2006 (paru en 2008), p. 35-52. FAU Jean, «Blaise Pascal, créateur d'entreprises », in LES LUNDIS DE PORT-ROYAL, PortRoyal pour notre temps, Voisins-le-Bretonneux, Les lundis de Port-Royal, 2008, p. 137-143. FERREYROLLES Gérard, «Conclusions », La campagne des Provinciales, Chroniques de PortRoyal, 58, Paris, 2008, p. 389-396.

794 GARAGNON Anne-Marie et CALAS Frédéric, «Les noms des pères: désignation des jésuites dans les Provinciales. De la nomination à la dé-nomination ", La campagne des Provinciales, Chroniques de Port-Royal, 58, Paris, 2008, p. 105-119.

GAY Jean-Pascal, «L'écriture de l'histoire Provinciales: révélateur des transformations des usages et des fonctions de la polémique ? ", La campagne des Provinciales, Chroniques de Port-Royal, 58, Paris, 2008, p. 35-49.

GERMANO E., " Pascal e Camus : o pensamento dos limites ", Princípios (UFRN), v. 14, 2008, p. 179-203.

GRASSET Bernard, "Le sens pascalien du mot esprit et les trois ordres », Revue philosophique de la France et de l'étranger, 1, 2008, p. 3-30. GRES-GAYER Jacques M., "La Sorbonne et les Provinciales», La campagne des Provinciales, Chroniques de Port-Royal, 58, Paris, 2008, p. 15-33. GUION Béatrice, Du bon usage de l'histoire. Histoire, morale et politique à l'âge classique, Paris, Champion, 2008. 
HOSSON Cécile de, « Blaise Pascal physicien : un nouvel élan pour l'enseignement de la physique ", in LES LUNDIS DE PORT-ROYAL, Port-Royal pour notre temps, Voisins-leBretonneux, Les lundis de Port-Royal, 2008, p. 67-85.

JOUSLIN Olivier, «La loi comme question et comme enjeu durant la campagne des Provinciales (janvier 1656-octobre 1659) », La campagne des Provinciales, Chroniques de Port-Royal, 58, Paris, 2008, p. 293-306.

KERBRAT-ORECCHIONI Catherine, "Les Provinciales: un texte "dialogal" et "dialogique" ", La campagne des Provinciales, Chroniques de Port-Royal, 58, Paris, 2008, p. 73-89.

La campagne des Provinciales, Chroniques de Port-Royal, 58, Paris, 2008.

LE GUERN Michel, "Sur le silence », in La rhétorique et les autres, Littérature, 149, mars 2008, p. 38-44.

LE GUERN Michel, "Les réactions de la police aux Provinciales ", La campagne des Provinciales, Chroniques de Port-Royal, 58, Paris, 2008, p. 51-58.

LES LUNDIS DE PORT-ROYAL, Port-Royal pour notre temps, Voisins-le-Bretonneux, Les lundis de Port-Royal, 2008.

MARINS I. C. M., " “Teu Deus será meu Deus” : a fé de Blaise Pascal de um ponto de vista pragmático ", Cognitio-Estudos (PUC-SP), v. 5, 2008, p. 75-92.

MÉCHOULAN Éric, "La force de la vérité et l'institution d'une subjectivité », La campagne des Provinciales, Chroniques de Port-Royal, 58, Paris, 2008, p. 153-164.

MERKER Claude, «La pensée des ordres dans les traités sur la roulette de Pascal », in DESCOTES Dominique et SERFATI Michel (dir.), Mathématiciens français du XVII siècle. Descartes, Fermat, Pascal, Clermont-Ferrand, Presses Universitaires Blaise Pascal, 2008, p. 199-238.

10 MESNARD Jean, « Pascal et la justice à Port-Royal », Commentaire, 121, printemps 2008, p. 163-173.

MESNARD Jean, « Ouverture de la première journée. Propos d'introduction sur le temps et l'espace dans les Provinciales », La campagne des Provinciales, Chroniques de Port-Royal, 58, Paris, 2008, p. 9-13.

MESNARD Jean, "Pascal ou la maîtrise de l'esprit », Bulletin de la Société française de philosophie, $\mathrm{n}^{\circ}$ 3, 2008, p. 1-38.

MICHON Hélène, "L'auteur des Provinciales: une autre figure du jésuite ", La campagne des Provinciales, Chroniques de Port-Royal, 58, Paris, 2008, p. 243-256.

14 MICHON Hélène, «Le concept de force chez Pascal peut-il être utile pour notre temps? ", in Les Lundis de Port-Royal, Port-Royal pour notre temps, Voisins-le-Bretonneux, Les lundis de Port-Royal, 2008, p. 107-119.

MOCHIZUKI Yuka, «Les Provinciales et le style janséniste ", La campagne des Provinciales, Chroniques de Port-Royal, 58, Paris, 2008, p. 137-151.

6 NATAN Stéphane, «Le pari de Pascal et ses ambiguïtés ", Commentaire, 121, 2008, p. 159-173.

7 NICA Dana, "Petits livres, petites lettres: des libelles aux Provinciales", in Analele Stiintifice ale Universitatii Alexandru Ioan Cuza din Iasi (serie nova), Limbi si Literaturi straine, t. XI, 2008, p. 187-208, p. 79-90. 

l'ADIREL, XXI, Genève, Droz, 2008, p. 147-158. p. 199-210. 58, Paris, 2008, p. 335-345. Philologia, 4/2008, p. 21-28. p. 257-268. Chroniques de Port-Royal, 58, Paris, 2008, p. 177-188. Chroniques de Port-Royal, 58, Paris, 2008, p. 399-414.

PAPASOGLI Benedetta, «Entre méditation et contemplation: la voix dans l'écriture spirituelle au XVII ${ }^{e}$ siècle ", in La spiritualité des écrivains, Travaux de littérature publiés par

PAPASOGLI Benedetta, La mémoire du cœur au XVII siècle, Paris, Champion, 2008.

PARISH Richard, "Les traductions en langue française des Lettres provinciales de Pascal », La campagne des Provinciales, Chroniques de Port-Royal, 58, Paris, 2008,

PASCAL Blaise, Pensées, éd. J. P. Marty, Paris, Flammarion, 2008.

PASCAL Blaise, Pensées, liasses II à VIII, éd. M. Le Guern, Paris, Folioplus, Gallimard, 2008.

PAVLOVITS Tamás, «Théologie morale et morale théologique. Le caractère rationnel de la morale dans les Provinciales ", La campagne des Provinciales, Chroniques de Port-Royal,

PAVLOVITS Tamás, "La figure de Jésus-Christ chez Pascal », in RESWEBER Jean-Paul (dir.), Le Jésus des philosophes, Strasbourg, Le Portique, 2008, p. 19-41.

PÉCHARMAN Martine, "L'analyse de l'action volontaire dans la $4^{\mathrm{e}}$ Provinciale ", La campagne des Provinciales, Chroniques de Port-Royal, 58, Paris, 2008, p. 277-292.

PEREPADIA A. et KHOMA O., "Blaise Pascal, Pensées », extraits de traduction juxtalinéaire en ukrainien, Philosophica Dymka, 5, 2008, p. 103-118.

PEZZINO Giuseppe, "Morale et casuistique dans les Provinciales", La campagne des Provinciales, Chroniques de Port-Royal, 58, Paris, 2008, p. 347-362.

POP Calin Cristian, "Tradition et coutume selon Blaise Pascal », in LASCU-POP R. et AURAIX-JONCHIÈRE P. (dir.), L'intergénérationnel, Studia Universitatis Babes Bolyai,

RAVAISSON Félix, La philosophie de Pascal, Paris, Éditions du Sandre, 2008.

RÉGENT-SUSINI Anne, "Rire des erreurs des hommes": les Provinciales, une comédie?», La campagne des Provinciales, Chroniques de Port-Royal, 58, Paris, 2008,

REGUIG-NAYA Delphine, "Pratiques herméneutiques dans les Provinciales», La campagne des Provinciales, Chroniques de Port-Royal, 58, Paris, 2008, p. 211-224.

RIBARD Dinah, "Énonciation individuelle et énonciation collective (II) - l'envers des Provinciales: Agir en quasi corps par l'écriture ", La campagne des Provinciales,

ROMEO Maria Vita, «Considerazioni su Hobbes e Pascal », Quaderni leif, Semestrale del laboratorio di Etica e Informazione Filosofica, 3, 2007, Catania, p. 63-100.

ROMEO Maria-Vita, "L'éthique du cœur dans les Provinciales", La campagne des Provinciales, Chroniques de Port-Royal, 58, Paris, 2008, p. 373-387.

SEDLEY David, «Irony and the vacuum in Pascal and Montaigne ", in LEUSHUIS Reiner et ZALLOUA ZAHI (dir.), Esprit généreux, esprit pantagruélicque; essays by his students in honor of François Rigolot, Genève, Droz, 2008, p. 279-297.

SHIOKAWA Tetsuya, "La campagne de la XVIII Provinciale», La campagne des Provinciales, Chroniques de Port-Royal, 58, Paris, 2008, p. 59-73.

SHIOKAWA Tetsuya, "La "pensée" selon Pascal», La campagne des Provinciales, 
SHIOKAWA Tetsuya, «Entre la pensée et l'œuvre : à propos de la critique valéryenne de Pascal», in NAKAJI Yooshikazu (dir.), L'autre de l'œuvre, Presses Universitaires de Vincennes, Paris, 2008, p. 39-48.

SIOUFFI Gilles, «Entre souci de définition et pouvoir des mots: Pascal sémanticien ambigu dans les Provinciales ", La campagne des Provinciales, Chroniques de Port-Royal, 58, Paris, 2008, p. 91-104.

"Sixième compte rendu du séminaire sur les Pensées de Pascal ", Courrier du Centre International Blaise Pascal, 32, 2010, p. 15-40.

SORMAN Richard, "Traditionalisme et modernisme dans les Pensées ", in Religions, ethics and history in the french long Seventeenth century, p. 329-339.

SOUSA J. P., "O papel do pirronismo em Pensées de Pascal », Revista Mosaicum, v. 01, 2008, p. 47-58.

SUSINI Laurent, «L'éloquence du "vrai combat" dans les Provinciales », La campagne des Provinciales, Chroniques de Port-Royal, 58, Paris, 2008, p. 121-135.

SUSINI Laurent, L'écriture de Pascal. La lumière et le feu. La "vraie éloquence » à l'œuvre dans les Pensées, Paris, Champion, 2008.

TAKEDA Hiroki, "L'esprit de justesse dans les Pensées de Pascal », Gallia, Bulletin de la société de langue et littérature françaises de l'université d'Osaka, 48, 2008, p. 1-10. TESSON Philippe, «Le pari réussi de Pascal au théâtre », Le Figaro Magazine, samedi 2 février 2008, p. 65.

THIROUIN Laurent, «Jansénisme et joie de vivre. Quelques réflexions sur la grâce », Le Collège supérieur, Lyon, $\mathrm{1}^{\mathrm{er}}$ trimestre $2008, \mathrm{n}^{\circ} 34, \mathrm{p} .2-7$.

THIROUIN Laurent, «La figure de saint Augustin dans les Provinciales ", La campagne des Provinciales, Chroniques de Port-Royal, 58, Paris, 2008, p. 225-242.

THIROUIN Laurent, "Pascal et la superstition ", in La religion des élites au XVII siècle, actes $d u$ colloque du Centre de recherches sur le XVII siècle européen (1600-1700), 2008, p. 237-256.

TSUKAMOTO Masanori, "La main de Pascal: écriture et détresse", in Nakaji Yooshikazu (dir.), L'autre de l'cuvre, Presses Universitaires de Vincennes, Paris, 2008, p. 213-223.

\section{Année 2009}

BARTOLI Silvana, Le vite di Jacqueline Pascal, Firenze, Leo S. Olschki, 2009.

BESANÇON Alain, "L'angoisse dans la relation de Pascal à son Dieu ", Les Pensées de Pascal: interprètes et éditeurs en débat, Revue des sciences philosophiques et théologiques, tome 93, $\mathrm{n}^{\circ} 1$, janvier-mars 2009, Paris Vrin, 2009, p. 3-11.

BOARINI Serge (dir.), La casuistique classique: genèse, formes, devenir, Publications de l'Université de Saint-Étienne, 2009.

BOARINI Serge, "Herméneutique du cas : dire le cas ", in BOARINI Serge (dir.), La casuistique classique: genèse, formes, devenir, Presses Universitaires de Saint-Étienne, 2009, p. 147-171.

BORD André, Jacqueline Pascal. Biographie, Perpignan, Tempora, Éditions du Jubilé, 2009.

Courrier du Centre international Blaise Pascal, 37 | 2015 
BOUCHILLOUX Hélène, «Donner raison au vrai christianisme », Les Pensées de Pascal: interprètes et éditeurs en débat, Revue des sciences philosophiques et théologiques, tome 93, $\mathrm{n}^{\mathrm{o}}$ 1, janvier-mars 2009, Paris Vrin, 2009, p. 69-84.

BRÉMONDY François, « Apologie de l'édition de Francis Kaplan ", Les Pensées de Pascal: interprètes et éditeurs en débat, Revue des sciences philosophiques et théologiques, tome 93, $\mathrm{n}^{\circ}$ 1, janvier-mars 2009, Paris Vrin, 2009, p. 83-144.

CARENA Carlo, «Filologia ed etica nelle Lettere Provinciali », in ROMEO Maria Vita (dir.), Le Provinciali oggi. Atti delle giornate Pascal 2007, Catane, CUECM, 2009, p. 21-32.

CHIRON Yves, Pascal. Biographie, Tempora, Paris, Éditions du Jubilé, 2009.

PASCAL Blaise, Il faut parier: pensées sur le pari, le jeu et le divertissement, éd. Y. Constantinidès, Paris, Hachette, 2009.

Courrier du Centre International Blaise Pascal, $\mathrm{n}^{\circ}$ 31, Clermont-Ferrand, 2009.

DE FRANCESCHI Sylvio Hermann, Entre saint Augustin et saint Thomas. Les jansénistes et le refuge thomiste (1653-1663) : à propos des $1^{\text {re }}, 2^{e}$ et $18^{e}$ Provinciales, Paris, Nolin, 2009.

DESCOTES Dominique, "Sur les figures dans quelques traités scientifiques du XVII ${ }^{e}$ siècle ", in COUTON Marie, FERNANDES Isabelle, JÉRÉMIE Christian et VÉNUAT Monique (dir.), Pouvoirs de l'image aux XVe, XVI et XVII siècles. Pour un nouvel éclairage sur la pratique des Lettres à la Renaissance, CERHAC, Clermont-Ferrand, Presses Universitaires Blaise Pascal, 2009, p. 511-575.

DESCOTES Dominique, "La mesa a punto dell'ordine nei frammenti di Pascal», in ROMEO Maria Vita (dir.), Le Provinciali oggi. Atti delle giornate Pascal 2007, Catane, CUECM, 2009, p. 33-45.

DESLOUIS Emmanuel et DERRIEN Loïc, «La découverte de la pression athmosphérique ", Science et Vie junior, $n^{\circ}$ 244, janvier 2010, p. 64-69 (bande dessinée).

DEVILLAIRS Laurence, "L'homme image de Dieu. Interprétations augustiniennes (Descartes, Pascal, Fénelon)», Archives de philosophie, tome 72-2, avril-juin 2009, p. 293-315.

ENTHOVEN Raphaël (dir.), FERREYROLLES Gérard, CLÉRO Jean-Pierre, THIROUIN Laurent, CARRAUD Vincent, LAZZERI Christian, Pascal ou les intermittences de la raison, Paris, Perrin/France Culture, 2009.

FERREYROLLES Gérard, «Le Provinciali nella tradizione della polemiqua cristiana », in ROMEO Maria Vita (dir.), Le Provinciali oggi. Atti delle giornate Pascal 2007, Catane, CUECM, 2009, p. 47-72.

9 FERREYROLLES Gérard, "Pascal et les adversaires de l'Église ", in SERVET P. et SERVET M.-H. (dir.), Polémiques en tous genres, Cahiers du GADGES, $\mathrm{n}^{\circ}$ 7, Université Jean Moulin, Genève, diffusion Droz, 2009, p. 191-212.

FERREYROLLES Gérard, «Éthique et polémique en christianisme: le cas des Provinciales », in DARMON J.-C. et DESAN P. (dir.), Pensée morale et genres littéraires, Paris, PUF, 2009, p. 63-80.

1 GATTI Roberto, «Il problema della giustizia in Pascal : un confronto tra le Provinciali e i Pensieri », in ROMEO Maria Vita (dir.), Le Provinciali oggi. Atti delle giornate Pascal 2007, Catane, CUECM, 2009, p. 3-107.

GOUVERNEUR Sophie, «Les Provinciales et la doctrine des équivoques à l'épreuve de la politique », XVII siècle, $\mathrm{n}^{\circ}$ 242, 2009, p. 149-158. 

p. 367-376. Press, 2009. mars 2009, Paris Vrin, 2009, p. 13-22. p. 141-164. Pascal, $n^{\circ}$ 31, Clermont-Ferrand, 2009, p. 4-5. 2009, p. 115-122. p. 131-204. mars 2009, Paris Vrin, 2009, p. 23-33. $\mathrm{n}^{\circ} 1$, janvier-mars 2009, Paris Vrin, 2009, p. 35-46. 2009, p. 6-16. Paris Vrin, 2009, p. 47-58.

GRASSET Bernard, «Pascal et la tradition face au judaïsme », Sens, 6, juin 2009,

HARRINGTON Thomas More, "Justice et jugement selon Pascal ", Cahiers d'histoire des littératures romanes, Universitätverlag, Winter, Heidelberg, 2009, p. 61-69.

HUNTER Michael, Boyle between God and science, New Haven and London, Yale University

JARNET Raymond, «Lire les Pensées de Pascal dans l'ordre ou dans le désordre? ", La lettre et l'esprit, Bulletin de la Société des Roseaux pensants, mars 2009, p. 4-14.

JOUSLIN Olivier, « Pour une approche contextualisée des Provinciales (1655-1659) », in Polémiques en tous genres, Cahiers du GADGES, nº 7, Genève, Droz, 2009, p. 171-189.

KAPLAN Francis, "La pensée des deux infinis ", Les Pensées de Pascal: interprètes et éditeurs en débat, Revue des sciences philosophiques et théologiques, tome $93, \mathrm{n}^{\circ} 1$, janvier-

KHOMA Oleg, «Les Pensées et l'herméneutique : la signification philosophique de la nouvelle apologétique de Pascal», in PASCAL Blaise, Pensées [en ukrainien], tr. d'A. Perepadia et O. Khoma, Kiev, L'esprit et la lettre, 2009, p. 395-407.

KHOMA Oleg, «Les motifs cartésiens dans l'œuvre de Pascal: le problème des fondements de la connaissance » [en ukrainien], Philosophska Doumka, 5, 2009,

"La traduction des Pensées de Pascal en ukrainien », Courrier du Centre International Blaise

LE GUERN Michel, «Pascal, Arnauld et les casuistes », in BOARINI Serge (dir.), La casuistique classique : genèse, formes, devenir, Publications de l'université de Saint-Étienne,

LESAULNIER Jean, « M. de Saint-Gilles e le Provinciali », in ROMEO Maria Vita (dir.), Le Provinciali oggi. Atti delle giornate Pascal 2007, Catane, CUECM, 2009, p. 109-130.

Les Pensées de Pascal: interprètes et éditeurs en débat, Revue des sciences philosophiques et théologiques, tome 93, nº 1, janvier-mars 2009, Paris Vrin, 2009.

LISSA Giuseppe, «L'eclisse del peccato originale : rischion antropologico », in ROMEO Maria Vita (dir.), Le Provinciali oggi. Atti delle giornate Pascal 2007, Catane, CUECM, 2009,

MAGNARD Pierre, «D'étincelles en parataxes », Les Pensées de Pascal: interprètes et éditeurs en débat, Revue des sciences philosophiques et théologiques, tome $93, \mathrm{n}^{\circ} 1$, janvier-

7 MARQUET Jean-François, « Point, centre et milieu chez Pascal », Les Pensées de Pascal : interprètes et éditeurs en débat, Revue des sciences philosophiques et théologiques, tome 93,

MERKER Claude, «Pascal et la Dimension d'un solide formé par le moyen d'une spirale autour d'un cône ", Courrier du Centre International Blaise Pascal, $\mathrm{n}^{\circ} 31$, Clermont-Ferrand,

MICHON Hélène, «Les raisons du cœur », Les Pensées de Pascal : interprètes et éditeurs en débat, Revue des sciences philosophiques et théologiques, tome 93, $\mathrm{n}^{\circ} 1$, janvier-mars 2009 , 
NATAN Stéphane, «Les Je non chrétiens dans les Pensées de Pascal », Les lettres romanes, 63, 2009, p. 173-180.

PAROLINI Rocco, « La tentazione del potere politico. Un percorso tra Pascal, Dostoevskij e Ratzinger ", in ROMEO Maria Vita (dir.), Le Provinciali oggi. Atti delle giornate Pascal 2007, Catane, CUECM, 2009, p. 205-216.

PASCAL Blaise, ARNAULD Antoine, DE NONANCOURT François, Géométries de Port-Royal, éd. D. Descotes, Paris, Champion, 2009.

PASCAL Blaise, Pensées en ukrainien, tr. d'A. Perepadia et O. Khoma, Kiev, L'esprit et la lettre, 2009.

PASCAL Blaise, Textes choisis et présentés par Philippe Sellier, Paris, Bibliothèque Essais, Seuil, 2009.

PASCAL Blaise, Pensées (liasses II à VIII). Lu par Didier Sandre, CD, Gallimard, 2009.

PASCAL Blaise, Trois discours sur la condition des Grands, éd. M. Escola, Mille et une nuits, Arthème Fayard, 2009.

PASCAL Blaise, Une pensée par jour, Paris, Mediaspaul, 2009.

PAVLOVITS Tamás, «Admiration, Fear, and Infinity in Pascal's Thinking ", in Philosophy Begins in Wonder. An Introduction to Early Modern Philosophy, Theology and Science, Michael Funk Deckard, Peter Losonczi (dir.), Eugene (Oregon), Pickwick Publication, 2009, p. 119-127.

PEREPADIA A. et KHOMA O., "Blaise Pascal, Les Pensées » [extraits de traduction juxtalinéaire en ukrainien], Philosophska Doumka, 5, 2009, p. 114-139.

PÉREZ ANDREO Bernardo, "Agnosticisme et religion chez Pascal et chez Hume », Les Pensées de Pascal: interprètes et éditeurs en débat, Revue des sciences philosophiques et théologiques, tome 93, $\mathrm{n}^{\circ}$ 1, janvier-mars 2009, Paris Vrin, 2009, p. 47-67.

PÉROUSE Marie, L'invention des Pensées de Pascal. Les éditions de Port-Royal (1670-1678), Paris, Champion, 2009.

RAFFELT Albert, "Blaise Pascal (1623-1662) als Schülr Augustins ", in FISCHER N., Augustinus, Spuren une Spielelungen seines Denkens, Band 2, Von Descartes bis in die Gegenwart, Hamburg, Meiner, 2009, p. 45-58.

ROMEO Maria Vita, Il re di concupiscenza. Saggio su Pascal etico-politico, Presentazione di Carmelo Vigna, Milano, Vita e pensiero, 2009.

ROMEO Maria Vita (dir.), Le Provinciali oggi. Atti delle giornate Pascal 2007, Catane, CUECM, 2009.

ROMEO Maria Vita, "Il messaggio cristiano di un pensatore moderno ", in ROMEO Maria Vita (dir.), Le Provinciali oggi. Atti delle giornate Pascal 2007, Catane, CUECM, 2009, p. 7-18.

ROMEO Maria Vita, "Calunnia e menzogna nelle Lettere Provinciali », in ROMEO Maria Vita (dir.), Le «Provinciali » oggi. Atti delle giornate Pascal 2007, Catane, CUECM, 2009, p. 217-235.

SELLIER Philippe, «Indications d'ordre et dossiers pascaliens », Les Pensées de Pascal: interprètes et éditeurs en débat, Revue des sciences philosophiques et théologiques, tome 93, $\mathrm{n}^{\mathrm{o}}$ 1, janvier-mars 2009, Paris Vrin, 2009, p. 145-154. 

Firenze, L. S. Olschki, 2009, p. 359-371. University of Tokyo, mars 2009. University of Tokyo, mars 2009, p. 51-59. of Tokyo, mars 2009, p. 61-73. p. 75-90. 91-10. $\mathrm{n}^{\circ}$ 68, Paris, Champion, été 2009, p. 117-130. 2009.

\section{Année 2010} Kimé, 2010. Boeck-Duculot, 2010, p. 259-276. Diderot, Kierkegaard, Lévinas, Paris, Kimé, 2010.

SELLIER Philippe, «Le Saint Augustin de Pascal », Rivista di storia e letteratura religiosa,

«Septième compte rendu du séminaire sur les Pensées de Pascal », Courrier du Centre International Blaise Pascal, $\mathrm{n}^{\circ}$ 31, Clermont-Ferrand, 2009, p. 17-38.

SHIOKAWA Tetsuya (dir.), Littérature et christianisme en France, Research project report,

SHIOKAWA Tetsuya, "Traduction et interprétation : à propos du nez de Cléopâtre », in SHIOKAWA Tetsuya (dir.), Littérature et christianisme en France, Research project report,

SHIOKAWA Tetsuya, "La place de l'apologétique dans les Pensées", in SHIOKAWA Tetsuya (dir.), Littérature et christianisme en France, Research project report, University

SHIOKAWA Tetsuya, "Quod bellum firmavit, pax ficta non auferat: de la campagne des Provinciales aux événements de mai 68 ", in SHIOKAWA Tetsuya (dir.), Littérature et christianisme en France, Research project report, University of Tokyo, mars 2009,

SHIOKAWA Tetsuya, "Pascal adversaire de Robert Challe dans les Difficultés sur la religion proposées au Père Malebranche", in SHIOKAWA Tetsuya (dir.), Littérature et christianisme en France, Research project report, University of Tokyo, mars 2009, p.

SIOUFFI Olivier, « Pouvoir des mots et émotions publiques au XVII ${ }^{\mathrm{e}}$ siècle : réflexions à partir de Pascal ", in Les émotions et leurs langages à l'âge classique, Littératures classiques,

SUSINI Laurent, "La thématisation avec détachement à gauche dans les Pensées de Pascal ", in SERVET Marie-Hélène et BOISSIERAS Fabienne (dir.), Hiérarchisation, énonciation, Louvain, Paris, Ma, Peeters, 2009, p. 221-232.

THIROUIN Laurent, "Deux visions de Port-Royal: Sainte-Beuve et Bremond", in Histoire et littérature chez Henri Bremond, éd. Jérôme Millon, 2009, p. 61-101.

WEAVER F. Ellen, Le domaine de Port-Royal. Histoire documentaire, 1669-1710, Paris, Nolin,

ADORNO Paolo Francesco, Pascal, Paris, Perrin, 2010.

ADORNO Paolo Francesco, La discipline de l'amour, Pascal, Port-Royal et la politique, Paris,

ANGEBAULT Christophe, «Force et violence dans la polémique sur le vide entre Blaise Pascal et le Père Étienne Noël (1647-1648) : un expérience critique? », in ALBERT Luce et NICOLAS Loïc (dir.), Polémique et rhétorique de l'antiquité à nos jours, Bruxelles, De

BARBÉ-PETIT Françoise, Marguerite Duras au risque de la philosophie: Pascal, Rousseau,

BERNIER Jean, La critique du Pentateuque de Hobbes à Calmet, Paris, Champion, 2010. 
BJøRNSTAD Hall, Créature sans créateur. Pour une anthropologie baroque dans les Pensées de Pascal, Éditions du CIERL, Québec, Presses de l'Université de Laval, 2010.

BOUCHILLOUX Hélène, "L'apologétique pascalienne: la raison comme juge ", in BRUCKER Nicolas (dir.), Apologétique 1650-1802. La nature et la grâce, Berne, Peter Lang, 2010, p. 41-53.

BOURGEOIS Muriel, "Visages du rire dans les Pensées» in DAGEN J. et BARROVECCHIO A.-S. (dir.), Le rire ou le modèle? Le dilemme du moraliste, Paris, Champion, 2010, p. 391-408.

BOVE Laurent, Vauvenargues ou le séditieux. Entre Pascal et Spinoza. Une philosophie pour la seconde nature, Paris, Champion, 2010.

BREMONDY François, "L'effroi de Pascal ", in SURYA Michel (dir.), Contre-attaques: perspective I, Marseille, Al Dante, 2010, p. 193-214.

BRUCKER Nicolas (dir.), Apologétique 1650-1802. La nature et la grâce, Berne, Peter Lang, 2010.

CARRAUD Vincent, L'invention du moi, Paris, PUF, 2010.

DELBOS Victor, Descartes Pascal, Houilles, Éditions Manucius, 2010.

DE SAINT-GERMAIN Charles-Éric, "Grâce et liberté. Le débat de Pascal avec les molinistes et les protestants et la défense de l'augustinisme ", in BRUCKER Nicolas (dir.), Apologétique 1650-1802. La nature et la grâce, Berne, Peter Lang, 2010, p. 23-40.

DESCOTES Dominique, "An unknown mathematical manuscript by Blaise Pascal», Historia mathematica, vol. 37, 3, août 2010.

DESCOTES Dominique, "Pascal mathématicien et les esprits forts", in La littérature philosophique clandestine et les sciences, La Lettre clandestine, $\mathrm{n}^{\circ}$ 18, PUPS, 2010, p. 89-132.

DESCOTES Dominique et PROUST Gilles, Édition électronique des Pensées de Pascal, www.penseesdepascal.fr. (490 fragments en ligne début 2015).

DEVILLAIRS Laurence, "La voie d'une apologétique rationaliste. De Descartes à Fénelon ", in BRUCKER Nicolas (dir.), Apologétique 1650-1802. La nature et la grâce, Berne, Peter Lang, 2010, p. 85-105.

D'OULTREMEONT Catherine, Les fruits de la solitude: quatre saisons à Port-Royal, Roman, Bruxelles, le Cri, 2010.

DUBOUCHER Georges, Port-Royal et la médecine, Paris, Nolin, 2010.

FERREYROLLES Gérard, "Saint Thomas et Pascal: les règles de la polémique chrétienne ", in Séries et variations. Études littéraires offertes à Sylvain Menant, Paris, PUPS, 2010, p. 687-703.

FRIGO Alberto, «Blaise Pascal et les "membres pensants": penser l'Église, régler l'amour », Courrier du Centre International Blaise Pascal, n 32, 2010, p. 56-60.

GATTI Roberto, Politica e trascenza, Saggio su Pascal, Roma, Edizioni Studium, 2010.

GENET Claude, Blaise Pascal : des mathématiques à la mystique, Paris, Salvator, 2011.

GIBERT Pierre, L'invention critique de la Bible, XV'-XVIII e siècle, Paris, NRF, Gallimard, 2010.

GRASSET Bernard, «Regard littéraire sur Pascal : André Suarès ", Revue d'éthique et de théologie morale, Cerf, $\mathrm{n}^{\circ}$ 259, 2010, p. 89-103.

GRASSET Bernard, Vers une pensée biblique, Nice, Ovadia, 2010. 
GRASSET Bernard, « Pascal et le feu du mystère », in Le feu, Thauma, Revue de philosophie et de poésie, $\mathrm{n}^{\circ}$ 7, 2010, p. 421-428.

ICARD Simon, «Éloge de la folie et désaveu de la raison dans les Pensées de Pascal », $X V I I^{e}$ siècle, $\mathrm{n}^{\circ} 247$, avril 2010, p. 235-245.

ICARD Simon, Port-Royal et saint Bernard de Clairvaux (1608-1709). Saint-Cyran, Jansénius, Arnauld, Pascal, Nicole, Angélique de Saint-Jean, Paris, Champion, 2010.

JUSTENS Daniel «La mathématique des paris", Tangente, $\mathrm{n}^{\circ} 136$, septembreoctobre 2010, p. 8-10.

KACHLIAVIK Kira, « Les traductions russes des Pensées de Pascal », in ZAREMBA Charles et DUTRAIT Noël (dir.), Traduire : un art de la contrainte, Aix-en-Provence, Publications de l'Université de Provence, 2010, p. 167-175.

LE NOXAÏC Armand et LAUGINIE Pierre, « Reconstitution de l'expérience des liqueurs de Blaise Pascal », Courrier du Centre International Blaise Pascal, $\mathrm{n}^{\circ} 32,2010$, p. 48-55.

Le Pascal des philosophes (1), Les études philosophiques, $\mathrm{n}^{\circ}$ 4, Paris, PUF, 2010.

LEPESQUEUR Yves, L'honneur de Blaise Pascal, L'atelier du roman, 61, 2010, p. 167-175.

McKENNA Antony, "Le dilemme de l'apologétique au XVIII ${ }^{\mathrm{e}}$ siècle ", in BRUCKER Nicolas (dir.), Apologétique 1650-1802. La nature et la grâce, Berne, Peter Lang, 2010, p. 9-20.

MEESSEN Yves, «La grâce suffisante qui ne suffit pas: une ironie pascalienne ", in BRUCKER Nicolas (dir.), Apologétique 1650-1802. La nature et la grâce, Berne, Peter Lang, 2010, p. 55-69.

MESNARD Jean, «Mythe janséniste et mythe jésuitique dans l'Europe d'après la Réforme », in Le jansénisme et l'Europe, Biblio 17, nº 188, Narr Verlag, 2010, p. 305-324.

MESNARD Jean, « Voltaire et Chateaubriand arbitres successifs de la destinée posthume de Pascal ", in Séries et variations. Études littéraires offertes à Sylvain Menant, Paris, PUPS, 2010, p. 267-284.

MICHON Hélène, «Dieu d'Abraham, d'Isaac et de Jacob, non des philosophes et des savants : la distinction pascalienne à l'épreuve du temps », in BRUCKER Nicolas (dir.), Apologétique 1650-1802. La nature et la grâce, Berne, Peter Lang, 2010, p. 71-83.

MONASTERIO Carmen, « Pascal ante el misterio de la gracia », Scripta theologica, vol. 42, 2010, p. 9-29.

PASCAL Blaise, Pensées, opuscules et lettres, éd. de Philippe Sellier, Paris, Garnier, 2010.

PASCAL Blaise, Les Provinciales, opuscules et lettres, éd. de L. Cognet et G. Ferreyrolles, Paris, Garnier, 2010.

PAUNOIU Augustin, « Pascal sau pariul credintei în modernitate », Lumina de duminica, 11 julie 2010, p. 12-13.

PASCAL Blaise, Les Provinciales, éd. L. Cognet et G. Ferreyrolles, Paris, Classiques Garnier, 2010.

PAVLOVITS Tamás, "Imagination et contemplation ou le bon usage de l'imagination selon Pascal », Philonsorbonne, nº 4, 2009-2010, p. 123-152 (http://edph.univ-paris1.fr/ phs.html).

PAVLOVITS Tamás, Blaise Pascal, a természettudománytól a vallási apológiáig («Blaise Pascal, de la science a l'apologétique »), Attraktor, Gödöllö, 2010. 

2010, p. 479-516. $\mathrm{n}^{\circ} 32,2010$, p. 4-55. 2010, p. 61-80. novembre 2010. douze études, Paris, Champion, 2010. 50, 2010, p. 13-22.

\section{Année 2011} Paris, Champion, 2011. Paris, Bibliothèque Mazarine, 2011, p. 229-245. Issue 3-4, p. 341-351. Century French Studies, 33-2, 2011, p. 72-79. Paris, Bibliothèque Mazarine, 2011, p. 77-94.

PÉCHARMAN Martine, «Il faut parier : Locke ou Pascal ? ", Les études philosophiques, 4,

POP Calin Cristian, "La connaissance claire-obscure de Dieu chez Pascal ", Studia Universitatis Babes-Bolyai, Theologia orthodoxa, $\mathrm{n}^{\circ}$ 1, 2010, p. 273-280.

POP Calin Cristian, «Le pari pascalien comme mode d'être. Des mathématiques à la phénoménologie », Philosphia, Studia Universitatis Babes-Bolyai, nº 2, 2010, p. 85-108.

PEZZINO Giuseppe, «Etica e politica nelle Provinciali », Quaderni leif, n 5, 2010, p. 81-98.

PROUST Gilles, «Les copies des Pensées», Courrier du Centre International Blaise Pascal,

ROMEO Maria Vita, «Legge e coscienza morale nelle Provinciali », Quaderni leif, n 5 ,

ROUGIER Louis, De Torricelli à Pascal, Introduction, notes et bibliographie par Simone Mazauric, Cahier spécial de la revue Philosophia Scientiae, 14-2, Paris, Kimé,

SELLIER Philippe, Port-Royal et la littérature, I, Pascal, Deuxième édition augmentée de

THIROUIN Laurent, «Éclats de rire pascaliens » in DAGEN J. et BARROVECCHIO A.-S. (dir.), Le rire ou le modèle? Le dilemme du moraliste, Paris, Champion, 2010, p. 363-390.

VOLTAIRE, Lettres philosophiques, éd. O. Ferret et A. McKenna, Paris, Garnier, 2010.

YAMAJO Hirotsugu, «La dignité de l'homme selon Pascal », Gallia, Université d'Osaka,

ARNAULD Antoine et NICOLE Pierre, La logique ou l'art de penser, éd. Dominique Descotes,

AUPETIT Hubert, « Démystification de l'infini et poétique de l'absurde », in DEVILLAIRS Laurence et TOUBOUL Patricia (dir.), Port-Royal et la philosophie, Chroniques de Port-Royal,

BERETTA PICCOLI Raffaele, «I concetti di stato e di ordine : spunti per una riflessione teoretica tra Blaise Pascal e Auguste Comte ", in Filosofia oggi (Periodico), 2011, Vol. 34,

BISCHOFF Jean-Louis, Les spécificités de l'humanisme pascalien, Paris, L'Harmattan, 2011.

BJøRNSTAD Hall, «Fail Better': Pascal and the Good Uses of Failure », Seventeenth-

BOSCO Domenico, "Philosophie et anti-philosophie à Port-Royal», in DEVILLAIRS Laurence et TOUBOUL Patricia (dir.), Port-Royal et la philosophie, Chroniques de Port-Royal,

BOUCHILlOUX Hélène, «Port-Royal et la philosophie moderne : les mots et les choses », in DEVILLAIRS Laurence et TOUBOUL Patricia (dir.), Port-Royal et la philosophie, Chroniques de Port-Royal, Paris, Bibiliothèque Mazarine, 2011, p. 247-261. 
1000 Le Pascal des philosophes (2), Les études philosophiques, Paris, PUF, 2011.

1001 LESAULNIER Jean, «Le château de Vaumurier, creuset de l'interrogation philosophique à Port-Royal ", in DEVILLAIRS Laurence et TOUBOUL Patricia (dir.), Port-Royal et la philosophie, Chroniques de Port-Royal, Paris, Bibliothèque Mazarine, 2011, p. 11-25. prince chrétien", in MERCIER LECA Florence (dir.), L'esprit et les lettres: hommage à Pierre-Alain Cahné, Paris, Presses Universitaires de Paris-Sorbonne, 2011, p. 51-56.

CARSIN Emmanuel, Pascal pas à pas, Paris, Ellipses, 2011.

DARRIULAT Jacques, «Blaise Pascal. Clermont-Ferrand, 19 juin 1623 -Paris, 19 août 1662 ", Commémorations nationales, 2012, Paris, Ministère de la culture et de la communication, 2011, p. 69-72.

DE FRANCESCHI Sylvio Hermann, La puissance et la gloire. L'orthodoxie thomiste au péril du jansénisme (1663-1724) : le zénith français de la querelle de la grâce, Paris, Nolin, 2011.

DESCOTES Dominique, « Un théorème géométrique parmi les Pensées de Pascal », Pour la science, $\mathrm{n}^{\circ} 400$, février 2011, p. 94-97.

DESCOTES Dominique, «Port-Royal et la philosophie des mathématiques ", DEVILLAIRS Laurence et TOUBOUL Patricia (dir.), Port-Royal et la philosophie, Chroniques de Port-Royal, Paris, Bibliothèque Mazarine, 2011, p. 211-228.

DEVILLAIRS Laurence et TOUBOUL Patricia (dir.), Port-Royal et la philosophie, Chroniques de Port-Royal, Paris, Bibliothèque Mazarine, 2011.

DEVILLAIRS Laurence, «L'homme image de Dieu. Interprétations augustiniennes: Descartes, Pascal, Fénelon », in DEVILLAIRS Laurence et TOUBOUL Patricia (dir.), PortRoyal et la philosophie, Chroniques de Port-Royal, Paris, Bibliothèque Mazarine, 2011, p. 57-75.

2 FERREYROLLES Gérard, «La preuve et l'épreuve : statut pascalien de l'expérience », in LEPLÂTRE O. (dir.), L'esprit des lettres, Mélanges offerts à Jean-Pierre Landry, Cahiers du Gadges, $n^{\circ}$ 8, Lyon, Université Jean-Moulin Lyon 3, 2011, p. 213-231.

GAY Jean-Pascal, Morales en conflit. Théologie et polémique au Grand Siècle (1640-1700), Paris, Cerf, 2011.

GRANDE Nathalie, Le rire galant. Usages du comique dans les fictions narratives de la seconde moitié du XVII siècle, Paris, Champion, 2011.

GRASSET Bernard, « Le temps pascalien », Filosofia oggi, XXXIV, 2011, p. 173-182.

GUENANCIA Pierre, Divertissements pascaliens, Paris, Hermann, 2011.

HARRINGTON Thomas, "Personnages et paroles dans les Pensées de Pascal ", Cahiers d'histoire des littératures romanes, 3/4, 2011, p. 269-305.

HERVOUET François-Xavier et RAYBAUD Nathalie, « Pascal : Pensées sur le justice, Trois discours sur la condition des grands", in HERVOUET François-Xavier et RAYBAUD Nathalie, et alii, La justice: résumé et analyse des ceuvres, étude approfondie du thème, dissertations corrigées, Paris, Flammarion, 2011, p. 57-108.

JAMES Edward, "Paradox and contradiction : Pascal and Bayle on faith and reason ", French studies, a quarterly supplement, 119, 2011, p. 32-34. 
1002 MESNARD Jean, « Pascal en quête d'une phénoménologie : le modèle de la raison des effets ", in MERCIER LECA Florence (dir.), L'esprit et les lettres : hommage à Pierre-Alain Cahné, Paris, Presses Universitaires de Paris-Sorbonne, 2011, p. 65-90.

1003 MESNARD Jean, «Philosophie de Port-Royal et philosophie de Pascal ", in DEVILLAIRS Laurence et TOUBOUL Patricia (dir.), Port-Royal et la philosophie, Chroniques de Port-Royal, Paris, Bibliothèque Mazarine, 2011, p. 174.

1004 MESNARD Jean, «Figure géométrique et construction philosophique chez Pascal ", Courrier du Centre International Blaise Pascal, $\mathrm{n}^{\circ}$ 33, Clermont-Ferrand, 2011, p. 4-13.

1005 MESNARD Jean, Sui Pensieri di Pascal, Lago di Lavagno, Morcelliana, 2011.

1006 MICHON Hélène, «Le plaisir à Port-Royal », in DEVILLAIRS Laurence et TOUBOUL Patricia (dir.), Port-Royal et la philosophie, Chroniques de Port-Royal, Paris, Bibliothèque Mazarine, 2011, p. 27-41.

1007 PASCAL Blaise, Pensées sur la religion et sur quelques autres sujets. Étude et édition comparative de l'édition originale avec les copies et les versions modernes, par Jean-Robert Armogathe et Daniel Blot, Paris, Champion, 2011.

1008 PASCAL Blaise, Pensées sur la justice, éd. L. Thirouin, Paris, La Découverte, 2011.

1009 PASCAL Blaise, Pensées, opuscules et lettres, éd. Ph. Sellier et L. Plazenet, Paris, Garnier, 2011.

1010 PASCAL Blaise et PASCAL Jacqueline, Les Mystères de Jésus. Recueil pascalien, éd. G.M. Janvier, Paris, Éditions Mille et une nuits, 2011.

1011 PASCAL Blaise, Pensées sur la justice, Trois discours sur la condition des grands, édition avec dossier, présentation de Marc Escola, Paris, Garnier-Flammarion, 2011.

1012 PERATONER Alberto, Pascal, Rome, Carocci, 2011.

1013 PERATONER Alberto, «Foi et raison à Port-Royal », in DEVILLAIRS Laurence et TOUBOUL Patricia (dir.), Port-Royal et la philosophie, Chroniques de Port-Royal, Paris, Bibliothèque Mazarine, 2011, p. 175-188.

1014 POP Calin Cristian, Problema infinitului la Pascal, Cluj-Napoca, EIKON, 2011.

1015 REGUIG Delphine, "Réécrire Montaigne au XVII ${ }^{\mathrm{e}}$ siècle : remarques sur les enjeux de l'imitation linguistique des Essais ", in Réécritures, Littératures classiques, 74, 2011, p. 49-69.

1016 RICHARDT Aimé, Le jansénisme de Jansénius à la mort de Louis XIV, Seconde édition, Paris, De Guibert, 2011.

1017 ROMEO Maria Vita, «L'éthique dans la Logique de Port-Royal », in DEVILLAIRS Laurence et TOUBOUL Patricia (dir.), Port-Royal et la philosophie, Chroniques de Port-Royal, Paris, Bibliothèque Mazarine, 2011, p. 189-209.

1018 ROMEO Maria Vita, «Coscienza e responsabilità : Hegel e Croce lettori di Pascal», Quaderni leif, Catania, 6, janv.-juin 2011, p. 5-37.

1019 ROMEO Maria Vita, “Uno studio su Pascall”, Quaderni leif, Catania, 6, janv.-juin 2011, p. 90-92.

1020 ROMEO Maria Vita, Le retentissement des Provinciales en Italie, Paris, Nolin, 2011.

1021 ROMEO Maria Vita, "Gioberti e le Lettere Proviciali », in ROTONDO A. (dir.), Studia humanitatis, Saggi in onore di Roberto Osculati, Viella, 2011, p. 364-373. 
ROMEO Maria Vita, «Chronique du colloque international Port-Royal et la philosophie, Catane, 8-10 novembre 2010", Courrier du Centre International Blaise Pascal, $\mathrm{n}^{\circ} 33$, Clermont-Ferrand, 2011, p. 14-22.

SELLIER Philippe, "Pascal et l'histoire de l'Église dans la campagne des Provinciales (1656-1658) », in L'esprit des lettres. Mélanges offerts à Jean-Pierre Landry, Cahiers du GADGES, n 8, Lyon, Université Jean-Moulin Lyon 3, 2011, p. 213-231.

SELLIER Philippe, «Salomon de Tultie : l'ombre portée de l'Ecclésiaste dans les Pensées », in DARMON Jean-Charles, Littérature et vanité: la trace de l'Ecclésiaste de Montaigne aux temps présents, Paris, PUF, 2011, p. 29-44.

SELLIER Philippe, « Port-Royal et le platonisme ", in DEVILLAIRS Laurence et TOUBOUL Patricia (dir.), Port-Royal et la philosophie, Chroniques de Port-Royal, Paris, Bibliothèque Mazarine, 2011, p. 43-56.

SHIOKAWA Tetsuya, "La génétique des opera interrupta: le cas de Pascal», in YOSHIKAWA Kazuyoshi et TAGUCHI Noriko (dir.), Comment naît une œeuvre littéraire? Brouillons, contextes culturels, évolutions thématiques, Paris, Champion, 2011, p. 14-24.

1027 SOLLERS Philippe, «L'infini de Pascal », in L'infini, 110, 2010, p. 6-8.

1028 SURYA Michel, "Beckett, Kafka, Pascal», in SURYA Michel (dir.), Contre-attaques: perspective I, Marseille, Al Dante, 2010, p. 31-37.

1029 SUSINI Laurent, «Pascal, Montaigne et la Bible. Un faux pastiche peut en cacher un vrai », in Réécritures, Littératures classiques, 74, 2011, p. 91-106.

1030 SZOBODY Paul, Lorsque la bête pense comme un ange. La possibilité d'une dogmatique pascalienne, Thèse de doctorat, Strasbourg, 2011.

1031 THEODORI Irene, «Caproni e Pascal : una scommessa impossibile», La Rassegna della letteratura italiana, I, 2011, p. 117-131.

1032 TRIGUEROS BUENA Felipe, La composicion del Entretien de M. Pascal avec M. de Sacy. Memorias, Confesiones, Estudio, Roma, Series canonica, Angelicum University Press, 2011.

1033 VIDAL Nathalie et VOGT Dominique, Les machines arithmétiques de Blaise Pascal, Clermont-Ferrand, Musée Henri-Lecoq, 2011.

\section{Année 2012}

1034 ANGELBAULT Christophe, "Pouvoir des clés, pénitence et correction fraternelle dans les querelles du jansénisme. De La fréquente communion d'Arnauld à la Dixième Provinciale de Pascal ", in GAY J.-P. et STIKER-MÉTRAL C.-O. (dir.), Les métamorphoses de la théologie. Théologie, littérature, discours religieux au XVII siècle, Paris, Champion, 2012, p. 45-68.

BENTIVEGNA Giuseppe, "I Pensieri di Pascal nella interpretazione di Jean Mesnard », Quaderni leif, 8, janvier-juin 2012, p. 21-35.

1036 Blaise Pascal. Spiritualité, Choix de textes présentés par Laurent Susini, Paris, Pocket, 2012.

BONNET Hervé, Blaise Pascal, coll. 5 concepts, Lons, Sils-Maria, 2012.

BORD André, La vie familiale chez les Pascal, Paris, Cerf, 2012.

BOSCO Domenico, «Il Pascal di Jean Mesnard. Un Pascal fedele... per tutti », Quaderni leif, 8, janvier-juin 2012, p. 17-19. 
1040 BOURGEOIS Muriel, «Y a-t-il un témoignage pascalien? », in LEVALLOIS Yannick, MALGOUZOU Yannick et VIGIER Luc (dir.), L'accréditation des discours testimoniaux, Toulouse, Éditions universitaires du Sud, 2011, p. 145-155.

1041 CANTILLON Alain, «Les “œuvres complètes” de Pascal, 1779-964 », in DIDIER Béatrice, NEEFS Jacques et ROLET Stéphane (dir.), Composer, rassembler, penser les " œuvres complètes ", Presses Universitaires de Vincennes, 2012, p. 199-242.

1042 CANTILLON Alain, « La vie infiniment plastique de Blaise Pascal, ou : La vie, la Vie, et les CEuvres de Pascal, 1665-1684 et 1776-1779 », in Écrire des vies (Espagne, France, Italie), Paris, Presses Sorbonne nouvelle, 2012, p. 135-144.

1043 CATALANO Chiara, "Remarques sur le fragment L 147: Pascal et Jansénius contre les stoïciens », Courrier du Centre International Blaise Pascal, 34, Clermont-Ferrand, 2012, p. 7-12.

1044 COSTA Enrico Sanchez, «La réception de Pascal chez les écrivains du renouveau catholique français (1890-1940)», Courrier du Centre International Blaise Pascal, 34, Clermont-Ferrand, 2012, p. 13-21.

1045 Courrier du Centre International Blaise Pascal, 34, Clermont-Ferrand, 2012.

1046 DESCOTES Dominique, «Jésuites violents et poissons volants ", Courrier du Centre International Blaise Pascal, 34, Clermont-Ferrand, 2012, p. 28-36.

1047 DEZA Elena et DEZA Michel Marie, Figurate numbers, World scientific, 2012.

1048 FERREYROLLES Gérard, « Mourir avec Pascal », Travaux de littérature publiés par l'ADIREL, XXV, 2012, p. 127-138.

1049 GHEERAERT Tony, «Les accidents de la vie. Maladie, traumatisme et création chez Blaise Pascal », XVII ${ }^{e}$ siècle, 255, avril 2012, p. 285-308.

1050 LETEY Claude, Apprendre à philosopher avec Pascal, Paris, Ellipses, 2012.

1051 MESNARD Jean, « Le livre et la vie », Quaderni leif, 8, janvier-juin 2012, p. 7-15.

1052 MISONO Keisuke, Écrire contre le jansénisme. Léonard de Marandé polémiste vulgarisateur, Paris, Champion, 2012.

1053 MONASTERIO Carmen, Pascal, une filosofía que se trasciende a sí misma, Pamplona, EUNSA, 2012.

1054 PASCAL Blaise, Gedanken, aus dem Franz von Ulrich Kunzmann, Berlin, Suhkamp, 2012.

1055 PERRIN Yvette, «Les probabilités au service des sciences morales, Blaise Pascal et Pierre Simon Laplace", Courrier du Centre International Blaise Pascal, 34, ClermontFerrand, 2012, p. 22-27.

1056 PLAZENET Laurence, «Le Port-Royal de Montherlant et ses sources », Revue d'Histoire littéraire de la France, mars 2012, 1, p. 179-213.

1057 Port-Royal. Une anthologie présentée par Laurence Plazenet, Paris, Flammarion, 2012.

1058 RACINE Jean, Abrégé de l'histoire de Port-Royal, éd. J. Lesaulnier, Paris, Champion, 2012.

1059 RAFFELT Albert, « Blaise Pascal. Eribnnbrung an ein Genie nach 350 Jahren », Stimmen der Zeit, Heft 8, August 2012, p. 541-580.

1060 ROCQUET Claude-Henri, Visite d'un jeune libertin à Blaise Pascal, Paris, Petits Platons, 2012.

1061 ROMEO Maria Vita, « Un sintetico bilancio », Quaderni leif, 8, janvier-juin 2012, p. 17-19. 
ROMEO Maria Vita, «Pascal e il gesuita Padre Noël : una polemica piena di vuoto ", Quaderni leif, 8, janvier-juin 2012, p. 57-81.

ROMEO Maria Vita, "Hommage », Courrier du Centre International Blaise Pascal, 34, Clermont-Ferrand, 2012, p. 37-41.

1064 SAINTE-BEUVE, Pascal, [extraits du Port-Royal], éd. M. Brix, Paris, Bartillat, 2012.

1065 SELLIER Philippe, "Pascal et le Contre Fauste», in BOCHET Isabelle (dir.), Augustin philosophe et prédicateur, Hommage à Goulven Madec, Coll. Études augustiniennes, Série Antiquité, n 195 , Paris, Institut d'Études augustiniennes, 2012, p. 523-536.

1066 SELLIER Philippe, Port-Royal et la littérature, II, Le siècle de saint Augustin, La Rochefoucauld, Mme de Lafayette, Mme de Sévigné, Sacy, Racine, Deuxième édition augmentée de six études, Paris, Champion, 2012.

1067 SHIOKAWA Tetsuya, Entre foi et raison: l'autorité. Études pascaliennes, Paris, Champion, 2012.

1068 TANOÜARN Guillaume de, Parier avec Pascal, Paris, Cerf, 2012.

1069 THIROUIN Laurent, «Pascal: la Vie ou l'œuvre ? ", in MOMBERT Sarah et ROSELLINI Michèle (dir.), Usages des vies. Le biographique hier et aujourd'hui (XVII ${ }^{e}$-XXI ${ }^{e}$ siècle), Presses Universitaires du Mirail, 2012, p. 267-294.

1070 VAN DAMME Stéphane, « Méditations mathématiques. Retour sur une pratique morale des sciences à l'âge classique », Annales, janvier-mars 2012, 1, Paris, Colin, p. 135-152.

1071 VIDAL Nathalie et VOGT Dominique, "Les machines arithmétiques de Blaise Pascal », Bulletin historique et scientifique de l'Auvergne, t. CXIII/1, n 792-793, janvier-juin 2012, p. 53-72.

1072 WAGNER Jacques, «Fin du secret et fin des Lumières : de Pascal à Saint-Martin », in Le tournant des Lumières, Paris, Garnier, 2012, p. 139-162.

1073 WOOD William D., «Axiology, self-deception, and moral wrongdoing in Blaise Pascal's Pensées ", The Journal of Religious Ethics, Vol. 37, Issue 2, 2009, p. 355-384.

1074 YAMAJO Hirotsugu, Pascal et la vie terrestre. Épistémologie, ontologie et axiologie du "corps" dans son apologétique, Memoirs of the graduate school of Osaka University, vol. LII-II, mars 2012.

\section{Année 2013}

1075 AUPETIT Hubert, «Pour en finir avec l'Apologie. Us et abus d'une hypothèse de lecture ", in Chroniques de Port-Royal, 63, Paris, 2013, p. 27-44.

1076 BAH OSTROWIECKI Hélène Jean, « Une apologie par l'extérieur : la place du corps dans les Pensées de Pascal », in Chroniques de Port-Royal, 63, Paris, 2013, p. 137-151.

1077 BASSET Guy, "Camus au pays du XVII e siècle français ", Revue d'Histoire Littéraire de la France, $\mathrm{n}^{\circ}$ 4, 2013, p. 807-814.

1078 BJORNSTAD Hall, Créature sans créateur. Pour une anthropologie baroque dans les Pensées de Pascal, Paris, Hermann, 2013.

1079 BJORNSTAD Hall, «Relire ce qu'on n'a jamais lu. Remarques sur la dignité du roseau pensant », in Chroniques de Port-Royal, 63, Paris, 2013, p. 101-112. 
1080 BJøRNSTAD Hall, « Twice Written, Never Read: Pascal's Mémorial between superstition and superbia ", Representations, 124, 2013, p. 69-95.

BJØRNSTAD Hall, " "Giving voice to the feeling of his age": Benjamin, Pascal and the Trauerspiel of the King Without Diversion ", Hall BJøRNSTAD and Katherine IBBETT éd, Walter Benjamin's Hypothetical French Trauerspiel, Yale French Studies, 124 (2013), p. 23-35.

1082 Blaise Pascal, le penseur, Musée d'art Roger-Quilliot, Clermont-Ferrand, 2013, 12 p.

1083 « Blaise Pascal permanent du Marq », Info Magazine, nº 1434, 24 juin 2013, p. 24.

1084 BOUCHILLOUX Hélène, «Science et athéisme : les enjeux philosophiques de l'apologie pascalienne ", in Chroniques de Port-Royal, 63, Paris, 2013, p. 255-267.

1085 «Blaise Pascal, le penseur, dans ses murs », Demain Clermont-Ferrand, n 297, juin 2013, p. 23-25.

1086 CARRAUD Vincent, «Le dessein de Pascal : De la vraie religion, ou une apologétique de la douceur », in Chroniques de Port-Royal, 63, Paris, 2013, p. 45-66.

1087 CANTILLON Alain, "Querelles, exhibition et vérité : le cas Blaise Pascal », in VIALA Alain et HOSTIOU Jeanne-Marie (dit.), Le temps des querelles, Littératures classiques, 81, Paris, Armand Colin, 2013, p. 63-77.

1088 CATTANI Paola, "Le Christ en Gethsémani de Charles Péguy entre Pascal et Renan ", Revue d'Histoire Littéraire de la France, Paris, PUF, $\mathrm{n}^{\circ}$ 2, avril 2013, p. 341-356.

1089 CHÉDOZEAU Bernard, L'univers biblique catholique au siècle de Louis XIV. La Bible de PortRoyal, I, Les Préfaces de l'Ancien Testament (1672-1693), II, Les Préfaces du Nouveau Testament (1696-1708), Paris, Champion, 2013.

1090 CHISTYAKOV Alexander, Les Pensées de Pascal dans la tradition apologétique, Thèse, Université Paris-Sorbonne (Paris IV), 23 novembre 2013.

1091 Courrier du Centre International Blaise Pascal, 35, Clermont-Ferrand, 2013.

1092 DECLOS Alexandre, «L'inquiétude dans les Pensées de Pascal », Revue de Métaphysique et de Morale, Paris, PUF, $\mathrm{n}^{\circ}$ 2, avril 2013, p. 1679-184.

1093 DESCOTES Dominique, «Les nombres dans les Pensées », in Chroniques de Port-Royal, 63, Paris, 2013, p. 199-219.

1094 EL YADARI Nawalle, «L'apologie pascalienne et les fondements de la subjectivité », in Chroniques de Port-Royal, 63, Paris, 2013, p. 123-135.

1095 FERREYROLLES Gérard, «Conclusions », XVII siècle, octobre 2013, nº 261, p. 663-667.

1096 FRIGO Alberto, «Morale chrétienne et apologétique ", in Chroniques de Port-Royal, 63, Paris, 2013, p. 183-198.

1097 GIBERT Pierre, «La quiétude comme expérience impossible », in Chroniques de PortRoyal, 63, Paris, 2013, p. 153-166.

1098 GIOCANTI Sylvia, "La relation entre exégèse et apologétique dans les Pensées ", in Chroniques de Port-Royal, 63, Paris, 2013, p. 235-241.

1099 HARRINGTON Thomas More, « Déchéance et rédemption de l'homme selon Pascal », Cahiers d'histoire des littératures romanes, 37, Heft 1/2, 2013, p. 51-79.

1100 « Hommage à Blaise Pascal », Demain Clermont-Ferrand, n 298, juillet-août 2013, p. 24. 
1101 HOUZEL Christian, «Blaise Pascal et les sections coniques », in RASHED R. et CROZET P. (dir.), Les courbes. Études sur l'histoire d'un concept, Paris, Blanchard, 2013, p. 87-105.

1102 KOLESNIK-ANTOINE Delphine, «La réception malebranchiste de l'anthropologie pascalienne. La question de la transmission du péché originel », in Chroniques de PortRoyal, 63, Paris, 2013, p. 269-283.

1103 LYONS John D., "Espace physique, espace conceptuel dans les Pensées ", XVII siècle, octobre 2013, n 261, p. 621-635.

1104 LYONS John D., "Pascal et les frontières du visible ", in GUYOT Sylvaine et CONLEY Tom (dir.), L'œil classique, Littératures classiques, 82, Paris, Colin, 2013, p. 145-157.

1105 MESNARD Jean, "Pascal, témoin moderne du christianisme », in Chroniques de PortRoyal, 63, Paris, 2013, p. 15-26.

1106 MESNARD Jean, « L'ordre dans les Pensées », XVII ${ }^{e}$ siècle, octobre 2013, n 261, p. 573-600.

1107 MEYNET Roland, "Les "trois ordres" de Pascal selon la rhétorique biblique ", Gregorianum, Rome, Pontificia Universitas Gregoriana, 2013, 94/1, p. 79-96.

1108 MEYNET Roland, «Le Mémorial à la lumière de la rhétorique biblique ", XVII ${ }^{e}$ siècle, octobre 2013, no 261, p. 601-619.

1109 MICHON Hélène, «Dieu d'Abraham, d'Isaac et de Jacob, non des philosophes et des savants : la distinction pascalienne à l'épreuve du temps ", in Chroniques de Port-Royal, 63, Paris, 2013, p. 285-295.

1110 NAGASE Haruo, «La machine arithmétique et les ordres pascaliens », XVII ${ }^{e}$ siècle, octobre 2013, $\mathrm{n}^{\circ} 261$, p. 669-683.

1111 PALMA RAMIREZ Manuel, La ambigua imaginación de la felicidad. Diversión y apuesta en el corazón de Blaise Pascal, Rome, Pontificio Istituto Biblico Gregoriano \& Biblical Press, 2013.

1112 PASCAL Blaise, Pensées et opuscules lus par Philibert Secretan, Paris, Cerf, 2013.

1113 PASCAL Blaise, L'essentiel des Pensées, Paris, Salvator, 2013.

1114 PASCAL Jacqueline, Il coraggio delle fanciulle, Lettere a cura di Silvana Bartoli, Milano, et al. Edizioni, 2013.

1115 PATIER Xavier et MÉRITENS Patrice de, « Pascal, l'insatiable génie », Figaro Magazine, 2-3 août 2013, p. 72-75.

1116 PAVLOVITS Tamàs, "Perspective et perspectivisme dans les Pensées ", in Chroniques de Port-Royal, 63, Paris, 2013, p. 221-233.

1117 PÉCHARMAN Martine, "Les Écrits sur la grâce, ou de la bonne manière d'être augustinien ", Seventeenth-century french studies, XXXV, 2, 2013, p. 106-115.

1118 PLAZENET Laurence, "Sordes et trivialités dans les Pensées : pour un Pascal écrivain », in Chroniques de Port-Royal, 63, Paris, 2013, p. 83-99.

1119 RABOURDIN David, Pascal. Foi et conversion, Paris, PUF, 2013.

1120 ROMEO Maria Vita, "L'échelle de la morale dans les Pensées ", in Chroniques de PortRoyal, 63, Paris, 2013, p. 167-182.

1121 SELLIER Philippe, "Petite méditation sur une maxime pascalienne », Quaderni leif, 10, juillet-décembre 2013, p. 71-80.

1122 SESÉ Bernard, Petite vie de Blaise Pascal, Paris, Desclée de Brouwer, 2013. 
1123 SHIOKAWA Tetsuya, «Le péché originel dans l'apologie pascalienne: stratégie et enjeux », in Chroniques de Port-Royal, 63, Paris, 2013, p. 243-255.

1124 SHIOKAWA Tetsuya, "Amour et justice: de l'observation moraliste à l'exhortation spirituelle », XVII ${ }^{e}$ siècle, octobre 2013, nº 261, p. 636-644.

1125 SUSINI Laurent, «Fondements de la rétorsion dans les Pensées de Pascal », in Chroniques de Port-Royal, 63, Paris, 2013, p. 113-122.

1126 THIROUIN Laurent, «Le pari au départ de l'apologie », in Chroniques de Port-Royal, 63, Paris, 2013, p. 67-82.

1127 THIROUIN Laurent, «La profession de raison ", XVII siècle, octobre 2013, $\mathrm{n}^{\circ}$ 261, p. 685-697.

1128 THIROUIN Laurent, « Pascal e la superstizione », Quaderni leif, 10, juillet-décembre 2013, p. 81-104.

1129 VINCIGUERRA Lucien, La représentation excessive, Descartes, Leibniz, Locke, Pascal, Presses Universitaires de Lille, éditions de Septentrion, 2013.

\section{Année 2014}

1130 AMODIO Paolo, «Pascal, Port-Royal (e Montaigne) : que sais-je ? Note in due tempo a margine di un libre et di un colloquio con Philippe Sellier », Quaderni leif, 12, Catane, juillet-décembre 2014, p. 5-16.

1131 ARNAULD Antoine et NICOLE Pierre, La Logique ou l'art de penser, éd. D. Descotes, Paris, Champion, 2014.

1132 BASSET Guy, «Regards de Camus sur Pascal », Albert Camus en scène: tout n'est-il que théâtre?, Rencontres méditerranéennes A. Camus, Avignon, A. Barthélémy, 2014.

1133 BOSCO Domenico, «Un Pascal “gaudioso”. Omaggio a Philippe Sellier », Quaderni leif, 12, Catane, juillet-décembre 2014, p. 17-40.

1134 BOUCHILLOUX Hélène, «Dieu sensible au cœur, ou la libido des philosophes », Quaderni leif, 12, Catane, juillet-décembre 2014, p. 41-53.

1135 CANTILLON Alain, Le Pari-de-Pascal, Paris, Vrin, 2014.

1136 CARENA Carlo, "Sul Pensiero 168 di Pascal», Quaderni leif, 12, Catane, juilletdécembre 2014, p. 55-59.

1137 CLÉRO Jean-Pierre, "Géométrie du hasard, assurances et catastrophes », in BERTRAND Dominique (dir.), Penser le risque à l'âge classique, Clermont-Ferrand, Presses Universitaires Blaise Pascal, 2014, p. 41-60.

1138 DESCOTES Dominique, «Pascal, père et fils », Des mathématiques en Auvergne. Histoires, progès et interactions, Revue d'Auvergne, 611-612, Clermont-Ferrand, 2014, p. 15-48.

1139 EIKELBOOM Lexi, « Why Stanley Hauerwas needs Blaise Pascal : Sin, Anthropology, and Christian Witness », Studies in Christian Ethics, Vol. 27, Issue 4, Nov. 2014, p. 404-416.

1140 GOODKIN Richard, "Pascal et le calcul des partis: unité de temps scientifique, mathématique, littéraire ", in Littérature et science: archéologie d'un litige (XVI ${ }^{e_{-}}$ XVIII ${ }^{e}$ siècles), Littératures classiques, Paris, Colin, 2014, p. 81-96.

1141 GRASSET Bernard, Philosophie et exégèse, Nice, Ovadia, 2014. 
1142 LAMBRE Hier, «Le triangle de Pascal de toutes les couleurs ", Des mathématiques en Auvergne. Histoires, progès et interactions, Revue d'Auvergne, 611-612, Clermont-Ferrand, 2014, p. 315-337.

1143 MOREAU Denis, « Le pari de Pascal », Philosophie, 79, mai 2014, p. 79-83.

1144 MORODO GONZÁLEZ Patricia, «El itinerario de la conversión en los Pensées de Blaise Pascal », Excerpta et Dissertationibus in Sacra Theologia, Vol. 62, 2014, p. 401-463.

1145 OSCULATI Roberto, «Attualità di Pascal», Quaderni leif, 12, Catane, juilletdécembre 2014, p. 61-65.

1146 PASCAL Blaise, Spirit e fineȚe, spirit de geometrie. De l'esprit géométrique, şi alte scrieri, éd. Doina Bălan-Nistor, Cluj-Napoca, Grinta, 2014.

1147 PESCE Antonio Giovanni Pesce, «La metafisica di Pascal e il sapere del profondo ", Quaderni leif, 12, Catane, juillet-décembre 2014, p. 67-82.

1148 PEZZINO Giuseppe, «Pascal : un compagno di viaggio nel deserto », Quaderni leif, 12, Catane, juillet-décembre 2014, p. 83-95.

1149 QUANTIN Jean-Louis, « Si mes Lettres sont condamnées à Rome... Les Provinciales devant le Saint-Office », XVII siècle, $\mathrm{n}^{\circ}$ 265, octobre 2014, p. 587-617.

1150 RAFFELT Albert, «Zur französischen Pascal-Renaissance im 19 Jahrhundert im Blick auf Maurice Blondel », in D. BURKARD et N. PRIENSCHING (dir.), Katholiken im langen 19. Jahrhundert: Akture-Kulturen-Mentalitäten. Festschrift für Otto Weiss, Regensburg, F. Pustet, 2014, p. 183-210.

1151 SELLIER Philippe, "Sept empreintes pascaliennes », Quaderni leif, 12, Catane, juilletdécembre 2014, p. 97-106.

1152 THIROUIN Laurent, "Préface ", Le pari de Pascal dans les Pensées, encart $\mathrm{n}^{\circ}$ 79, Philosophie, p. 2-3.

1153 VERHAEGHE Laure, «Rousseau interprète pascalien de Descartes : la troisième lettre morale », Les études philosophiques, janvier 2014-1, p. 115-136.

1154 VIDAL Nathalie, "Blaise Pascal et les mathématiques au muséum Henri-Lecoq », Des mathématiques en Auvergne. Histoires, progrès et interactions, Revue d'Auvergne, 611-612, Clermont-Ferrand, 2014, p. 49-54.

\section{Année 2015}

1155 CARRAUD Vincent, "Subtilités et suppositions métaphysiques dans la Lettre sur la possibilité des commandements : deux notes cartésiennes », Quaderni leif, 13, 2015, p. 7-21.

1156 COMTE-SPONVILLE André, Du tragique au matérialisme (et retour): vingt-six études sur Montaigne, Pascal, Spinoza, Nietzsche et quelques autres, Paris, PUF, 2015.

1157 Courrier du Centre International Blaise Pascal, 36 (2014), Clermont, 2015.

1158 DESCOTES Dominique, «Les images dans les œuvres scientifiques de Port-Royal », Actes du colloque Port-Royal et les images, CÉRÉdI, Rouen, http://ceredi.labos.univ-rouen.fr/ public/?les-images-dans-les-oeuvres.html.

1159 DESCOTES Dominique, «L'éloquence ecclésiastique dans les Écrits des curés de Paris composés par Pascal», in VÉNUAT Monique et JÉRÉMIE Christian, L'éloquence ecclésiastique de la pré-Réforme aux Lumières, Paris, Champion, 2015, p. 351-374. 
1160 DESCOTES Dominique, « Pascal et Bourzeis », Quaderni leif, 13, 2015, p. 23-47.

1161 FRIGO Alberto, « État présent des études sur les Écrits sur la grâce (1991-2015) », Quaderni leif, 13, 2015, p. 49-61.

1162 GRASSET Bernard, "Le “supplément d'âme”, la question de Dieu dans le spiritualisme français ", Courrier du Centre International Blaise Pascal, 36 (2014), Clermont, 2015, p. 29-34.

1163 HORINO Masamitsu, «Les trois écrits que la "plurilecture" a permis de reconstituer à partir du manuscrit de Divertissement », Courrier du Centre International Blaise Pascal, 36 (2014), Clermont, 2015, p. 13-23.

1164 JULLIEN Vincent, «Pascal via Duhem et van Fraassen », Courrier du Centre International Blaise Pascal, 36 (2014), Clermont, 2015, p. 5-12.

1165 JULLIEN Vincent (dir.), Seventeenth century indivisibles revisited, Heidelberg, Birkhäuser, 2015.

1166 KAMBOUCHNER Denis, « Pascal et le temps de la grâce », Quaderni leif, 13, 2015, p. 63-76.

1167 MESNARD Jean, «Conclusions ou perspectives sur le mystère de la grâce ", Quaderni leif, 13, 2015, p. 141-156.

1168 MONASTERIO Carmen, « ¿Caridad en Pascal?», Scripta theologica, Universidad de Navarra, vol. 46, $\mathrm{n}^{\circ}$ 3, déc. 2014, p. 635-649.

1169 MORIARTY Michael, « Pascal, Molina et le molinisme », Quaderni leif, 13, 2015, p. 77-90.

1170 NYANDWY Emmanuel, "Pascal à Alexandrie », Courrier du Centre International Blaise Pascal, 36 (2014), Clermont, 2015, p. 27-28.

1171 PARISH Richard, "Relire les Écrits sur la grâce à la lumière des écrits sur la grâce : orthodoxie et esthétique ", Quaderni leif, 13, 2015, p. 91-102.

1172 PEZZINO Giuseppe, "Conclusions, ou mieux une pause dans les travaux en cours ", Quaderni leif, 13, 2015, p. 157-160.

1173 RAFFELT Albert, «Zwischen "Historismus" und "Typologie" - Geschichte une exegese bei Blaise Pascal», in N. FISCHER et J. SIROVÁTKA, Vernunftreligion und Offenbarungsglaube, Fribourg-Bâle-Vienne, Herder, 2015, p. 155-169.

1174 Relire les Écrits sur la grâce, Quaderni leif, 13, Université de Catane, 2015.

1175 ROMEO Maria Vita, «Liberté et félicité dans les Écrits sur la grâce », Quaderni leif, 13, 2015, p. 103-121.

1176 ROMEO Maria-Vita, « Le Pascal de la joie et de la fidélité. Hommage à Philippe Sellier », Courrier du Centre International Blaise Pascal, 36 (2014), Clermont, 2015, p. 24-26.

1177 SELLIER Philippe, «Conclusions croisées », Quaderni leif, 13, 2015, p. 161-163.

1178 THIROUIN Laurent, «De la facilité des commandements», Quaderni leif, 13, 2015, p. 123-139. 
INDEX

Mots-clés : Pascal, bibliographie pascalienne

Keywords : Pascal, bibliography 